Torres Anthony Derek (Orcid ID: 0000-0002-0531-5883)

Keppel-Aleks Gretchen (Orcid ID: 0000-0003-2213-0044)

Doney Scott C. (Orcid ID: 0000-0002-3683-2437)

Luis Kelly (Orcid ID: 0000-0001-9975-3480)

Petri Christof (Orcid ID: 0000-0002-7010-5532)

Pollard David Frank (Orcid ID: 0000-0001-9923-2984)

Velazco Voltaire Almario (Orcid ID: 0000-0002-1376-438X)

Warneke Thorsten (Orcid ID: 0000-0001-5185-3415)

Wunch Debra (Orcid ID: 0000-0002-4924-0377)

Confidential manuscript submitted to the Journal of Geophysical Research: Atmospheres

\title{
A geostatistical framework for quantifying the imprint of mesoscale atmospheric transport on satellite trace gas retrievals
}

\section{Anthony D. Torres ${ }^{1}$, Gretchen Keppel-Aleks ${ }^{1}$, Scott C. Doney ${ }^{2,3}$, Michaela Fendrock $^{4}$, Kelly Luis ${ }^{5}$, Martine De Mazière ${ }^{6}$, Frank Hase ${ }^{7}$, Christof Petri ${ }^{8}$, David F. Pollard $^{9}$, Coleen M. Roehl ${ }^{10}$, Ralf Sussmann ${ }^{11}$, Voltaire A. Velazco ${ }^{9}$, Thorsten Warneke $^{8}$, and Debra Wunch ${ }^{12}$}

1 Climate and Space Sciences and Engineering, University of Michigan Ann Arbor, MI 48109 USA

2 Environmental Sciences, University of Virginia, Charlottesville, VA, 22904 USA

3 Marine Chemistry \& Geochemistry, Woods Hole Oceanographic Institution, Woods Hole, MA, 02543 USA

4 Earth, Atmospheric, and Planetary Sciences, Massachusetts Institute of Technology, Cambridge, MA, 02142 USA

5 School for the Environment, University of Massachusetts Boston, Boston, MA, 02125 USA

6 Royal Belgian Institute for Space Aeronomy, Brussels, Belgium

7 Karlsruhe Institute of Technology, IMK-ASF, Karlsruhe, Germany

8 Institute of Environmental Physics, University of Bremen, Bremen, Germany

9 National Institute of Water and Atmospheric Research, Lauder, New Zealand

10 Geological and Planetary Sciences, California Institute of Technology, Pasadena, CA, 91125 USA

This is the author manuscript accepted for publication and has undergone full peer review but has not been through the copyediting, typesetting, pagination and proofreading process, which may lead to differences between this version and the Version of Record. Please cite this article as doi: 10.1029/2018JD029933

This article is protected by copyright. All rights reserved. 
11 Karlsruhe Institute of Technology, IMK-IFU, Garmisch-Partenkirchen, Germany

12 Department of Physics, University of Toronto, Toronto, Canada

Corresponding Author: Anthony D. Torres (adtorres@umich.edu)

\section{Key Points:}

- We developed a framework to relate high-frequency spatial variations to transport-induced temporal fluctuations in atmospheric tracers

- We use geostatistical analysis to quantify the variance budget for $\mathrm{X}_{\mathrm{CO}_{2}}$ and $\mathrm{X}_{\mathrm{H}_{2} \mathrm{O}}$ retrieved from NASA's OCO-2 satellite

- Accounting for random errors, systematic errors, and real geophysical coherence in remotely sensed trace gas observations may yield improved flux constraints

This article is protected by copyright. All rights reserved. 


\begin{abstract}
NASA's Orbiting Carbon Observatory-2 (OCO-2) satellite provides observations of total column-averaged $\mathrm{CO}_{2}$ mole fractions $\left(\mathrm{X}_{\mathrm{CO}_{2}}\right)$ at high spatial resolution that may enable novel constraints on surface-atmosphere carbon fluxes. Atmospheric inverse modeling provides an approach to optimize surface fluxes at regional scales, but the accuracy of the fluxes from inversion frameworks depends on key inputs, including spatially and temporally dense $\mathrm{CO}_{2}$ observations and reliable representations of atmospheric transport. Since $\mathrm{X}_{\mathrm{CO}_{2}}$ observations are sensitive to both synoptic and mesoscale variations within the free troposphere, horizontal atmospheric transport imparts substantial variations in these data, and must be either resolved explicitly by the atmospheric transport model or accounted for within the error covariance budget provided to inverse frameworks. Here, we used geostatistical techniques to quantify the imprint of atmospheric transport in along-track OCO-2 soundings. We compare high-pass filtered ( $<250 \mathrm{~km}$, spatial scales that primarily isolate mesoscale or finer scale variations) along-track spatial variability in $\mathrm{X}_{\mathrm{CO}_{2}}$ and $\mathrm{X}_{\mathrm{H}_{2} \mathrm{O}}$ from OCO-2 tracks to temporal synoptic and mesoscale variability from ground-based $\mathrm{X}_{\mathrm{CO}_{2}}$ and $\mathrm{X}_{\mathrm{H}_{2} \mathrm{O}}$ observed by nearby Total Carbon Column Observing Network (TCCON) sites. Mesoscale atmospheric transport is found to be the primary driver of along-track, high frequency variability for OCO-2 $\mathrm{X}_{\mathrm{H}_{2} \mathrm{O}}$. For $\mathrm{X}_{\mathrm{CO}_{2}}$, both mesoscale transport variability and spatially coherent bias associated with other elements of the OCO-2 retrieval state vector are important drivers of the along-track variance budget.
\end{abstract}

\title{
Plain Language Summary
}

Numerous efforts have been made to quantify sources and sinks of atmospheric $\mathrm{CO}_{2}$ at regional spatial scales. A common approach to infer these sources and sinks requires accurate representation of variability of $\mathrm{CO}_{2}$ observations attributed to transport by weather systems. While numerical weather prediction models have a fairly reasonable representation of larger-scale weather systems, such as frontal systems, representation of smaller-scale features $(<250 \mathrm{~km})$, is less reliable. In this study, we find that the variability of total-column averaged $\mathrm{CO}_{2}$ observations attributed to these fine-scale weather systems accounts for up to half of the variability attributed to local sources and sinks. Here, we provide a framework for quantifying the drivers of spatial variability of atmospheric trace gases rather than simply relying on numerical weather prediction models. We use this framework to quantify potential sources of errors in measurements of total-column averaged $\mathrm{CO}_{2}$ and water vapor from NASA's Orbiting Carbon Observatory-2 (OCO-2) satellite. 


\section{Introduction}

Knowledge of regional surface-atmosphere carbon dioxide $\left(\mathrm{CO}_{2}\right)$ fluxes are required to understand anthropogenic and climatic influences on the global carbon cycle. Despite longstanding research efforts to develop a robust budget for surface fluxes of $\mathrm{CO}_{2}$ (Bolin and Keeling, 1963; Enting and Mansbridge, 1989; Tans et al., 1990; Keeling et al., 1996; Peters et al., 2005; Chevallier et al., 2010; Peylin et al., 2013; Basu et al., 2018), these studies diverge in their estimates of the geographic distribution of sources and sinks of $\mathrm{CO}_{2}$ (Gurney et al., 2002; Baker et al., 2006; Stephens et al., 2007). For example, Gurney et al. (2002) found uncertainties in regional scale carbon fluxes were greater than $0.5 \mathrm{Gt}$

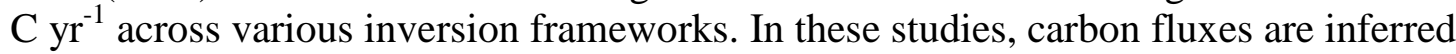
from spatial and temporal variations in atmospheric $\mathrm{CO}_{2}$ observations via atmospheric inverse methods. Atmospheric inversions typically apply Bayesian optimal estimation methods to optimize assumed (a priori) fluxes that have been used as boundary conditions to simulate spatiotemporal $\mathrm{CO}_{2}$ variations in an atmospheric transport model. Mismatches between the simulated and observed atmospheric $\mathrm{CO}_{2}$ provide the basis for scaling the assumed fluxes. The optimization requires rigorous attention to errors associated with the assumed flux structure, the observations, and the fidelity of atmospheric transport modeled by the framework (Rogers, 2000).

One limitation to inverse modeling studies has been the density and geographic distribution of atmospheric observations available to constrain surface fluxes (Gurney et al., 2002). Traditionally, observations of atmospheric $\mathrm{CO}_{2}$ have been measured in situ or via flask sampling within the atmospheric boundary layer. These observatories are concentrated within Northern Hemisphere temperate latitudes, and there is a scarcity of observations in key regions for the global carbon cycle, including the tropics (Stephens et al., 2007) and the Southern Ocean (Landschützer et al, 2015). The sparse in situ network for atmospheric $\mathrm{CO}_{2}$ observations was the impetus for the launch of several satellites, including Japan Aerospace Exploration Agency's (JAXA) Greenhouse gases Observing SATellite (GOSAT) (Yokota et al, 2009; Ross et al., 2013), NASA's Orbiting Carbon Observatory-2 satellite (OCO-2) (Crisp et al., 2004; Eldering et al., 2017), and Chinese National Space Administration's (CNSA) TanSat (Yang et al., 2018). These low Earth, polar-orbiting satellites measure the total column averaged dry air mole fraction of atmospheric $\mathrm{CO}_{2}$ (denoted as $\mathrm{X}_{\mathrm{CO}_{2}}$ ) at high spatial density. For example, OCO-2 acquires approximately 1 million soundings every day, each with a footprint on the order of $1 \mathrm{~km}^{2}$ (Crisp et al., 2004; Eldering et al., 2017). Theoretical studies have hypothesized that the high spatiotemporal density of $\mathrm{X}_{\mathrm{CO}_{2}}$ observations may allow for a reduction of errors in flux inferences from inversion models (Rayner and O'Brien, 2001; Baker et al, 2006; Miller et al., 2007). 
A second limitation to the fidelity of inverse modeling studies is the inverse modeling framework itself, via either incorrect parameterization of atmospheric transport (Masarie et al., 2011; Williams et al., 2014; Chevallier et al., 2010; Houwelling et al., 2015; Basu et al., 2018) or inappropriate representation of error covariance structures (Chevallier and O'Dell, 2013). The goal of this paper is to discuss the unique requirements for atmospheric transport fidelity and the description of variance budgets for $\mathrm{X}_{\mathrm{CO}_{2}}$ from the OCO-2 satellite. One advantage of measuring the column averaged mole fraction is that its variations can be used more effectively to constrain surface fluxes via mass balance. Measurements made within the planetary boundary layer are sensitive not only to fluxes at the surface, but also to the rate at which the surface flux signal is entrained into the free troposphere. The column, however, is unaffected by the vertical entrainment rate, so in theory it is more directly related to surface fluxes via mass balance (Rayner and O'Brien, 2001; Olsen and Randerson, 2004). For example, Basu et al. (2018) concluded that fluxes inferred from perfect, or error-free, satellite observations of $\mathrm{X}_{\mathrm{CO}_{2}}$ are less sensitive to uncertainty in atmospheric transport than perfect in situ observations of $\mathrm{CO}_{2}$ in the planetary boundary layer by applying flux inversion techniques to the output from different atmospheric transport models forced with the same $\mathrm{CO}_{2}$ initial and boundary conditions.

A potential complication of using $\mathrm{X}_{\mathrm{CO}_{2}}$, however, is that it is sensitive to $\mathrm{CO}_{2}$ within the free troposphere, where most weather occurs. The variance budget is therefore strongly affected by horizontal advection (Geels et al., 2004; Keppel-Aleks et al., 2011), not just surface fluxes, which are the real target of obtaining and inverting atmospheric observations. In fact, at subseasonal timescales, horizontal advection dominates the variance budget in $\mathrm{X}_{\mathrm{CO}_{2}}$ (Keppel-Aleks et al., 2011). Keppel-Aleks et al. (2012) used ground-based observations of $\mathrm{X}_{\mathrm{CO}_{2}}$ at several midlatitude sites in the Total Carbon Column Observing Network (TCCON) to show that synoptic-scale variations, which occur on spatial scales on the order of $1000 \mathrm{~km}$ and temporal scales of about one to two weeks, could be up to half the peak-to-trough seasonal cycle in $\mathrm{X}_{\mathrm{CO}_{2}}$. Likewise, horizontal advection drives up to 60 to $70 \%$ of diurnal variations of boundary layer $\mathrm{CO}_{2}$ in the midlatitudes (Parazoo et al., 2008), and these horizontal eddy-induced variations are roughly half the size of the seasonal $\mathrm{CO}_{2}$ variations driven by regional net ecosystem exchange of $\mathrm{X}_{\mathrm{CO}_{2}}$ (Parazoo et al., 2011). At finer spatial scales on the order of $100 \mathrm{~km}$, mesoscale variability in $\mathrm{X}_{\mathrm{CO}_{2}}$, which occurs on timescales of around one day, can be larger than diurnal variations in $\mathrm{X}_{\mathrm{CO}_{2}}$ resulting from $\mathrm{CO}_{2}$ exchange with the local terrestrial ecosystem (Keppel-Aleks et al., 2012). Mesoscale transport imposes especially large errors on flux inversions over cities at time scales smaller than a month (Lauvaux et al, 2016). However, even with global scale inversions, the variations on $\mathrm{X}_{\mathrm{CO}_{2}}$ imparted by fine scale transport may ultimately degrade the inverted fluxes. This is largely due to the 
fact that signal imposed by fine and large-scale atmospheric transport is spatially correlated, thus these variations cannot simply be addressed simply by averaging multiple observations (Miller et al, 2015).

Thus, efforts to use $\mathrm{X}_{\mathrm{CO}_{2}}$ from OCO-2 for flux inference must reliably account for transport-induced time/space variations, either through explicit simulation within the atmospheric transport model or by representation of transport-induced errors within the error covariance matrix. We note that larger-scale synoptic weather systems are more likely to be simulated explicitly by atmospheric inverse modeling frameworks, which generally have horizontal resolutions between $0.5^{\circ}$ to $5^{\circ}$ (Corbin et al., 2008), whereas mesoscale systems occur at spatial scales smaller than the grid-cell resolution for all but the highest resolution atmospheric transport models. These smaller mesoscale systems, therefore, may not be represented explicitly by atmospheric transport models despite affecting the distribution of $\mathrm{X}_{\mathrm{CO}_{2}}$. Because mesoscale or frontal systems may also have clouds, which obscure space-based $\mathrm{X}_{\mathrm{CO}_{2}}$ measurements, it is important to quantify the variance and spatial coherence of $\mathrm{X}_{\mathrm{CO}_{2}}$ that will be averaged from satellite measurements before for comparison with a single model grid-cell value (Corbin et al., 2008).

In this study, we use complementary information from space-based (OCO-2) and groundbased (TCCON) remote sensing of $\mathrm{X}_{\mathrm{CO}_{2}}$ to quantify the imprint of mesoscale atmospheric transport and to refine the variance budget of OCO-2 $\mathrm{X}_{\mathrm{CO}_{2}}$. While the current suite of carbon observing satellites provide spatially dense observations, the time in between satellite overpasses at a specific location is too long (16 days for OCO-2) to sample temporal variations of $\mathrm{X}_{\mathrm{CO}_{2}}$ driven by mesoscale (i.e., the duration of a thunderstorm) or synoptic-scale systems (i.e., the time in between frontal systems, which is typically on the order of a week in mid latitude regions). In contrast, ground-based networks, such as TCCON, provide temporally dense, but spatially sparse observations. To use these observations together, we must develop a framework that relates the spatial variations in OCO-2 data to the temporal variations in TCCON data.

Throughout our analysis, we are cognizant of the fact that observing system error may also introduce variance to satellite data (Baker et al., 2010; Chevallier et al., 2014). For example, Worden et al. (2017) showed that natural variability (i.e., variations due to natural surface fluxes, anthropogenic emissions, and atmospheric transport) of $\mathrm{X}_{\mathrm{CO}_{2}}$ along simulated representative OCO-2 tracks was negligibly small (approximately $0.08 \mathrm{ppm}$ over $100 \mathrm{~km}$ neighborhoods) in comparison to variations of $1.28 \mathrm{ppm}$ per $100 \mathrm{~km}$ attributed to instrument noise and slow varying biases, such as those caused by surface pressure or albedo variations, observed in OCO-2 data. Therefore, while the primary purpose of this study is to understand synoptic and mesoscale variations of $\mathrm{X}_{\mathrm{CO}_{2}}$, we also leverage retrievals of total column-averaged mole fractions of water vapor $\left(\mathrm{X}_{\mathrm{H}_{2} \mathrm{O}}\right)$ from 
OCO-2 (Nelson et al., 2016) and TCCON observations to validate our approach to estimating terms in Equation 5. Retrievals of water vapor from OCO-2 have a high signal-to-noise ratio (from several hundred to greater than 1000) (Nelson et al., 2016). Therefore, we expect that synoptic and mesoscale variations of atmospheric transport $\mathrm{X}_{\mathrm{H}_{2} \mathrm{O}}$ are more readily quantifiable from space-based observations.

This manuscript is organized around answering the following science questions.

1.) What is the imprint of synoptic and mesoscale systems on $\mathrm{X}_{\mathrm{CO}_{2}}\left(\right.$ and $\left.\mathrm{X}_{\mathrm{H}_{2} \mathrm{O}}\right)$ ?

2.) How predictive are large-scale spatial gradients in $\mathrm{X}_{\mathrm{CO}_{2}}$ (or $\mathrm{X}_{\mathrm{H}_{2} \mathrm{O}}$ ) of the imprint of synoptic and mesoscale atmospheric transport on OCO-2 observations?

3.) How large are other sources of fine-scale variation in $\mathrm{X}_{\mathrm{CO}_{2}}\left(\right.$ and $\left.\mathrm{X}_{\mathrm{H}_{2} \mathrm{O}}\right)$ in the OCO-2 variance budget?

In Section 2, we describe the methods and framework we used to quantify variability attributed to synoptic and mesoscale atmospheric transport from both TCCON and alongtrack OCO-2 observations of $\mathrm{X}_{\mathrm{CO}_{2}}$ and $\mathrm{X}_{\mathrm{H}_{2} \mathrm{O}}$. In Section 3, we describe the variance budgets for OCO-2 $\mathrm{X}_{\mathrm{CO}_{2}}$ and $\mathrm{X}_{\mathrm{H}_{2} \mathrm{O}}$ in the context of validation data from TCCON. In Section 4, we provide discussion and recommendations for future work toward robust flux influence from the satellite data.

\section{Methods}

\subsection{Framework to compare temporal and spatial variability of trace gases}

This article is protected by copyright. All rights reserved. 

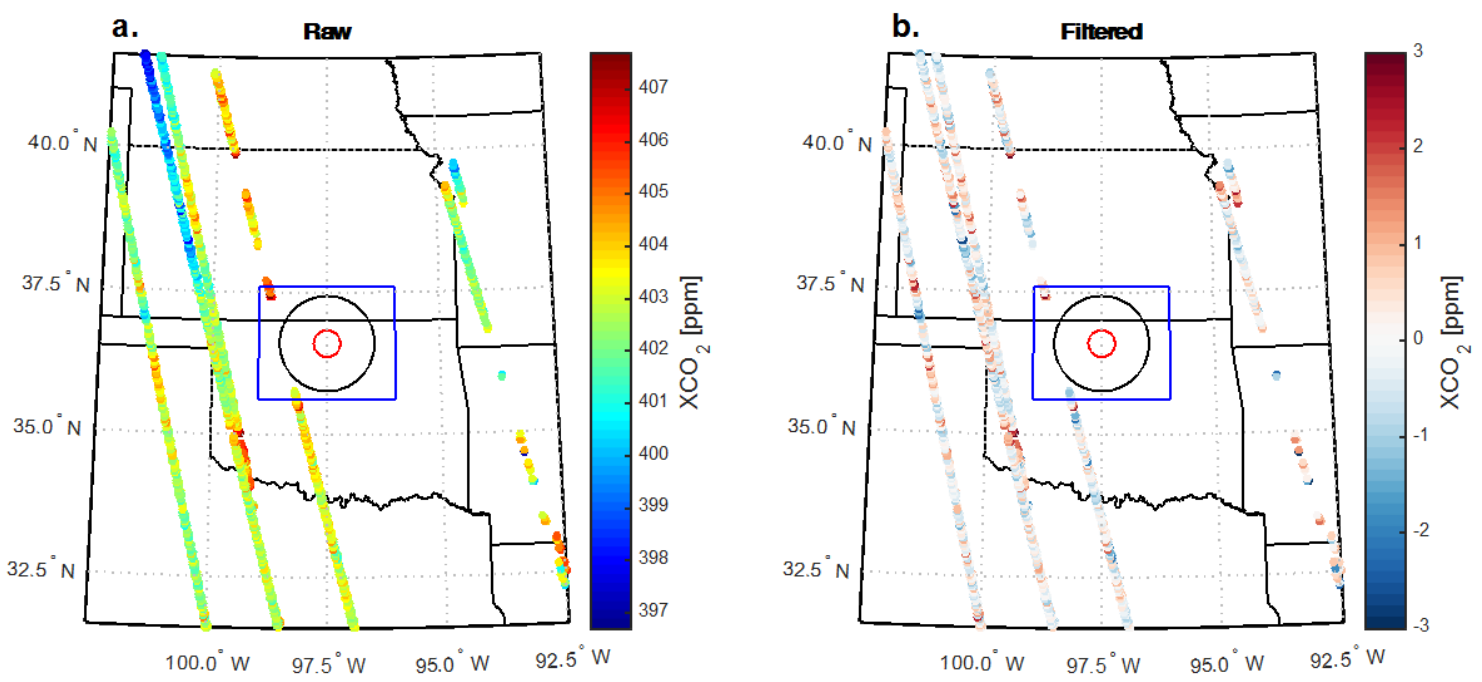

Figure 1. $\mathrm{X}_{\mathrm{CO}_{2}}$ tracks over a $10^{\circ} \times 10^{\circ}$ domain centered on Lamont, Oklahoma for one 16-day repeat cycle in early July 2016. (a.) Raw XCO2 soundings and (b.) High-pass filtered $\mathrm{X}_{\mathrm{CO}_{2}}$. The radius of the red and black circle represents the monthly mean range (denoted as $a_{\text {space }}$ ) of explained variability of $\mathrm{X}_{\mathrm{CO}_{2}}$ and $\mathrm{X}_{\mathrm{H}_{2} \mathrm{O}}$, respectively in July. The blue box represents a typical $3^{\circ} \times 2^{\circ}$ grid cell used in atmospheric inversion models, such as those used in Basu et al. (2018).

This framework provides the basis to which we compare temporal mesoscale variability of along-track $\mathrm{X}_{\mathrm{CO}_{2}}$ and $\mathrm{X}_{\mathrm{H}_{2} \mathrm{O}}$ observed at TCCON ground sites to along-track spatial mesoscale variability from OCO-2 data. We define along-track mesoscale spatial variability of $\mathrm{X}_{\mathrm{CO}_{2}}$ and $\mathrm{X}_{\mathrm{H}_{2} \mathrm{O}}$ for tracks that occur within a $10^{\circ}$ by $10^{\circ}$ box of TCCON sites (Fig. 1). The domains of analysis chosen were large enough to encompass several representative atmospheric transport model grid cells, such as the $3^{\circ}$ by $2^{\circ}$ grid cells used by Basu et al. (2018) to infer carbon fluxes.

We start from the tracer conservation equation in one dimension:

$$
\frac{\partial c}{\partial t}=-u \frac{\partial c}{\partial x}+S_{c}(\text { Equation } 1)
$$

where $c$ represents the tracer concentration, in this case $\mathrm{X}_{\mathrm{CO}_{2}}, u$ represents the columnweighted wind velocity in one direction (assumed along the OCO-2 track), and $S_{c}$ represents the column-average surface sources and sinks of $\mathrm{CO}_{2}$ (with appropriate scaling to convert from flux to $\mathrm{X}_{\mathrm{CO}_{2}}$ column-average variation). In this equation, we have neglected molecular diffusion of $\mathrm{X}_{\mathrm{CO}_{2}}$, which is small relative to the other terms, and any 
variations in $u$ and $\mathrm{CO}_{2}$ in the vertical profile by simply using the total column averages. We decompose $c$ into its mean and variable components (Equation 2)

$$
c=\bar{c}+c^{\prime} \text { (Equation 2) }
$$

and Reynolds average Equation 1 to yield an equation for the time rate of change of $\bar{c}$ (Equation 3). For our analysis, we assume that the filter used to determine the average concentration, $\bar{c}$, results in a $c^{\prime}$ that reflects mesoscale variations in the tracer concentration while synoptic and slower- and larger-scale variations remain in $\bar{c}$.

$$
\frac{\partial \bar{c}}{\partial t}=-\bar{u} \frac{\partial \bar{c}}{\partial x}-\frac{\partial \overline{u^{\prime} c^{\prime}}}{\partial x}+\overline{S_{c}}(\text { Equation } 3)
$$

The first term on the right hand side represents the advection of the mean gradient in $c$ by the mean wind, while the second term represents turbulent flux divergence. Equation 3 underscores that spatial gradients in the mean tracer concentration give rise to temporal variations through the action of atmospheric transport. We can subtract equation 3 from equation 1 , expanded by replacing $u$ and $c$ with the corresponding mean and anomaly terms from equation 2 (and equivalent equation for $u$ ), to yield an equation for the time rate of change for the fluctuating component, $c^{\prime}$ :

$$
\frac{\partial c^{\prime}}{\partial t}=-\bar{u} \frac{\partial c^{\prime}}{\partial x}-u^{\prime} \frac{\partial \bar{c}}{\partial x}-u^{\prime} \frac{\partial c^{\prime}}{\partial x}+\frac{\partial \overline{u^{\prime} c^{\prime}}}{\partial x}+S_{c}^{\prime}(\text { Equation 4) }
$$

In equation 4, the first term on the right hand side represents the advection of mesoscale gradients by the mean wind, the second term and third terms represent the production of mesoscale anomalies in $c$ by eddies acting on the mean gradient and mesoscale gradient, respectively. The fourth term represents the turbulent flux convergence. We can simplify equation 4 by assuming that the production term from eddies acting on mesoscale gradients and the turbulent flux convergence are both small. We also neglect variations in sources, $S_{c}^{\prime}$, since our framework accounts for only climatological mean surface fluxes (described in detail in 3.2.1 below). We can then use scaling arguments to approximate these terms:

$$
\frac{\left\langle c^{\prime}\right\rangle_{\text {time }}}{\tau_{\text {time }}}=\bar{u} \frac{\left\langle c^{\prime}\right\rangle_{\text {space }}}{a_{\text {space }}}+\left\langle u^{\prime}\right\rangle\left\langle\frac{\partial \bar{c}}{\partial x}\right\rangle(\text { Equation 5) }
$$

In equation $5,\left\langle c^{\prime}\right\rangle_{\text {time }}$ represents the characteristic magnitude of temporal variations at a TCCON site over a relevant mesoscale timescale $\tau_{\text {time }}$. The variable $\left\langle c^{\prime}\right\rangle_{\text {space }}$ represents the characteristic magnitude of along-track spatial variations from OCO-2 over a relevant 
mesoscale length scale, $a_{\text {space }}$. The last term on the right-hand side (RHS) represents the advection of the mean gradient $\left\langle\frac{\partial \bar{c}}{\partial x}\right\rangle$ by mesoscale transport $\left\langle u^{\prime}\right\rangle$.

The crux of our analysis is to compare $\left\langle c^{\prime}\right\rangle_{\text {time }}$ and $\tau_{\text {time }}$ inferred from empirical analysis of TCCON observations with $\left\langle c^{\prime}\right\rangle_{\text {space }}$ and $a_{\text {space }}$ inferred from geostatistical analysis of high-pass filtered OCO-2 tracks. This analysis is conducted with an eye toward using the OCO-2 derived estimates of $\left\langle c^{\prime}\right\rangle_{\text {space }}$ and $a_{\text {space }}$ to improve the representation of fine scale transport errors within the error covariance budget provided to inverse models used for flux inference.

\subsection{TCCON}

We quantified temporal synoptic and mesoscale variations in $\mathrm{X}_{\mathrm{CO}_{2}}$ and $\mathrm{X}_{\mathrm{H}_{2} \mathrm{O}}$ using ground-based remote sensing data from sites in the TCCON network (Table 1). TCCON sites are instrumented with ground-based Fourier Transform Spectrometers that acquire direct solar absorption spectra approximately every two minutes during sunny conditions (Wunch et al., 2015). TCCON instruments obtain near infrared spectra in the same spectral region as OCO-2 $(0.65-2.63 \mu \mathrm{m})$, and total column $\mathrm{CO}_{2}$ is retrieved in the 1.58 and $1.60 \mu \mathrm{m}$ absorption bands and total column $\mathrm{H}_{2} \mathrm{O}$ is retrieved in the $1.54-1.65 \mu \mathrm{m}$ absorption bands using the GFIT algorithm (Wunch et al., 2011). Because TCCON measures direct solar absorption spectra, the signal to noise ratio is higher compared to that of OCO-2, and the uncertainties on TCCON X $\mathrm{CO}_{2}$ have a calibration accuracy of 0.4 ppm (Wunch et al., 2010). TCCON data are calibrated to the World Meteorological Organization (WMO) standard ensuring absolute accuracy of measurements better than $0.25 \%$ (Washenfelder et al., 2006; Wunch et al., 2011). We analyzed data from TCCON sites that have data records longer than 5 years and that observe across a full annual cycle to minimize biases introduced by seasonal and interannual variations. 


\begin{tabular}{|l|l|l|l|}
\hline TCCON Site & Location & Observational Periods & Citation \\
\hline Bialystok, & $53.33^{\circ} \mathrm{N}$, & March 13, 2009- April & Deustcher et al. (2014) \\
Poland & $23.03^{\circ} \mathrm{E}$ & 14,2017 & \\
\hline Karlsruhe, & $49.10^{\circ} \mathrm{N}$, & April 19, 2010- & Hase et al. (2014) \\
Germany & $8.44^{\circ} \mathrm{E}$ & January 24, 2018 & \\
\hline Orleans, France & $47.97^{\circ} \mathrm{N}$, & August 29, 2009- & Warneke et al. (2014) \\
& $2.11^{\circ} \mathrm{E}$ & April 29, 2017 & \\
\hline Garmisch, & $47.48^{\circ} \mathrm{N}$, & July 16, 2007- March & Sussman and Rettinger (2014) \\
Germany & $11.06^{\circ} \mathrm{E}$ & 16,2018 & \\
\hline $\begin{array}{l}\text { Park Falls, } \\
\text { Wisconsin }\end{array}$ & $45.95^{\circ} \mathrm{N}$, & June 2, 2004- & Wennberg et al. (2014a), Washenfelder et al. \\
& $90.27^{\circ} \mathrm{E}$ & December 31, 2017 & (2006) \\
\hline Lamont, & $36.60^{\circ} \mathrm{N}$, & July 6, 2008- & Wennberg et al. (2014b) \\
Oklahoma & $97.49^{\circ} \mathrm{W}$ & December 31, 2017 & \\
\hline Darwin, & $12.42^{\circ} \mathrm{S}$, & August 28, 2005- & Griffith et al. (2014), Deutscher et al., (2010) \\
Australia & $130.89^{\circ} \mathrm{E}$ & March 28, 2017 & \\
\hline Reunion Island, & $20.90^{\circ} \mathrm{S}$, & September $16,2011-$ & De Mazière et al. (2014) \\
France & $55.49^{\circ} \mathrm{E}$ & January 30, 2018 & \\
\hline Lauder, New & $45.04^{\circ} \mathrm{S}$, & February 2, 2010- & Sherlock et al. (2014) \\
Zealand & $169.69^{\circ} \mathrm{E}$ & November 1, 2017 & \\
\hline
\end{tabular}

Table 1. Locations of TCCON sites and observational periods analyzed in this study with associated references.

\subsubsection{Removing diurnal cycle climatology of $\mathrm{X}_{\mathrm{H}_{2} \mathrm{O}}$ and $\mathrm{X}_{\mathrm{CO}_{2}}$ to quantify temporal synoptic and mesoscale variability}

We separated the imprint of synoptic and mesoscale systems on variations in TCCON $\mathrm{X}_{\mathrm{CO}_{2}}$ and $\mathrm{X}_{\mathrm{H}_{2} \mathrm{O}}$ by assuming that the only sources of variations were surface fluxes or atmospheric transport. For both $\mathrm{X}_{\mathrm{CO}_{2}}$ and $\mathrm{X}_{\mathrm{H}_{2} \mathrm{O}}$, we assumed that flux-driven diurnal variations could be accounted for by calculating a monthly climatological daily cycle of $\mathrm{X}_{\mathrm{CO}_{2}}$ variations for each site, since atmospheric transport patterns may be random but surface fluxes are phase-locked to the diurnal cycle. We note there are changes in surface fluxes in response to physical climate changes, such as thunderstorms/rain, cloud coverage, or boundary layer temperature, induced by mesoscale and synoptic-scale systems (Baldocchi et al., 2001). There is, however, no easy way to attribute the changes in $\mathrm{X}_{\mathrm{CO}_{2}}$ and $\mathrm{X}_{\mathrm{H}_{2} \mathrm{O}}$ to either changing fluxes or synoptic/mesoscale transport without running a coupled atmosphere/land model. We choose instead to use an empirical, datadriven approach that necessitates neglecting weather-driven changes in surface fluxes. 
For each calendar month, we binned all available observations (after removing the longterm trend) from the multi-year time series into half-hour increments to reveal the characteristic diurnal cycle (Fig. S1-2). For any given month, we limited our analysis to daytime observations obtained at solar zenith angle less than $75^{\circ}$ to reduce the influence of spectroscopic errors at high air masses. We then removed the climatological daily cycle from each calendar day with observations, and assumed that the residual was the component of variability driven by transport. We note that this approach is a simplification, and expect that at least some of the residual were due to synoptic, intraseasonal, and interannual variability of surface fluxes. Our approach does, however, allow us to approximate the influence of local fluxes on the observations without relying on an ecosystem model or sparse flux tower data with limited spatial footprints

Given our assumption that temporal variability of $\mathrm{X}_{\mathrm{CO}_{2}}$ and $\mathrm{X}_{\mathrm{H}_{2} \mathrm{O}}$ is derived from either local fluxes or atmospheric transport, we can then estimate the influence of atmospheric transport-driven variations from the time series of residuals. We calculated the standard deviation from the half-hourly bin averaged residuals at bi-weekly time intervals to approximate variability at synoptic and smaller timescales. We likewise calculated the standard deviation of the residuals within each day to approximate mesoscale variability. These time periods were sufficient to sample variability attributed to multiple synoptic scale weather systems, such as high and low pressure systems and frontal passages, or mesoscale systems, such as individual thunderstorms.

We evaluate our approach for calculating the influence of climatological fluxes on the diurnal cycle of $\mathrm{X}_{\mathrm{CO}_{2}}$ at the Park Falls TCCON site since it is co-located with an Ameriflux eddy covariance (EC) tower that provides observations of diurnally varying NEE (Desai et al 2015). We estimate the influence that the observed eddy covariance fluxes have on the daily cycle of $\mathrm{X}_{\mathrm{CO}_{2}}$ (and denote this quantity as $\mathrm{X}_{\mathrm{CO}_{2}, E C}$ using equations 6 and 7:

$$
\begin{array}{r}
\left\langle\frac{d X_{C O_{2}, E C}}{d t}\right\rangle=\frac{N E E_{E C} \cdot g \cdot M W_{\text {dry air }}}{P_{S}} \\
\mathrm{X}_{\mathrm{CO}_{2}, E C}=\int_{\tau_{A M}}^{\tau_{P M}}\left\langle\frac{d X_{C O_{2}, E C}}{d t}\right\rangle d \tau
\end{array}
$$

where $N E E_{E C}$ represents the observed net ecosystem exchange, $g$ represents the gravitational constant of $9.81 \mathrm{~ms}^{-2}, M W_{\text {dry air }}$ represents the molecular weight of dry air, $P_{s}$ represents the surface pressure, and $\tau$ represents time. We calculated $\mathrm{X}_{\mathrm{CO}_{2}, E C}$ at hourly time steps over a period $\tau$ from when the local solar zenith angle crosses 70 degrees in the morning and afternoon. The seasonal cycle of the within-day variation in $\mathrm{X}_{\mathrm{CO}_{2}}$ 
observed by the TCCON instrument agrees well with the seasonal cycle of the expected within-day variation in $\mathrm{X}_{\mathrm{CO}_{2}}$ from NEE observations $\left(\mathrm{R}^{2}\right.$ of 0.8 ; Fig. 2a). The magnitude of the error bars derived from NEE, which represent the standard deviation among individual days, are substantially smaller than the magnitude of the error bars derived from the TCCON $\mathrm{X}_{\mathrm{CO}_{2}}$ drawdown (Fig. 2b). During winter, the average standard deviation for $\mathrm{X}_{\mathrm{CO}_{2}, E C}$ is less than $0.1 \mathrm{ppm}$ while the average standard deviation from $\mathrm{X}_{\mathrm{CO}_{2}, F T S}$ is about $0.4 \mathrm{ppm}$. In contrast, the average summer standard deviation is about

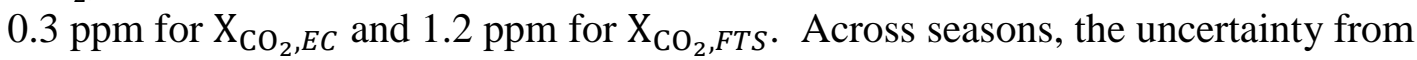
assuming a climatological within-day drawdown therefore reflects at most $30 \%$ of the total variability across the days on which observations are obtained. This suggests that most of the within-in day variation for $\mathrm{X}_{\mathrm{CO}_{2}}$ results from processes other than local fluxes, confirming the motivation of the present study.
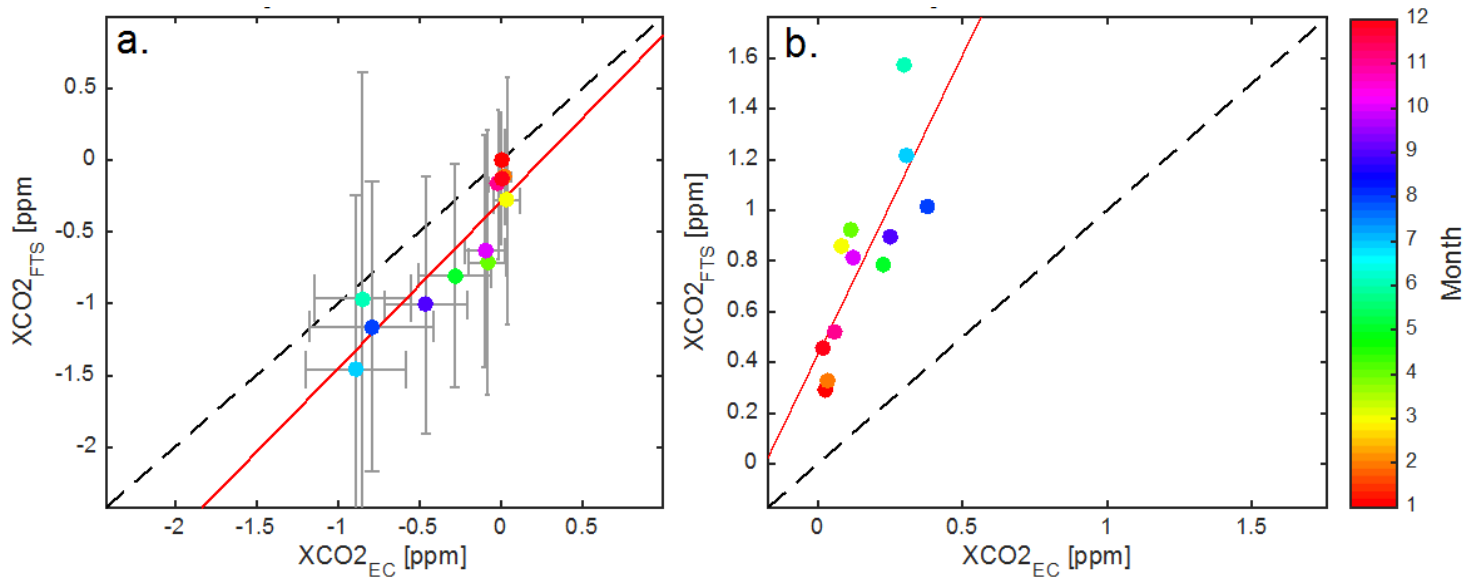

Figure 2. (a.) A comparison of the climatological monthly mean diurnal mean amplitude of $\mathrm{X}_{\mathrm{CO}_{2}}$ observed at the TCCON site $\left(\mathrm{X}_{\mathrm{CO}_{2}, F T S}\right)$ compared to the estimated imprint of drawdown based on the observed net ecosystem exchange at the adjacent FluxNet eddy covariance tower in Park Falls, Wisconsin $\left(\mathrm{X}_{\mathrm{CO}_{2}, E C}\right)$. (b. $)$ The standard deviation of monthly mean $\mathrm{X}_{\mathrm{CO}_{2}, F T S S}$ compared to the standard deviation of $\mathrm{X}_{\mathrm{CO}_{2}, E C}$ plotted in panel a. Note that the axes in panel b. are different.

\subsection{OCO-2}

We analyzed spatial variations in $\mathrm{X}_{\mathrm{CO}_{2}}$ and $\mathrm{X}_{\mathrm{H}_{2} \mathrm{O}}$ retrieved from OCO-2 satellite observations. OCO-2 is a sun-synchronous, polar-orbiting satellite with a spatial footprint for individual soundings of $2.4 \mathrm{~km}$ along-track and $1.25 \mathrm{~km}$ cross-track; the instrument measures 8 cross-track bins at each time step resulting in a narrow ( $10 \mathrm{~km}$ wide) sampling swath (Eldering et al., 2017). The satellite acquires a repeat cycle of 
approximately every 16 days using three scanning modes, described below. The instrument comprises three grating spectrometers that measure radiances from reflected near-infrared sunlight in two $\mathrm{CO}_{2}$ bands, the 1.61 weak absorption band $\left(\mathrm{WCO}_{2}\right)$ and the $2.06 \mu \mathrm{m}$ strong $\mathrm{CO}_{2}\left(\mathrm{SCO}_{2}\right)$ absorption band, and in the $0.72 \mu \mathrm{m}$ oxygen $\left(\mathrm{O}_{2} \mathrm{~A}\right)$ absorption band. These radiances are used in a full physics retrieval algorithm (version 8r, O'Dell et al., 2012; 2018), which uses optimal estimation to infer the vertical column of both $\mathrm{CO}_{2}$ and $\mathrm{O}_{2}$ while simultaneously adjusting other elements of the retrieval state vector, including the surface albedo for each band, aerosol optical depth (AOD), and other parameters that affect measured radiances (O'Dell et al., 2012; 2018). The reported error for each $\mathrm{X}_{\mathrm{CO}_{2}}$ sounding is estimated using instrument noise, and then post-processed to account for errors associated with the forward model used in the retrieval algorithm (O'Dell et al., 2012; Wunch et al., 2017). The measurements are bias-corrected by accounting for biases in individual cross-track observations using multivariate linear regression to identify physically unrealistic correlations between $\mathrm{X}_{\mathrm{CO}_{2}}$ and other elements of the retrieval state vector (such as surface pressure, aerosols, or unphysical variations of the retrieved vertical profile of $\mathrm{CO}_{2}$ ) and systematic offsets of OCO-2 $\mathrm{X}_{\mathrm{CO}_{2}}$ target mode retrievals in comparison to TCCON observations (O'Dell et al., 2018). The (lower bound) bias-corrected single sounding errors for retrieved $\mathrm{X}_{\mathrm{CO}_{2}}$ are generally less than 1 ppm (compared to a mean global value of approximately 410 ppm; Tans and Keeling, 2018), with the largest errors over land and higher latitudes (generally above $45^{\circ} \mathrm{N}$ or S) and smallest errors over the ocean (Eldering et al., 2017). Similarly, $\mathrm{X}_{\mathrm{H}_{2} \mathrm{O}}$ was retrieved from OCO-2 using the 1.61 and $2.06 \mu$ m weak and strongly absorbing $\mathrm{H}_{2} \mathrm{O}$ spectral bands with mean biases of approximately $70 \mathrm{ppm}$, compared to typical $\mathrm{X}_{\mathrm{H}_{2} \mathrm{O}}$ concentrations that varies from roughly 700 to 9000 ppm globally (Nelson et al., 2016).

OCO-2 uses three scanning modes to optimize retrievals over land and ocean surfaces, including nadir (land only), glint (over ocean and land), where the instrument is pointed at the glint angle to maximize reflected light over water surfaces, and target where the instrument angle is adjusted to point towards a targeted location (typically a groundbased validation site). In this analysis, we investigate nadir and glint observations separately, and only used soundings without a quality warning flag (Osterman et al., 2018). In the figures, we report averages of nadir and glint observations since the only systematic differences were at coastal locations where there were not sufficient nadir observations. Note that many tracks exhibit significant missing data because of cloud cover.

\subsubsection{Geostatistical analysis}

We used geostatistical analysis to quantify the variance budget for OCO-2 data. We removed low frequency variations using a $250 \mathrm{~km}$ Hamming high-pass filter. To apply 
the filter, the data were pre-processed by averaging up to 8 cross-track soundings into 1.1 $\mathrm{km}$ bins in nadir mode or $1.3 \mathrm{~km}$ bins in glint mode to create a 1-dimensional track. We gap-filled empty bins with a distance-weighted mean of the nearest filled bin. For each $10^{\circ}$ by $10^{\circ}$ box, we filtered tracks containing valid observations in at least 96 bins in glint mode or 113 bins in nadir mode (i.e. one-half of the rolling window filter size). To minimize edge effects on the high-pass filter, we attached a 250-point buffer made up of the average of the first 250 bins (i.e. the length of variability passed through the high pass filter) to the beginning and end of each satellite track. After running the filter, we repopulated each sounding with the filtered bin-averaged and gap-filled values and began our semivariogram analysis described below.

We separated variance of $\mathrm{X}_{\mathrm{CO}_{2}}$ and $\mathrm{X}_{\mathrm{H}_{2} \mathrm{O}}$ along OCO-2 tracks into random errors ("unexplained variance") and the component that is spatially coherent, or systematic, ("explained variance") by calculating semivariograms for the high frequency component of $\mathrm{X}_{\mathrm{H}_{2} \mathrm{O}}$ and $\mathrm{X}_{\mathrm{CO}_{2}}$. We calculated the semivariance $\left(\gamma^{*}\right)$ for lag $d$ at position $x_{k}$ for sounding values $Z$ using Equation 6,

$$
\gamma^{*}(d)=\frac{1}{2 N(d)} \sum_{k=1}^{N}\left[Z\left(\vec{x}_{k}\right)-Z\left(\vec{x}_{k}+d\right)\right]^{2} \text { (Equation 8) }
$$

where $N$ is the number of soundings separated by lag $d$ (Cressie and Hawkins, 1980). We fit a spherical model (Equation 7) to estimate the total variance, $c_{\infty}$, and the spatial range of total variance, denoted as $a_{\text {space }}$ (as in equation 5), for each semivariogram (Fig. S3). For the spherical model fits, we fixed the unexplained variance, $c_{0}$, to the semivariance calculated from the observations at the smallest observed lag $(1.1 \mathrm{~km}$ in nadir or $1.3 \mathrm{~km}$ in glint mode).

$$
\gamma(d)=\left\{\begin{array}{cl}
c_{0}+\left(c_{\infty}-c_{0}\right)\left[\frac{3 d}{2 a_{\text {space }}}-\frac{1 d^{3}}{2 a_{\text {space }}^{3}}\right] & \text { for } d \leq a_{\text {space }} \\
c_{\infty} & \text { for } d>a_{\text {space }}
\end{array}\right. \text { (Equation 9) }
$$

We calculated the explained variance, denoted as $\left\langle c^{\prime}\right\rangle_{\text {space }}$, by subtracting the unexplained variance from the total variance, $c_{\infty}-c_{0}$. In this framework, the explained variance relates to spatially coherent patterns, which could be due to real atmospheric gradients owing to fine scale transport or errors arising from spatially coherent correlations between $\mathrm{X}_{\mathrm{H}_{2} \mathrm{O}}$ and $\mathrm{X}_{\mathrm{CO}_{2}}$ and other elements of the state vector. We compared the square root of unexplained and explained variances, denoted as unexplained and explained variability, to temporal variations observed at adjacent TCCON sites, described in more detail in Section 2.2. 


\subsubsection{North-south gradient calculation}

To investigate the mesoscale tracer transport term on the RHS of Equation 5, we quantified the relationship between fine-scale spatial variations and the large-scale gradient in $\mathrm{X}_{\mathrm{H}_{2} \mathrm{O}}$ and $\mathrm{X}_{\mathrm{CO}_{2}}$. We calculated the North-South (N-S) gradient from three different datasets. For OCO-2, we aggregated data within a $10^{\circ}$ by $10^{\circ}$ box centered at the TCCON sites listed in Table 1 . We calculated the gradient for each track within the targeted domain by fitting OCO-2 soundings to a simple least squares linear regression model weighted by self-reported errors from the version 8 level 2 retrieval algorithm. Because OCO-2 tracks may have data gaps associated with seasonal variations or cloud cover, we filtered the north-south gradients by quantifying the uncertainty $\left(\sigma_{N S}^{2}\right)$ of the estimated N-S gradient using Equation 8 (Glover et al., 2011), where $x_{i}$ represents the latitude and $\sigma_{i}$ is the OCO-2 reported retrieval error at point $i$ for $N$ total soundings. We then discarded regression fits that had an uncertainty larger than $0.01 \mathrm{ppm}^{\text {degree }}$. $^{-1}$.

$$
\sigma_{N S}^{2}=\frac{\sum_{i=1}^{N} \frac{1}{\sigma_{i}^{2}}}{\sum_{i=1}^{N} \frac{1}{\sigma_{i}^{2}} \cdot \sum_{i=1}^{N} \frac{x_{i}^{2}}{\sigma_{i}^{2}}-\left(\sum_{i=1}^{N} \frac{x_{i}}{\sigma_{i}^{2}}\right)^{2}} \text { (Equation 10) }
$$

We compared monthly mean observed N-S gradients from OCO-2 to two additional datasets: the monthly mean N-S gradients derived from assimilated 2017 CarbonTracker (CT2017) output from the OCO-2 period (from 2014-2017, with observations ongoing) and the N-S gradients inferred from the High-Performance Instrumented Airborne Platform for Environmental Research (HIAPER) Pole-to-Pole Observations (HIPPO) flight transects over the Pacific Ocean that took place between 2009 and 2011. CarbonTracker is a data assimilation system that provides three-dimensional atmospheric $\mathrm{CO}_{2}$ fields based on assimilating surface $\mathrm{CO}_{2}$ observations from NOAA's cooperative sampling network (Peters et al., 2007; with updates documented at http://carbontracker.noaa.gov). $\mathrm{X}_{\mathrm{CO}_{2}}$ was computed in their 2017 (CT2017) dataset with simple pressure-weighted vertical integration of $\mathrm{CO}_{2}$. During the HIPPO campaign, partial columns of $\mathrm{CO}_{2}$ were measured from roughly 300 to $8500 \mathrm{~m}$ altitude from aircraft transects spanning from $67^{\circ} \mathrm{S}$ to $85^{\circ} \mathrm{N}$ across the Pacific Ocean during all seasons between 2009 and 2011 (Wofsy et al., 2011). $\mathrm{X}_{\mathrm{CO}_{2}}$ was then inferred by integrating a pressure-weighted mean concentration using reference static pressure from the GV Paroscientific Model 1000 sensor (Wofsy et al., 2017). We did not apply averaging kernels to either the CT2017 or HIPPO data since we were not attempting to directly compare individual columns to their OCO-2 or TCCON counterparts, but rather to approximate the large-scale features in $\mathrm{X}_{\mathrm{CO}_{2}}$.

With sufficient data density, the N-S gradients derived from OCO-2 overpasses were 
broadly consistent with CT2017 output and HIPPO transects. However, when satellite data were characterized by gaps or low coverage during the winter season, the satellite estimate of the N-S gradient was inconsistent with HIPPO and CarbonTracker. Given this pattern of agreement and the need for year-round N-S gradient information, we used the CarbonTracker gradient to quantify monthly-mean N-S gradients and to evaluate the impact of the gradient on temporal synoptic-scale and mesoscale variability and alongtrack high frequency explained variability.

\section{Results}

\subsection{Temporal Variations at TCCON}

\subsubsection{Flux-driven diurnal variations}

Local diurnal fluxes account for up to 1 to $2.0 \mathrm{ppm}$ of within-day temporal variability of $\mathrm{X}_{\mathrm{CO}_{2}}$ during the growing season, with the largest diurnal signal observed during boreal summer (Fig. 3a). For example, in Lamont, Oklahoma, local ecosystem drawdown contributed a decrease of $\mathrm{X}_{\mathrm{CO}_{2}}$ of 1.1 ppm between 7:00 am to 5:30 pm LST (local standard time) in July, whereas it showed almost no change throughout the day (10 am to $2 \mathrm{pm}$ ) during winter months (Fig. S1), as expected given the relatively dormant winter biosphere. At most midlatitude TCCON sites, local diurnal fluxes of $\mathrm{X}_{\mathrm{CO}_{2}}$ accounted for less than $0.3 \mathrm{ppm}$ of within-day variability during the winter (Fig. 3a). The seasonal cycle of $\mathrm{X}_{\mathrm{CO}_{2}}$ variability driven by diurnal fluxes at tropical TCCON sites, such as Darwin, Australia, was tied to the onset of the wet and dry seasons and varied from $0.1 \mathrm{ppm}$ and $1.1 \mathrm{ppm}$ (Fig. 3a). We note that these are typical within-day variations of $\mathrm{X}_{\mathrm{CO}_{2}}$ attributed to diurnal fluxes, and that the actual diurnal fluxes depend on weather, anthropogenic, and other natural interactions. 


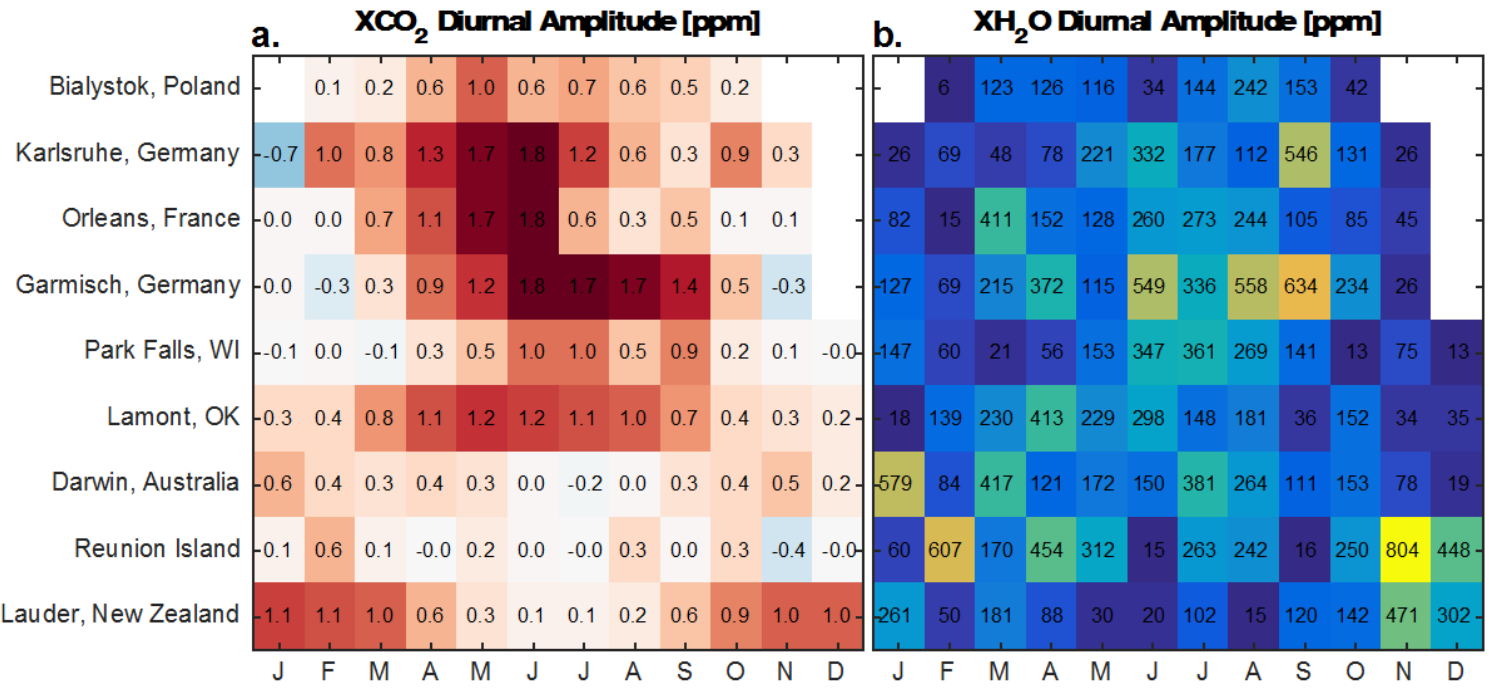

Figure 3. Climatological daytime diurnal range of a. $\mathrm{X}_{\mathrm{CO}_{2}}$ and b. $\mathrm{X}_{\mathrm{H}_{2} \mathrm{O}}$. We calculate the range between morning and evening, with a limit of solar zenith angle less than $75^{\circ}$.

The climatological diurnal cycle of $\mathrm{X}_{\mathrm{H}_{2} \mathrm{O}}$ had a strong seasonal cycle across all TCCON sites, with defined wet and dry seasons in the tropics, and lower winter and higher summer peak-to-trough diurnal cycle amplitudes in the midlatitudes (Fig. 3b). In the Northern Hemisphere midlatitudes, the within-day local imprint was maximum in the summer (around 200-600 ppm) and smallest during boreal winter (around 5-100 ppm). Within-day, flux-driven variations were largest at the two tropical TCCON sites, which are both located in the Southern Hemisphere tropics. Within-day variations in these regions could exceed 500 ppm during austral summer but were generally 300-500 ppm during austral winter (Fig. 3b). We note that while many atmospheric processes are analogous for $\mathrm{X}_{\mathrm{CO}_{2}}$ and $\mathrm{X}_{\mathrm{H}_{2} \mathrm{O}}$, condensation and precipitation drive additional spatial and temporal variability in $\mathrm{X}_{\mathrm{H}_{2} \mathrm{O}}$ (Dai and Wang, 2002). The values we report in Fig. $3 \mathrm{~b}$ are the peak-to-trough difference in within-day $\mathrm{X}_{\mathrm{H}_{2} \mathrm{O}}$ climatology. During summer, most TCCON sites showed a maximum value of $\mathrm{X}_{\mathrm{H}_{2} \mathrm{O}}$ in mid-to-late afternoon (1400 to 1700h, Fig. S2), consistent with the diurnal phasing of precipitable water reported by Dai and Wang (2002). 


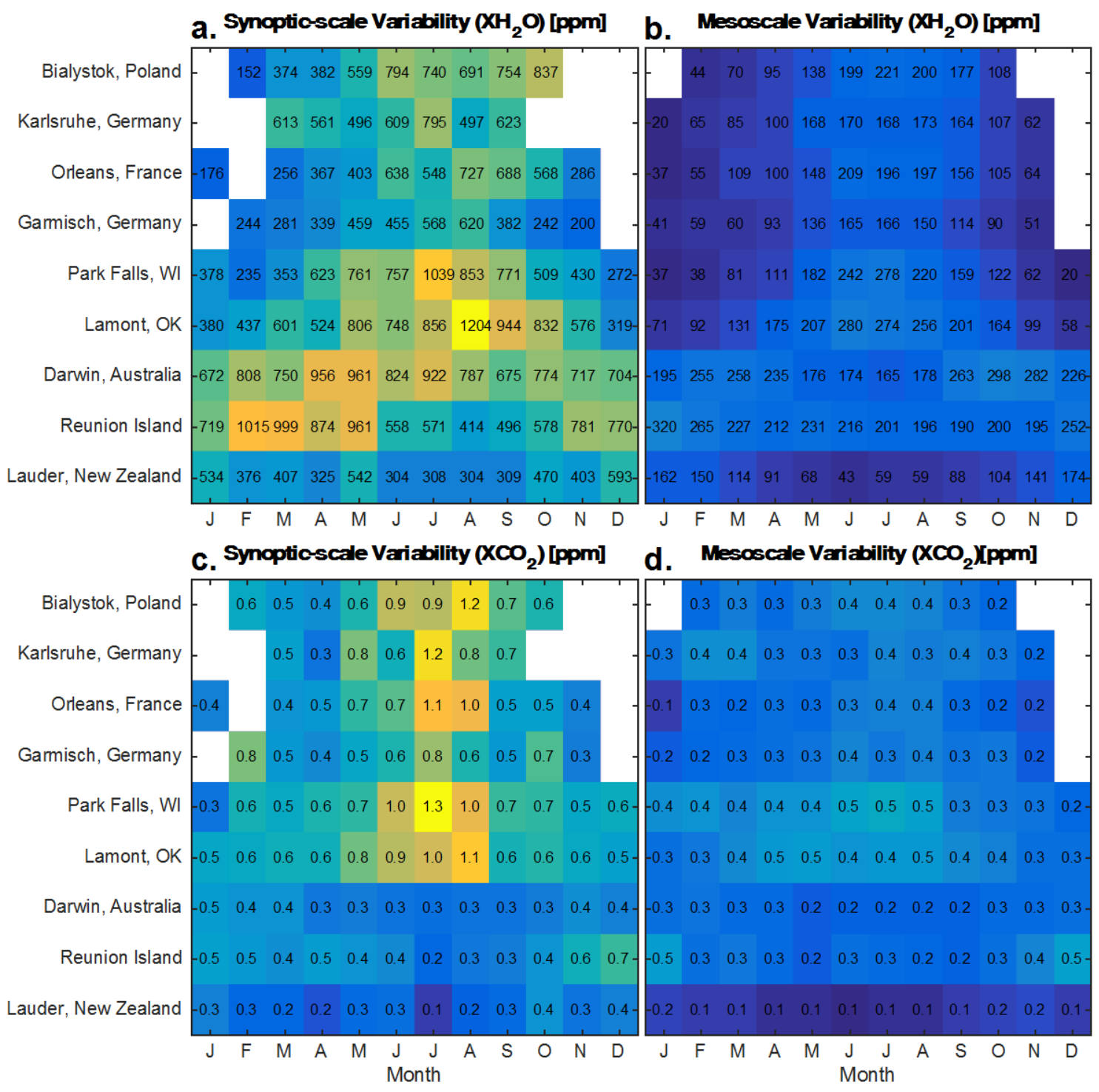

Figure 4. Comparison of synoptic-scale and variability in TCCON observations. (a.) $\mathrm{X}_{\mathrm{H}_{2} \mathrm{O}}$ monthly mean synoptic-scale (bi-weekly) variability, (b.) $\mathrm{X}_{\mathrm{H}_{2} \mathrm{O}}$ mesoscale (withinday) variability, (c.) $\mathrm{X}_{\mathrm{CO}_{2}}$ monthly mean synoptic-scale variability, and (d.) $\mathrm{X}_{\mathrm{CO}_{2}}$ monthly mean mesoscale variability. Note that the color scales for $\mathrm{X}_{\mathrm{H}_{2} \mathrm{O}}$ and $\mathrm{X}_{\mathrm{CO}_{2}}$ are different. 

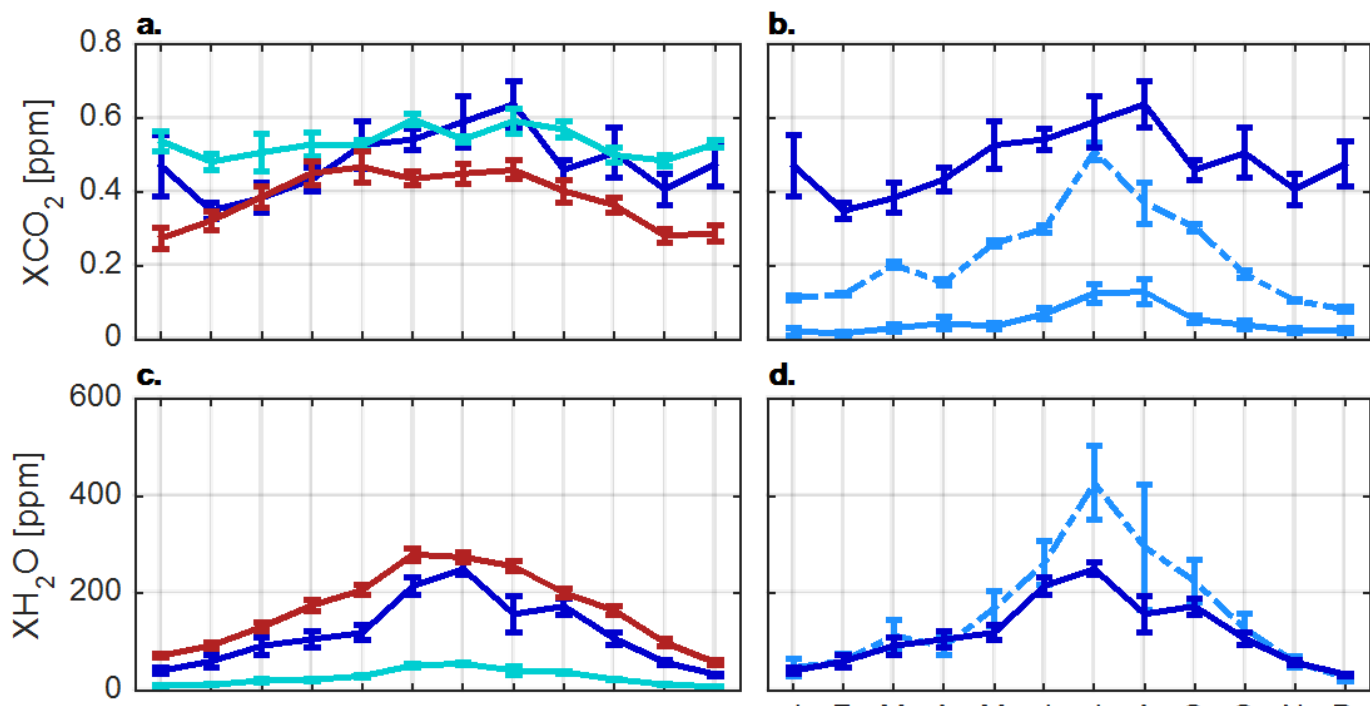

d.
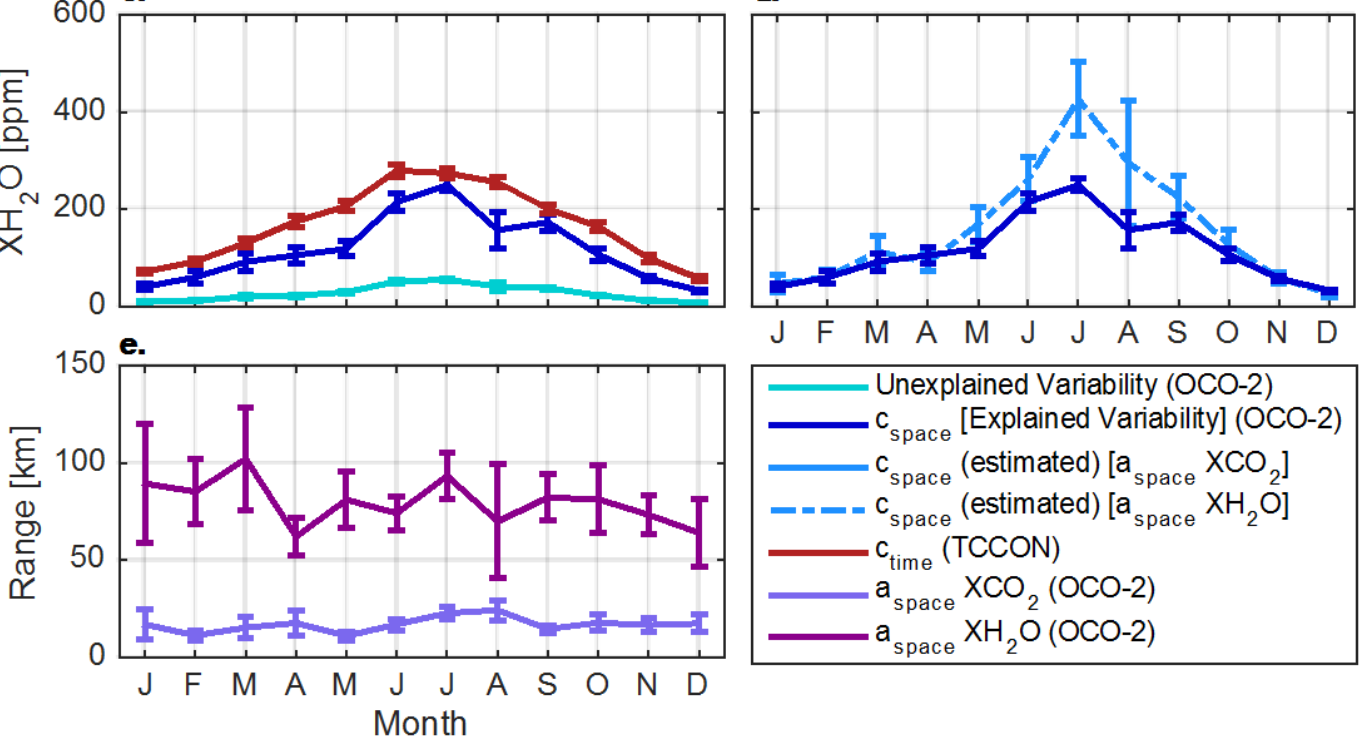

Figure 5. A comparison of monthly mean TCCON temporal mesoscale $\left\langle c^{\prime}\right\rangle_{\text {time }}$ (withinday) variability (red), OCO-2 observed along-track high frequency unexplained (teal) and explained $\left(\left\langle c^{\prime}\right\rangle_{\text {space }}\right)$ (dark blue) spatial variability, and explained variability $\left(\left\langle c^{\prime}\right\rangle_{\text {space }}\right)$ estimated from Equation 12 (light blue) using ranges $\left(\mathrm{a}_{\text {space }}\right)$ observed by OCO-2 for $\mathrm{X}_{\mathrm{H}_{2} \mathrm{O}}$ (dashed line) and $\mathrm{X}_{\mathrm{CO}_{2}}$ (solid line). Panels (a.-b.) shows variability for $\mathrm{X}_{\mathrm{CO}_{2}}$ and panels (c.-d.) $\mathrm{X}_{\mathrm{H}_{2} \mathrm{O}}$ in Lamont, Oklahoma. The bottom panel, e., represents the range $\left(a_{\text {space }}\right)$ of along-track high frequency explained spatial variability of $\mathrm{X}_{\mathrm{H}_{2} \mathrm{O}}$ (dark purple) and $\mathrm{X}_{\mathrm{CO}_{2}}$ (light purple). The error bars for observed parameters represent the standard error. For estimated $\left\langle c^{\prime}\right\rangle_{\text {space }}$, the error bars represent the error propagation using climatological monthly mean standard error of each observed parameter.

\subsubsection{Synoptic-scale (bi-weekly) variability}


Mean temporal synoptic-scale (bi-weekly) variations in both $\mathrm{X}_{\mathrm{H}_{2} \mathrm{O}}$ and $\mathrm{X}_{\mathrm{CO}_{2}}$ from TCCON were larger in magnitude to the typical daily cycle (Fig. 3 and 4). For $\mathrm{X}_{\mathrm{H}_{2} \mathrm{O}}$, synoptic-scale variations were, on average, 4 times larger than variability attributed to diurnal fluxes (Fig. 3 and 4). For some months, synoptic-scale variability of $\mathrm{X}_{\mathrm{H}_{2} \mathrm{O}}$ was over 10 times larger than the magnitude of the imprint of local diurnal fluxes. For $\mathrm{X}_{\mathrm{CO}_{2}}$ mean synoptic-scale variations were approximately twice as large local flux-driven variability, although for both gases, the differences varied seasonally. These variations in both $\mathrm{X}_{\mathrm{H}_{2} \mathrm{O}}$ and $\mathrm{X}_{\mathrm{CO}_{2}}$ were also tied to the seasonal cycle in the large-scale N-S gradient (Table 2). As described in Section 2.2.1, we quantified temporal synoptic-scale variability by taking the standard deviation of the bi-weekly residual in $\mathrm{X}_{\mathrm{H}_{2} \mathrm{O}}$ and $\mathrm{X}_{\mathrm{CO}_{2}}$ after accounting for the climatological peak-to-trough within-day signal at each TCCON site.

Temporal synoptic-scale variations of $\mathrm{X}_{\mathrm{H}_{2} \mathrm{O}}$ across all TCCON sites were of order 100 to 1000 ppm with strong regional and seasonal dependence (Fig. 4a). For example, we observe synoptic-scale variations in $\mathrm{X}_{\mathrm{H}_{2} \mathrm{O}}$ of 200-400 ppm in Lamont and Park Falls during boreal winter and peak synoptic-scale variability of over $1000 \mathrm{ppm}$ during the Northern Hemisphere summer (Fig. 4a). At similar latitudinal regions in Europe, synoptic scale variability of $\mathrm{X}_{\mathrm{H}_{2} \mathrm{O}}$ only varies from 150 to $800 \mathrm{ppm}$ throughout the year. We acknowledge that on multi-week timescales, many processes other than atmospheric transport can alter the atmospheric water vapor mole fraction, including diabatic processes in the atmosphere. This complexity is evident in the different seasonal patterns in and magnitudes of bi-weekly variability at TCCON sites, which varies even within a given latitude band. We therefore present this analysis to parallel the $\mathrm{X}_{\mathrm{CO}_{2}}$ analysis described below.

For $\mathrm{X}_{\mathrm{CO}_{2}}$, typical synoptic-scale variations ranged from 0.1 to $1.3 \mathrm{ppm}$ across all TCCON sites, with the largest variations (in excess of $1 \mathrm{ppm}$ ) observed over Northern Hemisphere TCCON sites during July and August (Fig. 4c). These locations also had the largest seasonal cycles of synoptic-scale variability (Fig. 4c). There was less pronounced synoptic-scale variability of $\mathrm{X}_{\mathrm{CO}_{2}}$ in the tropics and the southern hemisphere, where synoptic-scale variability ranged from 0.1 in the boreal summer to $0.7 \mathrm{ppm}$ in boreal winter (Fig. 4c). The magnitude and seasonality of these variations are mostly tied to the meridional (N-S) gradient in $\mathrm{X}_{\mathrm{CO}_{2}}$, as we discuss below.

Synoptic-scale variations of $\mathrm{X}_{\mathrm{CO}_{2}}$ were correlated with the magnitude of the N-S gradient at northern hemisphere midlatitude TCCON sites (Table 2). As described in Section 2.3.2, we fit a regression slope to estimate the absolute value of $\mathrm{N}-\mathrm{S}$ gradients of $\mathrm{X}_{\mathrm{CO}_{2}}$ derived from OCO-2 overpasses to those derived from CT2017 output and HIPPO 
transects (Fig. S4). In the Northern Hemisphere midlatitudes, the correlation between monthly mean temporal synoptic-scale variations observed from TCCON (Fig 4c.) and the monthly mean N-S gradient (Fig. S4-S6) was generally around 0.6 to 0.9 (Table 2). This relationship is consistent with the argument that synoptic variations arise from transient eddies acting on the large-scale gradient, as indicated by the second RHS term in Equation 5. The weaker correlation $(\mathrm{R}=0.41)$ observed at Garmisch, Germany was an outlier among Northern Hemisphere midlatitude TCCON sites, which may be due to limited observations. In the tropics and Southern Hemisphere, the relative absence of N-S gradients of $\mathrm{X}_{\mathrm{CO}_{2}}$ resulted in weak relationship with synoptic-scale variations. We note that the length-scales estimated from many of the slopes of our best-fit linear regressions between synoptic scale variability and the $\mathrm{N}-\mathrm{S}$ gradient of $\mathrm{X}_{\mathrm{CO}_{2}}\left(2.1^{\circ}\right.$ to $6.5^{\circ}$; or roughly 200 to $600 \mathrm{~km}$ at Northern Hemisphere midlatitude TCCON sites) are on the smaller end of those of typical synoptic-scale systems.

The temporal synoptic variability of $\mathrm{X}_{\mathrm{H}_{2} \mathrm{O}}$ correlates with the $\mathrm{N}-\mathrm{S}$ gradient of $\mathrm{X}_{\mathrm{H}_{2} \mathrm{O}}$ across most TCCON sites (Table 2). The correlation coefficients were between 0.4 to 0.9 across TCCON sites. The highest correlation coefficients were observed at mid-latitude TCCON sites (Bialystok, Orleans, Park Falls, and Lamont), and at these sites, the slope of the relationship was consistently between 7 and $9 \mathrm{ppm} /(\mathrm{ppm} /$ degree) (which can be written as a length scale, degree). This is approximately consistent with typical length scales of synoptic-scale variability of the order of magnitude of $1000 \mathrm{~km}$ and larger than that estimated for $\mathrm{X}_{\mathrm{CO}_{2}}$.

\subsubsection{Mesoscale (within-day) variability}

Mesoscale variations (Fig. 4b, 5c) of $\mathrm{X}_{\mathrm{H}_{2} \mathrm{O}}$ are, on average, a factor of 1.4 times larger in magnitude to variability attributed to local diurnal fluxes (Fig. 3b). For $\mathrm{X}_{\mathrm{H}_{2} \mathrm{O}}$, mesoscale variations were generally a factor of 5 smaller than synoptic-scale variability across all TCCON sites (Fig. 4b). As expected based on synoptic scale variations in $\mathrm{X}_{\mathrm{H}_{2} \mathrm{O}}$, patterns of mesoscale variation showed strong regional variations. For example, TCCON sites in North America (Park Falls and Lamont), mesoscale variations of $\mathrm{X}_{\mathrm{H}_{2} \mathrm{O}}$ were almost 300 ppm during the boreal summer, but less than 100 ppm during the boreal winter (Fig. 4b, 5c). In contrast, at TCCON sites at similar latitudes in Europe, mesoscale variations of $\mathrm{X}_{\mathrm{H}_{2} \mathrm{O}}$ were generally less than $200 \mathrm{ppm}$ all year. At tropical TCCON sites, such as Darwin and Reunion Island, mesoscale variations were between 160 and 320 ppm all year round, with lower $(<200 \mathrm{ppm})$ mesoscale variations occurring during the dry season (Fig. 4b).

Mesoscale variations of $\mathrm{X}_{\mathrm{H}_{2} \mathrm{O}}$, like synoptic variations, were generally correlated with the $\mathrm{N}-\mathrm{S}$ gradient of $\mathrm{X}_{\mathrm{H}_{2} \mathrm{O}}$ across all midlatitude TCCON sites ( $\mathrm{R}$ values of 0.4 to 0.9 at 
TCCON sites with statistically significant slopes; Table 2). The slopes, however, were much lower, typically around $2^{\circ}$. We expect that these correlations do not necessarily suggest that the large-scale $\mathrm{N}-\mathrm{S}$ gradient drives mesoscale variations, but rather to the fact that both quantities change seasonally and have strong temperature dependence via the Clausius-Clapeyron relationship.

Temporal mesoscale variability in $\mathrm{X}_{\mathrm{CO}_{2}}$, which we assume is primarily driven by advection from small-scale weather features, was less than $0.5 \mathrm{ppm}$ across all TCCON sites and all months (Fig. 4, 5). This represents about half the magnitude of variability attributed to local diurnal fluxes during the growing season at northern hemisphere TCCON sites (Fig. 4). In the winter, mesoscale variations of $\mathrm{XCO}_{2}$ become larger than the imprint of variability attributed to local diurnal fluxes. In Park Falls, Wisconsin, the combined imprint of mesoscale and synoptic scale transport was 1 to $2 \mathrm{ppm}$ during summer (Fig. 4), substantially larger than the potential bias from assuming climatological fluxes of about $0.3 \mathrm{ppm}$ (Fig. 2). These mesoscale variations were approximately 30 to $50 \%$ magnitude of synoptic-scale variability (Fig. 4c and 4d). Mesoscale variations in $\mathrm{X}_{\mathrm{CO}_{2}}$ were only moderately correlated with $\mathrm{N}-\mathrm{S}$ gradients (R-values less than 0.52 ) in the mid-to-high latitudes in both the northern and southern hemispheres (Table 2), consistent with our expectation that the length scale of mesoscale systems is small in comparison to the length scale of the $\mathrm{N}-\mathrm{S}$ gradient. In the tropics, there was likewise no correlation between mesoscale variability and the $\mathrm{N}-\mathrm{S}$ gradient of $\mathrm{X}_{\mathrm{CO}_{2}}$ (Table 2).

We calculated a typical timescale for mesoscale (within-day) variations based on the autocorrelation of within-day residuals with climatological local fluxes removed (Fig. S7). We found that the autocorrelation of the residuals typically decayed to values between $\mathrm{e}^{-1}$ and 0 over about 3 hours. This timescale was consistent for both $\mathrm{X}_{\mathrm{H}_{2} \mathrm{O}}$ and $\mathrm{X}_{\mathrm{CO}_{2}}$ across all TCCON sites. We therefore used this mean lag time as $\tau_{\text {time }}$ in Equation 5 to compare temporal variations to spatial variations of $\mathrm{X}_{\mathrm{H}_{2} \mathrm{O}}$ and $\mathrm{X}_{\mathrm{CO}_{2}}$ (Section 3.2.1)

Table 2. [attached as separate file] Regression statistics for magnitude of variability in trace gases versus their $\mathrm{N}-\mathrm{S}$ gradient. We report the slope ( $\pm 95 \%$ confidence interval $)$ in units of degrees and the correlation coefficient, $\mathrm{R}$, of a best-fit linear regression line for the $\mathrm{N}-\mathrm{S}$ gradient of $\mathrm{X}_{\mathrm{H}_{2} \mathrm{O}}$ and $\mathrm{X}_{\mathrm{CO}_{2}}$ output from CT2017 compared to bi-weekly (synoptic-scale) and within-day (mesoscale) temporal variability of $\mathrm{X}_{\mathrm{H}_{2} \mathrm{O}}$ observed by TCCON, and explained along-track high frequency spatial variability observed by OCO2. Bolded slopes and regressions indicate statistically significant fits at the $95 \%$ confidence interval. 


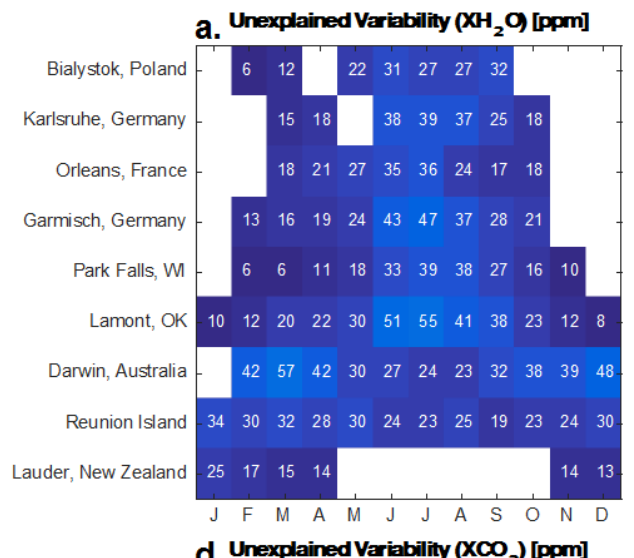

b. Explained Variability $\left(\mathbf{X H}_{2} \mathbf{O}\right)[\mathrm{ppm}]$

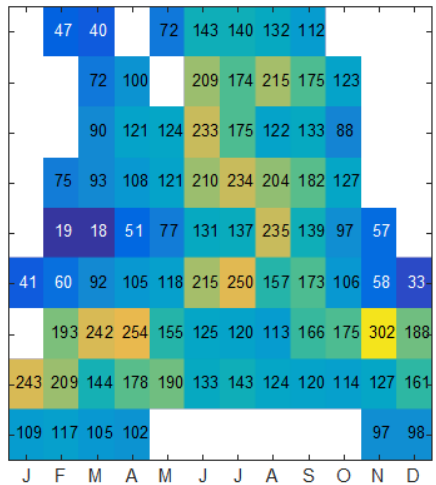

e. Explained Variability $\left(\mathrm{XCO}_{2}\right)$ [ppm]

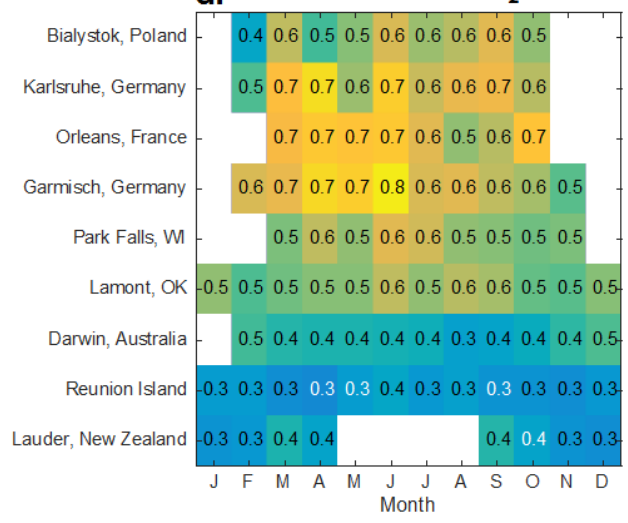

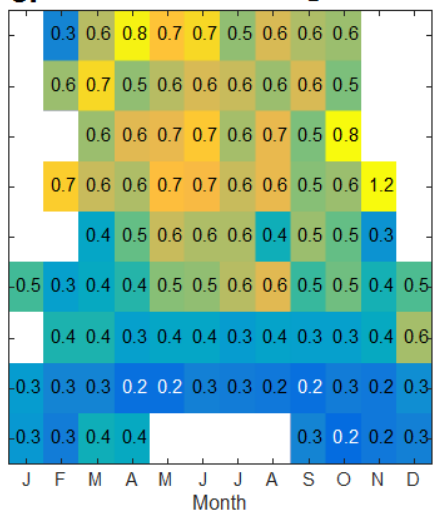

C. Mesoscale Variability $\left(\mathrm{XH}_{2} \mathbf{O}\right)$ [ppm]

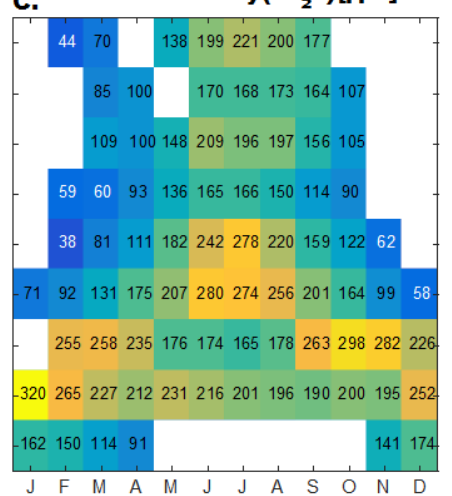

f. Mesoscale Variability $\left(\mathrm{XCO}_{2}\right)$ [ppm]

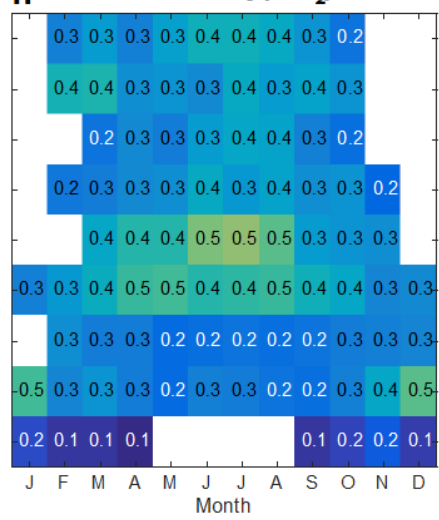

Figure 6. Variability metrics for remotely sensed $\mathrm{X}_{\mathrm{H}_{2} \mathrm{O}}$ and $\mathrm{X}_{\mathrm{CO}_{2}}$. Monthly mean (a.) unexplained variability for $\mathrm{X}_{\mathrm{H}_{2} \mathrm{O}}$ and (b.) explained variability for $\mathrm{X}_{\mathrm{H}_{2} \mathrm{O}}$ derived from high-pass filtered OCO-2 observations. c. Monthly mean temporal mesoscale (withinday) variability in $\mathrm{X}_{\mathrm{H}_{2} \mathrm{O}}$ derived from TCCON observations. Panels $\mathbf{d}-\mathbf{f}$ are similar, except we show values for $\mathrm{X}_{\mathrm{CO}_{2}}$ from OCO-2 (d-e) and TCCON (f) observations. 

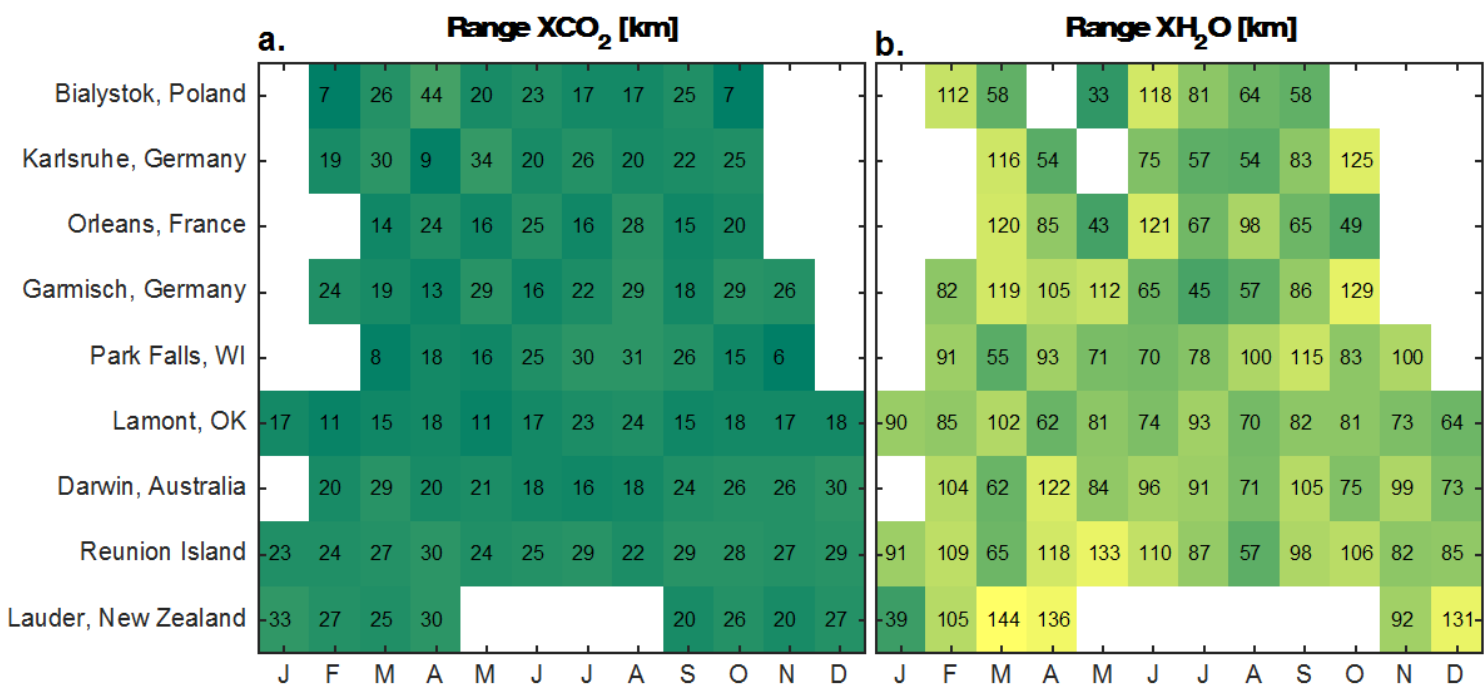

Figure 7. Monthly mean spatial range $\left(a_{\text {space }}\right)$ of a. $\mathrm{X}_{\mathrm{H}_{2} \mathrm{O}}$ and b. $\mathrm{X}_{\mathrm{CO}_{2}}$ derived from OCO-2 data near each TCCON site. Note both panels use the same color scale.

\subsection{OCO-2 along-track spatial variability}

This section compares the relationship between the high-frequency along-track spatial variability observed by OCO-2 to mesoscale temporal variability of $\mathrm{X}_{\mathrm{H}_{2} \mathrm{O}}$ and $\mathrm{X}_{\mathrm{CO}_{2}}$ from TCCON using the theoretical framework outlined in Section 2.1. Variations in both $\mathrm{X}_{\mathrm{H}_{2} \mathrm{O}}$ and $\mathrm{X}_{\mathrm{CO}_{2}}$ evolve in response to local surface fluxes and atmospheric transport, and for $\mathrm{X}_{\mathrm{H}_{2} \mathrm{O}}$, condensation, evaporation, and precipitation within the atmosphere. While the details of the surface fluxes and in situ atmospheric processes differ for the two tracers, they experience the same atmospheric advection and mixing fields. The advantage of a joint analysis of these two gases is that both $\mathrm{X}_{\mathrm{H}_{2} \mathrm{O}}$ and $\mathrm{X}_{\mathrm{CO}_{2}}$ are observed simultaneously by TCCON and OCO-2, and the precision of $\mathrm{X}_{\mathrm{H}_{2} \mathrm{O}}$ is substantially larger, providing a framework for assessing the $\mathrm{X}_{\mathrm{CO}_{2}}$ results. Specifically, if the calculated and observed explained variability of either species, $\left\langle c^{\prime}\right\rangle_{\text {space }}$, are in agreement, then we can assume that mesoscale atmospheric transport is the dominant source of high-frequency variability of that gas.

\subsubsection{Explained variability $\left(\left\langle c^{\prime}\right\rangle_{\text {space }}\right)$}

Along-track, high frequency $\left(<250 \mathrm{~km}\right.$ ) explained spatial variations of $\mathrm{X}_{\mathrm{H}_{2} \mathrm{O}}$ from OCO-2 spanned between 20 and 300 ppm across all TCCON sites (Fig. 6b). The smallest 
explained variations (20 to $60 \mathrm{ppm}$ ) were observed at Northern Hemisphere midlatitude sites during the boreal winter. The largest explained variations (> $200 \mathrm{ppm}$ ) occurred over most Northern Hemisphere midlatitude sites during the boreal summer and over the tropical sites (Darwin and Reunion Island) during the local wet season. Across all months and TCCON sites, the spatial range $\left(a_{\text {space }}\right)$ of explained variability generally spanned between 40 to $140 \mathrm{~km}$ (Fig. 7b).

The explained high-frequency spatial variability of $\mathrm{X}_{\mathrm{CO}_{2}}$ was generally between 0.2 and $1.0 \mathrm{ppm}$ across all TCCON sites (Fig. 6e). The highest explained variations $(>0.5 \mathrm{ppm})$ were observed over Northern Hemisphere TCCON sites. Smaller explained variations ( 0.2 to $0.5 \mathrm{ppm})$ were observed at southern hemisphere TCCON sites. In contrast to $\mathrm{X}_{\mathrm{H}_{2} \mathrm{O}}$, the $a_{\text {space }}$ for $\mathrm{X}_{\mathrm{CO}_{2}}$ occurred at much smaller spatial scales from 10 to $40 \mathrm{~km}$, with mean $a_{\text {space }}$ values for explained variability around $20 \mathrm{~km}$ (Fig. 7a).

We can put the explained spatial variability of both $\mathrm{X}_{\mathrm{H}_{2} \mathrm{O}}$ and $\mathrm{X}_{\mathrm{CO}_{2}}$ along OCO-2 tracks $\left(\left\langle c^{\prime}\right\rangle_{\text {space }}\right)$ by comparing variations in each gas with the corresponding mesoscale variations at TCCON sites (Section 2.3.1) using Equation 5 to relate temporal variations at a given location to tracer anomaly advection and turbulent production. We expect the time tendency (Term A in Equation 9) to be balanced by the advection of tracer variations by the mean wind (Term B) or by small-scale production of variation by eddies acting on the mean gradient (Term $\mathrm{C}$ ). Take, for example, a typical temporal mesoscale variation of $\mathrm{X}_{\mathrm{H}_{2} \mathrm{O}},\left\langle c^{\prime}\right\rangle_{\text {time }}$, of about $280 \mathrm{ppm}$ (as is approximately the case in Lamont, Oklahoma in June; Figs. 4-6). We computed the following scales:

$$
\begin{gathered}
\text { (A) } \frac{\left\langle c^{\prime}\right\rangle_{\text {time }}}{\tau_{\text {time }}}=\frac{280 \mathrm{ppm}}{3 \text { hours }}=90 \frac{\mathrm{ppm}}{\mathrm{hour}} \\
\text { (B) } \bar{u} \frac{\left\langle c^{\prime}\right\rangle_{\text {space }}}{a_{\text {space }}}=8\left(\frac{\mathrm{m}}{\mathrm{s}}\right) \frac{210 \mathrm{ppm}}{70 \mathrm{~km}}=90 \frac{\mathrm{ppm}}{\mathrm{hour}} \\
\text { (C) }\left\langle u^{\prime}\right\rangle\left\langle\frac{\partial \bar{c}}{\partial x}\right\rangle=1\left(\frac{\mathrm{m}}{\mathrm{s}}\right)\left(140 \frac{\mathrm{ppm}}{\mathrm{deg} .}\right)=5 \frac{\mathrm{ppm}}{\mathrm{hour}}
\end{gathered}
$$

(Equation 11)

We used a within-day period ( $\tau_{\text {time }}$ ) of 3 hours (Section 3.1.3; Fig. S7). For Lamont in June, we computed total column pressure and $\mathrm{H}_{2} \mathrm{O}$ vertical profile weighted mean horizontal wind speed $(\bar{u})$ of $8 \mathrm{~m} / \mathrm{s}$ and mesoscale variability of horizontal winds $\left(u^{\prime}\right)$ of 1 $\mathrm{m} / \mathrm{s}$ by vertically integrating wind output from CT2017 (Fig. S8). Since CarbonTracker is run at relatively coarse resolution, we compare these values against calculations derived from the North American Regional Reanalysis (NARR, Mesinger et al., 2006), which 
provides wind fields at 0.3 degrees resolution. At the two North American TCCON sites, $u$ was the same as that estimated from CarbonTracker fields, while $u^{\prime}$ was larger by a factor of two (about $2 \mathrm{~m} / \mathrm{s}$ ), an expected result given the higher horizontal resolution of NARR. Nevertheless, when we apply this larger $u^{\prime}$ estimate into Equation 11, our scale analysis remains unchanged. We also used CT2017 output to calculate a typical summertime Northern Hemisphere midlatitude N-S gradient of around 140 ppm degree ${ }^{-1}$ (Fig. S5). The scaling exercise suggests that the time tendency is mostly balanced by the mesoscale anomaly advection term (Term B) rather than the turbulent production term (Term C), at least for these time-scales. The small contribution of the production term is consistent with the fact that mesoscale variations at TCCON sites were not highly correlated with the mean N-S gradient. This analysis can also be applied to relate spatial and temporal mesoscale variations in $\mathrm{X}_{\mathrm{CO}_{2}}$ or another atmospheric tracer.

Based on the scaling arguments above, we rearrange Equation 5 to solve for the expected $\left\langle c^{\prime}\right\rangle_{\text {space }}$ along OCO-2 tracks and neglect the turbulent production term (Equation 12):

$$
\left\langle c^{\prime}\right\rangle_{\text {space }}=\frac{a_{\text {space }}}{\bar{u}}\left(\frac{\left\langle c^{\prime}\right\rangle_{\text {time }}}{\tau_{\text {time }}}-\left\langle u^{\prime}\right\rangle\left\langle\frac{\partial \bar{c}}{\partial x}\right\rangle\right) \approx \frac{a_{\text {space }}}{\bar{u}}\left(\frac{\left\langle c^{\prime}\right\rangle_{\text {time }}}{\tau_{\text {time }}}\right) \text {. (Equation 12) }
$$

We then use Equation 12 to estimate the expected magnitude of $\left\langle c^{\prime}\right\rangle_{\text {space }}$ for $\mathrm{X}_{\mathrm{H}_{2} \mathrm{O}}$ in Lamont in June as approximately $226 \mathrm{ppm}$ which agrees within $10 \%$ with the observed explained variability of $214 \mathrm{ppm}$ from OCO-2 (Fig. 6b and 8b). We found that if we applied Equation 12 to compute $\left\langle c^{\prime}\right\rangle_{\text {space }}$ at each TCCON site and each month, our estimated $\left\langle c^{\prime}\right\rangle_{\text {space }}$ values match observed explained variations from OCO-2 to within $30 \%$ (Fig. 8a and 8b). The agreement between the observed and estimated $\left\langle c^{\prime}\right\rangle_{\text {space }}$ of $\mathrm{X}_{\mathrm{H}_{2} \mathrm{O}}$ suggests that the observed explained variations of $\mathrm{X}_{\mathrm{H}_{2} \mathrm{O}}$ from OCO-2 are primarily driven by mesoscale atmospheric transport (Fig. 5 and 8a,b). These results also validate our choice of a $250 \mathrm{~km}$ high-pass filter to isolate mesoscale transport and exclude largerscale synoptic systems.

We likewise calculated the $\left\langle c^{\prime}\right\rangle_{\text {space }}$ of $\mathrm{X}_{\mathrm{CO}_{2}}$ in Lamont in June using the estimated total column pressure and $\mathrm{CO}_{2}$ vertical profile weighted mean horizontal wind speed $(\bar{u}) \mathrm{m} / \mathrm{s}$ and a spatial range, $a_{\text {space }}$, of $20 \mathrm{~km}$ fit from semivariogram analysis (Fig. 7a). Using this framework, the calculated spatial mesoscale variability of $0.1 \mathrm{ppm}$ was much smaller than the observed $\left\langle c^{\prime}\right\rangle_{\text {space }}(0.6 \mathrm{ppm})$. The empirical $a_{\text {space }}$ of $20 \mathrm{~km}$ for $\mathrm{X}_{\mathrm{CO}_{2}}$ is suspect, since mesoscale variations in $\mathrm{X}_{\mathrm{H}_{2} \mathrm{O}}$ from OCO-2 showed an $a_{\text {space }}$ of $70 \mathrm{~km}$ in the same month and are consistent with the expected length-scale for mesoscale systems. When we instead used $a_{\text {space }}$ of $70 \mathrm{~km}$ based on the analysis of $\mathrm{X}_{\mathrm{H}_{2} \mathrm{O}}$, estimated mesoscale variability increases to $0.3 \mathrm{ppm}$ (Equation 14). 


$$
\left\langle c^{\prime}\right\rangle_{\text {space }, X_{\mathrm{CO}_{2}}}=\frac{70 \mathrm{~km}}{10 \frac{\mathrm{m}}{\mathrm{s}}}\left(\frac{0.4 \mathrm{ppm}}{3 \text { hours }}\right) \cong 0.3 \mathrm{ppm}(\text { Equation } 14)
$$

We note that an estimate of $0.3 \mathrm{ppm}$, while more reasonable in magnitude, is still about $40 \%$ smaller than the observed value of $0.5 \mathrm{ppm}$ for the OCO-2 explained $\mathrm{X}_{\mathrm{CO}_{2}}$ variability.

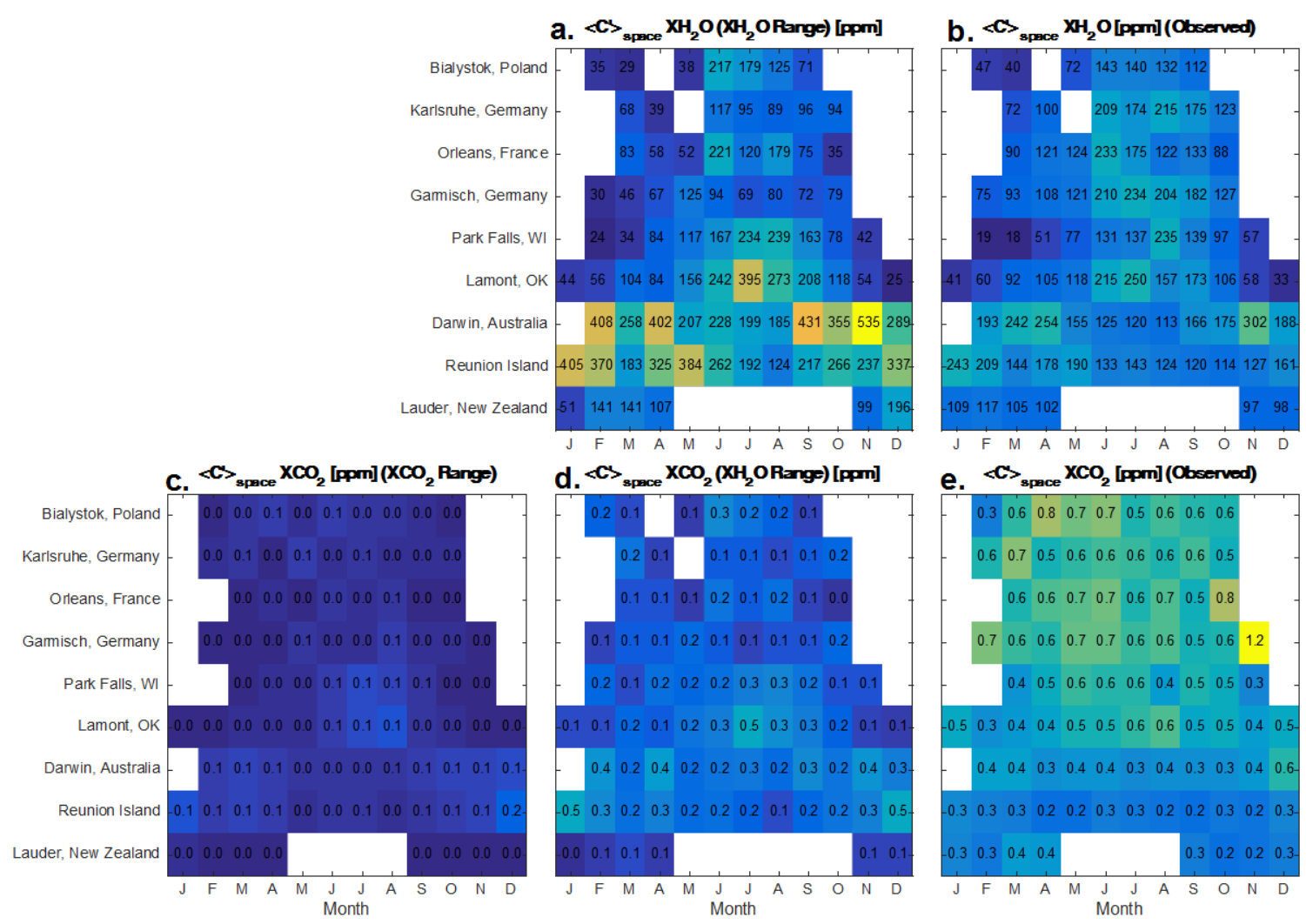

Figure 8. Comparison of calculated and observed $\left\langle c^{\prime}\right\rangle_{\text {space }}$. The top row shows (a.) Calculated annual cycle in $\left\langle c^{\prime}\right\rangle_{\text {space }}$ for $\mathrm{X}_{\mathrm{H}_{2} \mathrm{O}}$ using Equation 12, assuming $a_{\text {space }}$ values derived from $\mathrm{X}_{\mathrm{H}_{2} \mathrm{O}}$ (Figure $7 \mathrm{~b}$ ) and $\left\langle c^{\prime}\right\rangle_{\text {time }}$ values from TCCON mesoscale variations (Fig. 4b). (b.) Observed annual cycle in $\left\langle c^{\prime}\right\rangle_{\text {space }}$ for $\mathrm{X}_{\mathrm{H}_{2} \mathrm{O}}$. Note that this quantity is identical to the explained variability of $\mathrm{X}_{\mathrm{H}_{2} \mathrm{O}}$ (Figure $6 \mathrm{~b}$ ). The bottom row shows the same quantities, except for $\mathrm{X}_{\mathrm{CO}_{2}}$. (c.) Calculated annual cycle in $\left\langle c^{\prime}\right\rangle_{\text {space }}$ for $\mathrm{X}_{\mathrm{CO}_{2}}$ using Equation 12, assuming $a_{\text {space }}$ values for $\mathrm{X}_{\mathrm{CO}_{2}}$ (Fig. 7a) and $\left\langle c^{\prime}\right\rangle_{\text {time }}$ values from TCCON (Fig. 4d). (d.) Calculated annual cycle in $\left\langle c^{\prime}\right\rangle_{\text {space }}$, except we use $a_{\text {space }}$ values from $\mathrm{X}_{\mathrm{H}_{2} \mathrm{O}}$. (e.) Observed annual cycle in $\left\langle c^{\prime}\right\rangle_{\text {space }}$ for $\mathrm{X}_{\mathrm{CO}_{2}}$ (identical to Fig. 6e). 
Together, these relationships suggest first that the temporal and spatial scaling within our framework is consistent with mesoscale variations of $\mathrm{X}_{\mathrm{H}_{2} \mathrm{O}}$ quantified using TCCON and OCO-2 data. Second, the spatial range $\left(a_{\text {space }}\right)$ for $\mathrm{X}_{\mathrm{CO}_{2}}$ variability derived from the geostatistical analysis of OCO-2 data is too small to be driven by mesoscale systems. Third, the results suggest that the $\mathrm{X}_{\mathrm{CO}_{2}}\left\langle c^{\prime}\right\rangle_{\text {space }}$ value is larger than what is calculated assuming mesoscale systems are the only driver of high frequency spatial variability along OCO-2 tracks. As shown for Lamont, Oklahoma, there is no overlap between the estimated and observed $\left\langle c^{\prime}\right\rangle_{\text {space }}$ even when accounting for uncertainty in both terms (Fig. 5b). We estimated the uncertainty $\left\langle c^{\prime}\right\rangle_{\text {space }}$ using error propagation of the standard error of each of the measured terms in equation 12. Although we only plot the uncertainty on the $\left\langle c^{\prime}\right\rangle_{\text {space }}$ calculation for Lamont (Fig. 5), we quantified uncertainty across all TCCON sites presented in the paper and this result is robust, meaning that the differences between the calculated $\left\langle c^{\prime}\right\rangle_{\text {space }}$ (Fig. 8c,d) and the observed $\left\langle c^{\prime}\right\rangle_{\text {space }}($ Fig. 8e) represent real and significant disagreement. Thus, we conclude that some other factor imparts spatially coherent variability on OCO- $2 \mathrm{X}_{\mathrm{CO}_{2}}$ that depresses the $a_{\text {space }}$ and augments the $\left\langle c^{\prime}\right\rangle_{\text {space }}$. One possibility is coherent biases or errors in the OCO-2 $\mathrm{X}_{\mathrm{CO}_{2}}$ retrieval, as discussed more in section 3.3. These relationships are true across all TCCON sites (Fig. $8 \mathrm{c}$ and $8 \mathrm{e}$ ), where the observed $\mathrm{X}_{\mathrm{CO}_{2}}\left\langle c^{\prime}\right\rangle_{\text {space }}$ was generally larger than what would be expected based on $\left\langle c^{\prime}\right\rangle_{\text {time }}$ and the observed $\mathrm{X}_{\mathrm{CO}_{2}} a_{\text {space }}$ was small relative to the value calculated from $\mathrm{X}_{\mathrm{H}_{2} \mathrm{O}}$ observations (Fig. 8a and 8b). We found that $\mathrm{X}_{\mathrm{CO}_{2}}\left\langle c^{\prime}\right\rangle_{\text {space }}$ was more comparable to observed explained variations from OCO-2 when we used observed $a_{\text {space }}$ values for $\mathrm{X}_{\mathrm{H}_{2} \mathrm{O}}$ (Fig. 8d and 8e).

We do not expect that the inflated $\mathrm{X}_{\mathrm{CO}_{2}}\left\langle c^{\prime}\right\rangle_{\text {space }}$ values result from aliasing of synoptic scale variability. First, the water vapor analysis confirmed that our $250 \mathrm{~km}$ filter properly isolates mesoscale atmospheric transport. Second, the explained variability from OCO-2 was not correlated with the N-S gradients (Table 2). If our $\left\langle c^{\prime}\right\rangle_{\text {space }}$ values reflected synoptic scale variability, these quantities should be correlated.

\subsubsection{Unexplained variability}

The unexplained high frequency spatial variability of $\mathrm{X}_{\mathrm{H}_{2} \mathrm{O}}$ was up to $50 \mathrm{ppm}$ (Fig. 5 and 6 ), about $50 \%$ larger than the random errors reported by the v8 OCO-2 retrieval algorithm data product. These results were consistent with arguments from Connor et al. (2008) that reported random errors from the OCO-2 retrieval algorithm represent a lower bound on actual error. However, our estimate for unexplained variability along OCO-2 tracks was still less than $20 \%$ of the temporal and spatial mesoscale $\mathrm{X}_{\mathrm{H}_{2} \mathrm{O}}$ variability (Fig. 5 and 6), suggesting that the signal-to-noise ratio of $\mathrm{X}_{\mathrm{H}_{2} \mathrm{O}}$ retrievals are large enough to 
observe mesoscale variations.

The unexplained spatial variability in $\mathrm{X}_{\mathrm{CO}_{2}}$ was 0.3 to $0.8 \mathrm{ppm}$, which is the same order of magnitude as the spatial and temporal variations that may reflect mesoscale variations and is also generally consistent with random errors reported by the v8 OCO- 2 retrieval algorithm data product (Fig. 6d). These unexplained variations were consistent with the mean standard deviation of the cross-track soundings we averaged into each along-track bin (Section 2.3.2; Fig. S9). OCO-2 tracks adjacent to Southern Hemisphere TCCON sites typically had smaller unexplained variations $(0.3-0.4 \mathrm{ppm})$, while tracks adjacent to Northern Hemisphere TCCON sites had slightly larger unexplained variations (0.5-0.7 ppm). This difference appears to arise due to the fact that the Southern Hemisphere and tropical OCO-2 tracks we analyzed contained ocean observations, whereas the Northern Hemisphere tracks contained only land observations. When we conducted semivariogram analysis around the latitude band between 40-50 degrees North, the unexplained variations over the ocean were approximately half the magnitude observed over land (Fig. 9). Errors associated with retrieving $\mathrm{X}_{\mathrm{CO}_{2}}$ over land, where topography and albedo can influence the $\mathrm{X}_{\mathrm{CO}_{2}}$ retrieval, likely increase the unexplained variability. The unexplained variations over land did not show dependence on nadir versus glint observing mode. We note that the estimates for unexplained variability were not sensitive to the cutoff for the high-pass filter and were also robust when we explicitly fitted, rather than fixed, the unexplained variance in the spherical semivariogram model. 

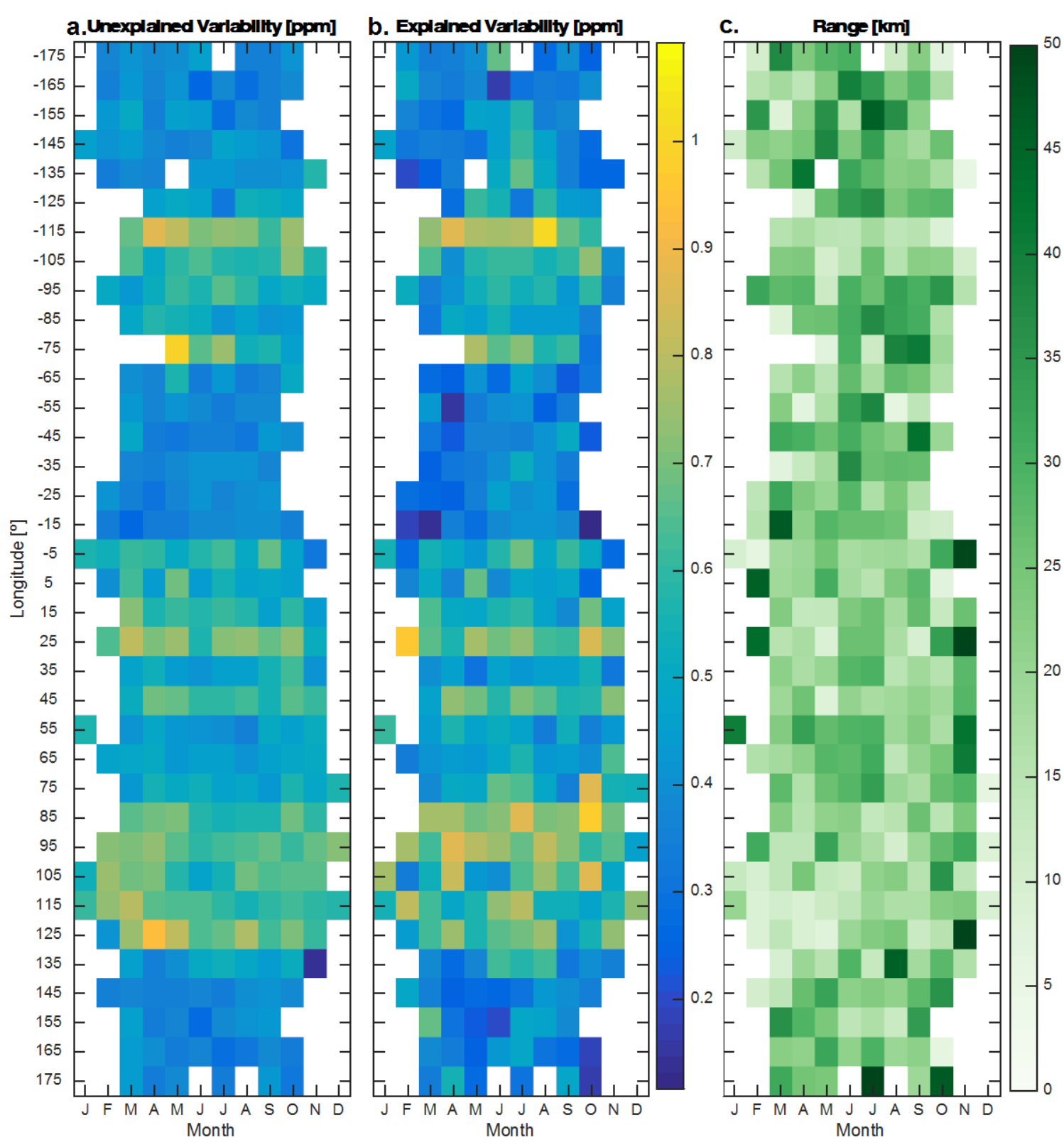

Figure 9. Global analysis of along-track high-frequency spatial (a.) unexplained variability, (b.) explained variability, and (c.) range of explained variability $\left(a_{\text {space }}\right)$ of $\mathrm{X}_{\mathrm{CO}_{2}}$ within $10^{\circ} \times 10^{\circ}$ grid cells across a latitudinal band centered at $45^{\circ} \mathrm{N}$. In general, grid cells over ocean show lower values of explained and unexplained error than those over land. 


\subsection{Spatially correlated variance from the state vector}

Correlations between high frequency along-track spatial variations in $\mathrm{X}_{\mathrm{CO}_{2}}$ and other elements of the OCO-2 retrieval state vector likely contributed to the larger than expected spatially coherent (explained) variability in OCO-2 $\mathrm{X}_{\mathrm{CO}_{2}}$, compared to mesoscale variations at corresponding TCCON sites (Table 4), and the smaller geostatistical spatial range $\left(a_{\text {space }}\right)$ for $\mathrm{X}_{\mathrm{CO}_{2}}$ than $\mathrm{X}_{\mathrm{H}_{2} \mathrm{O}}$. We therefore tested whether the total and high frequency along-track spatial variability of $\mathrm{X}_{\mathrm{CO}_{2}}$ were correlated with other elements of the OCO-2 retrieval state vector. We selected aerosol optical depth (AOD) and albedo in the $\mathrm{O}_{2}$ and weak and strong $\mathrm{CO}_{2}$ absorption bands as variables that were likely to have spatial structures that, if correlated with $\mathrm{X}_{\mathrm{CO}_{2}}$, could obscure spatially coherent transport patterns. The correlations between elements of the state vector and both the total variations and the high frequency along-track spatial variations of $\mathrm{X}_{\mathrm{CO}_{2}}$ were small $(\mathrm{R} \leq$ 0.2 ; Table 3), but statistically significant. This analysis suggests that correlations between $\mathrm{X}_{\mathrm{CO}_{2}}$ and these state vector elements may have depressed the apparent $a_{\text {space }}$ and increased the explained variability along OCO- 2 tracks. We note that the analysis of albedo and AOD presented here was in no way exhaustive, but rather, our results show that these correlations were important contributors to the overall variance budget.

In contrast, high frequency variations in $\mathrm{X}_{\mathrm{H}_{2} \mathrm{O}}$ were generally independent of other state vector elements. There were some weak to moderate, statistically significant correlations between the unfiltered $\mathrm{X}_{\mathrm{H}_{2} \mathrm{O}}$ data and albedo or AOD (Table 3). These correlations could represent real geophysical relationships among $\mathrm{X}_{\mathrm{H}_{2} \mathrm{O}}$, albedo, and AOD, but could also be attributed large-scale, coherent systematic biases in the retrieval of $\mathrm{X}_{\mathrm{H}_{2} \mathrm{O}}$ that can be attributed to errors in AOD and albedo. When we high-pass filtered these variables, however, the correlations between the high frequency variations of $\mathrm{X}_{\mathrm{H}_{2} \mathrm{O}}$ and albedo were not statistically significant, with the exception of AOD. This result suggests that at smaller spatial scales (less than $250 \mathrm{~km}$ ), the variations in $\mathrm{X}_{\mathrm{H}_{2} \mathrm{O}}$ were independent of the state vector elements we tested here and therefore the explained variability did not contain the imprint of spatially coherent biases

Table 3. [attached as separate file] Mean correlation coefficients between OCO-2 trace gases and other elements of the state vector, including aerosol optical depth (AOD), and surface albedo in the oxygen-absorbing band $\left(\mathrm{O}_{2} \mathrm{~A}\right)$, weakly absorbing $\mathrm{CO}_{2}$ band $\left(\mathrm{WCO}_{2}\right)$, and strongly absorbing $\mathrm{CO}_{2}$ band $\left(\mathrm{SCO}_{2}\right)$ retrieved from OCO-2 observations. Bolded values denote statistically significant non-zero mean correlation coefficients at a $95 \%$ confidence interval. 


\section{Discussion and Conclusions}

We developed a framework that allows us to leverage spatially dense soundings from the OCO-2 satellite and temporally dense soundings from TCCON to quantify the variance budget for $\mathrm{X}_{\mathrm{H}_{2} \mathrm{O}}$ and $\mathrm{X}_{\mathrm{CO}_{2}}$, with a focus on estimating the imprint of mesoscale transport on OCO-2 observations. We first developed a method to separate variations from local diurnal surface-atmosphere fluxes, synoptic-scale atmospheric transport, and mesoscale atmospheric transport from the overall variability in TCCON observations. We found that variability from synoptic-scale transport was, on average, 3 times larger than that attributed to diurnal fluxes for $\mathrm{X}_{\mathrm{H}_{2} \mathrm{O}}$ and of 2 times larger magnitude for $\mathrm{X}_{\mathrm{CO}_{2}}$. On average, and mesoscale variations in $\mathrm{X}_{\mathrm{H}_{2} \mathrm{O}}$ and $\mathrm{X}_{\mathrm{CO}_{2}}$ were similar in magnitude to the variability from local diurnal fluxes. The large contributions of mesoscale and synoptic scale transport in driving tracer variability underscores the importance of accounting for uncertainties in atmospheric transport and its subgrid-scale impact when using $\mathrm{X}_{\mathrm{CO}_{2}}$ in a carbon flux inference system.

Second, we used geostatistical analysis to quantify explained (spatially coherent) and unexplained (random) variations in $\mathrm{X}_{\mathrm{CO}_{2}}$ and $\mathrm{X}_{\mathrm{H}_{2} \mathrm{O}}$ along OCO-2 tracks. We applied a 250-km high pass filter that, for $\mathrm{X}_{\mathrm{H}_{2} \mathrm{O}}$, isolated mesoscale variations that were the primary driver of along-track high frequency variability of $\mathrm{X}_{\mathrm{H}_{2} \mathrm{O}}$ from OCO-2. We confirmed that the explained variations in $\mathrm{X}_{\mathrm{H}_{2} \mathrm{O}}$ were primarily related to mesoscale transport using the tracer transport framework to compare temporal variability to spatial variations. For $\mathrm{X}_{\mathrm{H}_{2} \mathrm{O}}$, observed explained spatial variations of $\mathrm{X}_{\mathrm{H}_{2} \mathrm{O}}$ were consistent with estimated explained variations within this framework (Fig. 8a and 8b).

In contrast, we were not able to fully characterize the variance budget for $\mathrm{X}_{\mathrm{CO}_{2}}$. Within our physical framework, the explained variations of $\mathrm{X}_{\mathrm{CO}_{2}}$ observed by OCO-2 (Fig. 8c and 8e) were too large to be explained solely by mesoscale atmospheric transport. We note that this mismatch was particularly acute when using the geostatistically-estimated $a_{\text {space }}$ from OCO-2 (around $20 \mathrm{~km}$ ) for $\mathrm{X}_{\mathrm{CO}_{2}}$, but was also true when we substituted the observed $a_{\text {space }}$ for $\mathrm{X}_{\mathrm{H}_{2} \mathrm{O}}$ (Fig. 8d). Together, these suggest another source of spatially coherent variance in OCO-2 $\mathrm{X}_{\mathrm{CO}_{2}}$ that both shortens the length scale of coherence and contributes additional spatially coherent variability. Based on correlation analysis with other elements of the state vector, we conclude that high-pass filtered $\mathrm{X}_{\mathrm{CO}_{2}}$ fields from v8 of the OCO-2 Level $2 \mathrm{X}_{\mathrm{CO}_{2}}$ retrieval impart such structure and may explain part, though perhaps not all, of the mismatch in mesoscale time-space $\mathrm{X}_{\mathrm{CO}_{2}}$ variability from TCCON and OCO-2. Correlations among elements of the retrieval state vector have also manifested in biases in $\mathrm{X}_{\mathrm{CO}_{2}}$ retrieval output from GOSAT data, resulting in uncertainty of the magnitude and sign of posterior regional-scale flux estimates (Chevallier et al., 
2014).

Our estimates of explained and unexplained variability can be compared against other studies that leverage the OCO-2 data set. For instance, Worden et al., (2017) analyzed the contribution of natural variations simulated by NASA's high resolution GEOS-5 simulation to the OCO-2 error budget. They found that the natural variability of $\mathrm{X}_{\mathrm{CO}_{2}}$ within $100 \mathrm{~km}$ neighborhoods was only about $0.08 \mathrm{ppm}$, and that the observed variability from OCO-2 exceeded this value due to bias from other elements of the OCO2 v7 retrieval vector. We used our framework to estimate the natural (or mesoscale) contribution to variations in $\mathrm{X}_{\mathrm{CO}_{2}}$ with our space-for-time framework. Based on mesoscale variations at northern hemisphere TCCON stations, we expect that the imprint of mesoscale systems along the satellite track should be about 0.4 ppm (over $250 \mathrm{~km}$ ). That our value is larger than the natural variability in model output reported by Worden et al. (2017) underscores the utility of our geostatistical approach for quantification of the variance budget based on observations themselves, rather than model output that may contain its own set of biases. Further, our methodology enables us to quantify the random error in the observations (unexplained variability) as well as the spatially coherent error (the portion of the explained variability caused by systematic bias in the retrieval).

Our results suggest that our analysis framework yields robust quantification of the influence of mesoscale transport for $\mathrm{X}_{\mathrm{H}_{2} \mathrm{O}}$, despite the fact that local surface processes are likely also to impart local variations on this quantity. We acknowledge that our method to subtract local influence based on a climatological diurnal signal may result in biases of up to $30 \%$ of the fraction of variability in TCCON data being attributed to transport (Fig. 2). Ultimately, the methodology to account for local signals at TCCON sites would benefit from additional information on local fluxes across all sites, either from observations, such as eddy covariance fluxes, or from mechanistic coupled atmosphere-land models. Despite this caveat, the agreement between TCCON and $\mathrm{X}_{\mathrm{H}_{2} \mathrm{O}}$ variations suggests that the $250 \mathrm{~km}$ filter used and the assumptions made in this manuscript are sufficient to account for the structure imparted by fine spatial scale transport.

Although there were complications with $\mathrm{X}_{\mathrm{CO}_{2}}$, our results are promising for the use of geostatistical methods for parameterizing errors in inverse modeling frameworks. While we had hypothesized that our approach would allow us to separate the influence of mesoscale transport on $\mathrm{X}_{\mathrm{CO}_{2}}$, we note that for robust flux inference, proper accounting for spatially coherent non-transport structures within the data is also necessary. The approach presented in this study can be applied to each subsequent data release, and we anticipate that as the retrieval algorithm becomes more mature, the importance of correlated errors will decrease and the role of mesoscale transport will be revealed more clearly. Our results highlight the importance of continued development of the OCO-2 retrieval 
algorithm, since correlations between $\mathrm{X}_{\mathrm{CO}_{2}}$ and other elements of the state vector may induce bias and spurious spatial correlation in $\mathrm{X}_{\mathrm{CO}_{2}}$ that mask the influence of atmospheric transport.

Our results also highlight the importance of constraining variations of $\mathrm{X}_{\mathrm{CO}_{2}}$ attributed to atmospheric transport for improved inferences of carbon fluxes from inversion models. While the influence of random errors can be minimized by averaging multiple soundings, transport-driven processes introduce variability on $\mathrm{X}_{\mathrm{CO}_{2}}$ observations that are both spatially and temporally correlated. For example, taking a $10 \mathrm{~s}$ average of $\mathrm{X}_{\mathrm{CO}_{2}}$ observations along the OCO-2 track (about $70 \mathrm{~km}$ ), similar to the method presented in Crowell et al. (2019) will reduce the unexplained error (Fig. 6d) by $\frac{1}{\sqrt{N}}$ where $\mathrm{N}$ is the number of soundings in the averaging bin, because the unexplained errors for each sounding are assumed to be independent. In contrast the mean error for a bin decreases only by $\frac{1}{\sqrt{N_{\text {effective }}}}$ for the spatially correlated transport variability (Fig. 6e), where $\mathrm{N}_{\text {effective }}$ can be approximated as the bin length divided by the geostatistical range (or autocorrelation length), which for $\mathrm{X}_{\mathrm{CO}_{2}}$ is roughly 2-3 and may actually be closer to 1 if the $\mathrm{X}_{\mathrm{H}_{2} \mathrm{O}}$ ranges are used as more appropriate. Since the length-scales at which the resolved variability is correlated are comparable to the spatial distance encompassed by a 10-s along track average (Figure 7), the mesoscale variance is a key element of the signal that will be used in the inversions even when observations are aggregated. Given that the imprint of mesoscale and synoptic scale variance is not spatially or temporally uniform, ignoring it in an inverse modeling framework will lead to over confidence in some observational aggregates and underconfidence in others, ultimately shifting the distribution of fluxes. This is analogous to conducting a simple linear regression in which uniform error bars are assumed instead of assigning realistic errors to individual points; the resulting slope and intercept will differ depending on the method of assigning errors. Inversion techniques typically require uncertainty estimates and their correlations on the inversion grid-scale, which spans from roughly mesoscale $(\sim 100 \mathrm{~km})$ to several times mesoscale depending on the transport model resolution. The appropriate uncertainty estimate will incorporate both instrument and algorithm error and spatially/temporally coherent subgrid-scale variability induced by transport and surface flux processes. Based on our analysis of both TCCON and OCO-2, the coherent mesoscale variability signal for $\mathrm{X}_{\mathrm{CO}_{2}}$ is substantial relative to sounding errors alone and may be larger than transport variability estimates produced by most carbon cycle models, which may inadequately resolve mesoscale dynamics. Since mesoscale systems may have also been associated with frontal cloud coverage, lack of ability to constrain mesoscale variations may have resulted in large representation errors in inverse modeling (Corbin et al. 2008). Our results suggested that as a first step, we could use the explained variability 
derived from geostatistical analysis of OCO-2 data to inflate error estimates within inverse modeling systems. As a next step, we recommend the development of coupled high-resolution $\mathrm{CO} 2$-weather models that fully capture fine-to-large scale spatial and temporal variations in carbon fluxes, as an alternative to constrain the imprint of atmospheric transport from $\mathrm{X}_{\mathrm{CO}_{2}}$ observations provided by OCO-2, OCO-3, and other emerging $\mathrm{CO}_{2}$ monitoring satellites."

\section{Acknowledgments}

The authors thank the leadership and participants of the NASA OCO-2 mission and acknowledge financial support from NASA Award NNX15AH13G. A.D. Torres also acknowledges support from the NASA Earth and Space Science Fellowship Award 80NSSC17K0382. We thank TCCON for providing observations. We thank A. Jacobson and the National Oceanographic and Atmospheric Administration Earth System Research Laboratory in Boulder, CO for providing CarbonTracker CT2017 data, available online at http://carbontracker.noaa.gov. We thank S. Wofsy for providing HIPPO data, funded by the National Science Foundation and NOAA and available online at https://www.eol.ucar.edu/field_projects/hippo. The TCCON Principal Investigators acknowledge funding from their national funding organizations. TCCON data were obtained from the archive at https://tccondata.org. NARR data provided by the NOAA/OAR/ESRL PSD, Boulder, Colorado, USA, from their Web site at https://www.esrl.noaa.gov/psd/.

\section{References}

Baker, D. F., Law, R. M., Gurney, K. R., Rayner, P., Peylin, P., Denning, A. S., et al. (2006). TransCom 3 inversion intercomparison: Impact of transport model errors on the interannual variability of regional $\mathrm{CO}_{2}$ fluxes, 1988-2003. Global Biogeochemical Cycles, 20(1), GB1002. https://doi.org/10.1029/2004GB002439

Baker, D.F., H. Bösch, S.C. Doney, D. O’Brien, and D.S. Schimel, 2010: Carbon source/sink information provided by column $\mathrm{CO}_{2}$ measurements from the Orbiting Carbon Observatory, Atmosp. Chem. Physics, 10, 4145-4165. https://doi.org/10.5194/acp-10-4145-2010

Baldocchi, D., Falge, E., Gu, L., Olson, R., Hollinger, D., Running, S., ... Wofsy, S. (2001). FLUXNET: A New Tool to Study the Temporal and Spatial Variability of Ecosystem-Scale Carbon Dioxide, Water Vapor, and Energy Flux Densities. Bulletin of the American Meteorological Society, 82(11), 24152434. https://doi.org/10.1175/1520-0477(2001)082<2415:fantts>2.3.co;2 
Basu, S., Baker, D. F., Chevallier, F., Patra, P. K., Liu, J., \& Miller, J. B. (2018). The impact of transport model differences on $\mathrm{CO}_{2}$; surface flux estimates from OCO-2 retrievals of column average $\mathrm{CO}_{2}$; Atmospheric Chemistry and Physics, 18(10), 7189-7215. https://doi.org/10.5194/acp-18-7189-2018

Bolin, B., \& Keeling, C. D. (1963). Large-scale atmospheric mixing as deduced from the seasonal and meridional variations of carbon dioxide. Journal of Geophysical Research, 68(13), 3899-3920. https://doi.org/10.1029/jz068i013p03899

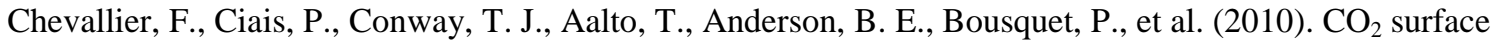
fluxes at grid point scale estimated from a global 21 year reanalysis of atmospheric measurements. Journal of Geophysical Research, 115(D21), D21307. https://doi.org/10.1029/2010JD013887

Chevallier, F., \& O’Dell, C. W. (2013). Error statistics of Bayesian $\mathrm{CO}_{2}$ flux inversion schemes as seen from GOSAT. Geophysical Research Letters, 40(6), 1252-1256. https://doi.org/10.1002/grl.50228

Chevallier, F., Palmer, P. I., Feng, L., Boesch, H., O’Dell, C. W., \& Bousquet, P. (2014). Toward robust and consistent regional $\mathrm{CO}_{2}$ flux estimates from in situ and spaceborne measurements of atmospheric $\mathrm{CO}_{2}$. Geophysical Research Letters, 41(3), 1065-1070. https://doi.org/10.1002/2013g1058772

Connor, B. J., Boesch, H., Toon, G., Sen, B., Miller, C., \& Crisp, D. (2008). Orbiting Carbon Observatory: Inverse method and prospective error analysis. Journal of Geophysical Research: Atmospheres, 113(D5), D05305. https://doi.org/10.1029/2006jd008336

Corbin, K. D., Denning, A. S., Lu, L., Wang, J.-W., \& Baker, I. T. (2008). Possible representation errors in inversions of satellite $\mathrm{CO}_{2}$ retrievals. Journal of Geophysical Research, 113(D2), D02301. https://doi.org/10.1029/2007jd008716

Cressie, N., \& Hawkins, D. M. (1980). Robust estimation of the variogram: I. Journal of the International Association for Mathematical Geology, 12(2), 115-125. https://doi.org/10.1007/BF01035243

Crowell, S., Baker, D., Schuh, A., Basu, S., Jacobson, A. R., Chevallier, F., et al. (2019, in review). The 2015-2016 Carbon Cycle As Seen from OCO-2 and the Global In Situ Network. Atmospheric Chemistry and Physics Discussions, 1-79. https://doi.org/10.5194/acp-2019-87

Crisp, D., Atlas, R.., Breon, F.-M., Brown, L.., Burrows, J.., Ciais, P., et al. (2004). The Orbiting Carbon Observatory (OCO) mission. Advances in Space Research, 34(4), 700-709. https://doi.org/10.1016/j.asr.2003.08.062

Dai, A., Wang, J., Ware, R. H., \& Van Hove, T. (2002). Diurnal variation in water vapor over North America and its implications for sampling errors in radiosonde humidity. Journal of Geophysical Research: Atmospheres, 107(D10), ACL 11-1-ACL 11-14. https://doi.org/10.1029/2001JD000642

De Mazière, M., Sha, M. K., Desmet, F., Hermans, C., Scolas, F., Kumps, N., et al. (2014). TCCON data from Reunion Island (La Reunion), France, Release GGG2014R0. https://doi.org/10.14291/tccon.ggg2014.reunion01.R0/1149288 
Desai, A. (2016). AmeriFlux US-PFa Park Falls/WLEF [Data set]. AmeriFlux; University of Wisconsin. https://doi.org/10.17190/amf/1246090

Deutscher, N. M., Griffith, D. W. T., Bryant, G. W., Wennberg, P. O., Toon, G. C., Washenfelder, R. A., et al. (2010). Total column $\mathrm{CO}_{2}$ measurements at Darwin, Australia - site description and calibration against in situ aircraft profiles. Atmospheric Measurement Techniques, 3(4), 947-958. https://doi.org/10.5194/amt-3-947-2010

Deutscher, N., Notholt, J., Messerschmidt, J., Weinzierl, C., Warneke, T., Petri, C., et al. (2014). TCCON data from Bialystok, Poland, Release GGG2014R1. https://doi.org/10.14291/tccon.ggg2014.bialystok01.R1/1183984

Eldering, A., O’Dell, C. W., Wennberg, P. O., Crisp, D., Gunson, M. R., Viatte, C., et al. (2017). The Orbiting Carbon Observatory-2: first 18 months of science data products. Atmospheric Measurement Techniques, 10(2), 549-563. https://doi.org/10.5194/amt-10-549-2017

Enting, I. G., \& Mansbridge, J. V. (1989). Seasonal sources and sinks of atmospheric $\mathrm{CO}_{2}$ : Direct inversion of filtered data. Tellus B: Chemical and Physical Meteorology, 41(2), 111-126. https://doi.org/10.3402/tellusb.v41i2.15056

Geels, C., Doney, S. C., Dargaville, R., Brandt, J., \& Christensen, J. H. (2004). Investigating the sources of synoptic variability in atmospheric $\mathrm{CO} 2$ measurements over the Northern Hemisphere continents: a regional model study. Tellus B: Chemical and Physical Meteorology, 56(1), 35-50. https://doi.org/10.3402/tellusb.v56i1.16399

Glover, D. M., Jenkins, W. J., \& Doney, S. C. (2011). Modeling Methods for Marine Science. Cambridge: Cambridge University Press. https://doi.org/10.1017/CBO9780511975721

Griffith, D. W. T., Deutscher, N., Velazco, V. A., Wennberg, P. O., Yavin, Y., Aleks, G. K., et al. (2014). TCCON data from Darwin, Australia, Release GGG2014R0. https://doi.org/10.14291/tccon.ggg2014.darwin01.R0/1149290

Gurney, K. R., Law, R. M., Denning, A. S., Rayner, P. J., Baker, D., Bousquet, P., et al. (2002). Towards robust regional estimates of $\mathrm{CO} 2$ sources and sinks using atmospheric transport models. Nature, 415(6872), 626-630. https://doi.org/10.1038/415626a

Hase, F., Blumenstock, T., Dohe, S., Gross, J., \& Kiel, M. (2014). TCCON data from Karlsruhe, Germany, Release GGG2014R1. https://doi.org/10.14291/tccon.ggg2014.karlsruhe01.R1/1182416

Houweling, S., Baker, D., Basu, S., Boesch, H., Butz, A., Chevallier, F., et al. (2015). An intercomparison of inverse models for estimating sources and sinks of $\mathrm{CO}_{2}$ using GOSAT measurements. Journal of Geophysical Research: Atmospheres, 120(10), 5253-5266. https://doi.org/10.1002/2014JD022962

Keeling, R. F., Piper, S. C., \& Heimann, M. (1996). Global and hemispheric $\mathrm{CO}_{2}$ sinks deduced from changes in atmospheric O2 concentration. Nature, 381(6579), 218-221. https://doi.org/10.1038/381218a0 
Confidential manuscript submitted to the Journal of Geophysical Research: Atmospheres

Keppel-Aleks, G., Wennberg, P. O., \& Schneider, T. (2011). Sources of variations in total column carbon dioxide. Atmospheric Chemistry and Physics, 11(8), 3581-3593. https://doi.org/10.5194/acp-113581-2011

Keppel-Aleks, G., Wennberg, P. O., Washenfelder, R. A., Wunch, D., Schneider, T., Toon, G. C., et al. (2012). The imprint of surface fluxes and transport on variations in total column carbon dioxide. Biogeosciences, 9(3), 875-891. https://doi.org/10.5194/bg-9-875-2012

Landschützer, P., Gruber, N., Haumann, F. A., Rödenbeck, C., Bakker, D. C. E., van Heuven, S., et al. (2015). The reinvigoration of the Southern Ocean carbon sink. Science, 349(6253), 1221-1224. https://doi.org/10.1126/science.aab2620

Masarie, K. A., Pétron, G., Andrews, A., Bruhwiler, L., Conway, T. J., Jacobson, A. R., et al. (2011). Impact of CO2 measurement bias on CarbonTracker surface flux estimates. Journal of Geophysical Research, 116(D17), D17305. https://doi.org/10.1029/2011JD016270

Mesinger, F., DiMego, G., Kalnay, E., Mitchell, K., Shafran, P. C., Ebisuzaki, W., et al. (2006). North American Regional Reanalysis. Bulletin of the American Meteorological Society, 87(3), 343-360. https://doi.org/10.1175/bams-87-3-343

Miller, C. E., Crisp, D., DeCola, P. L., Olsen, S. C., Randerson, J. T., Michalak, A. M., et al. (2007). Precision requirements for space-based data. Journal of Geophysical Research: Atmospheres, 112(D10), D10314. https://doi.org/10.1029/2006JD007659

Miller, S. M., Hayek, M. N., Andrews, A. E., Fung, I., \& Liu, J. (2015). Biases in atmospheric $\mathrm{CO}_{2}$; estimates from correlated meteorology modeling errors. Atmospheric Chemistry and Physics, 15(5), 2903-2914. https://doi.org/10.5194/acp-15-2903-2015

Miller, S. M., Michalak, A. M., Yadav, V., \& Tadić, J. M. (2018). Characterizing biospheric carbon balance using $\mathrm{CO}_{2}$; observations from the OCO-2 satellite. Atmospheric Chemistry and Physics, 18(9), 6785-6799. https://doi.org/10.5194/acp-18-6785-2018

Nelson, R. R., Crisp, D., Ott, L. E., \& O’Dell, C. W. (2016). High-accuracy measurements of total column water vapor from the Orbiting Carbon Observatory-2. Geophysical Research Letters, 43(23), 12,212261,269. https://doi.org/10.1002/2016gl071200

O’Dell, C. W., Connor, B., Bösch, H., O’Brien, D., Frankenberg, C., Castano, R., et al. (2012). The ACOS $\mathrm{CO}_{2}$ retrieval algorithm-Part 1: Description and validation against synthetic observations. Atmospheric Measurement Techniques, 5(1), 99-121. https://doi.org/10.5194/amt-5-99-2012

O’Dell, C. W., Eldering, A., Wennberg, P. O., Crisp, D., Gunson, M. R., Fisher, B., et al. (2018). Improved Retrievals of Carbon Dioxide from the Orbiting Carbon Observatory-2 with the version 8 ACOS algorithm. Atmospheric Measurement Techniques Discussions, 1-57. https://doi.org/10.5194/amt2018-257 
Olsen, S. C., and J. T. Randerson (2004), Differences between surface and column atmospheric CO2 and implications for carbon cycle research, J. Geophys. Res., 109, D02301. https://doi.org/10.1029/2003JD003968

Parazoo, N. C., Denning, A. S., Kawa, S. R., Corbin, K. D., Lokupitiya, R. S., \& Baker, I. T. (2008). Mechanisms for synoptic variations of atmospheric $\mathrm{CO}_{2}$ in North America, South America and Europe. Atmospheric Chemistry and Physics, 8(23), 7239-7254. https://doi.org/10.5194/acp-8-72392008

Parazoo, N. C., Denning, A. S., Berry, J. A., Wolf, A., Randall, D. A., Kawa, S. R., et al. (2011). Moist synoptic transport of $\mathrm{CO}_{2}$ along the mid-latitude storm track. Geophysical Research Letters, 38(9), L09804. https://doi.org/10.1029/2011g1047238

Peters, W., Miller, J. B., Whitaker, J., Denning, A. S., Hirsch, A., Krol, M. C., et al. (2005). An ensemble data assimilation system to estimate $\mathrm{CO}_{2}$ surface fluxes from atmospheric trace gas observations. Journal of Geophysical Research, 110(D24), D24304. https://doi.org/10.1029/2005jd006157

Peters, W., Jacobson, A. R., Sweeney, C., Andrews, A. E., Conway, T. J., Masarie, K., et al. (2007). An atmospheric perspective on North American carbon dioxide exchange: \{CarbonTracker\}. Proceedings of the National Academy of Sciences, 104(48), 18925-18930. https://doi.org/10.1073/pnas.0708986104

Peylin, P., Law, R. M., Gurney, K. R., Chevallier, F., Jacobson, A. R., Maki, T., et al. (2013). Global atmospheric carbon budget: Results from an ensemble of atmospheric $\mathrm{CO} 2$ inversions. Biogeosciences, 10(10), 6699-6720. https://doi.org/10.5194/bg-10-6699-2013

Rayner, P. J., \& O'Brien, D. M. (2001). The utility of remotely sensed $\mathrm{CO}_{2}$ concentration data in surface source inversions. Geophysical Research Letters, 28(1), 175-178. https://doi.org/10.1029/2000gl011912

Rodgers, C. D. (2000). Inverse Methods for Atmospheric Sounding: Theory and Practice. Singapore: World Scientific. https://doi.org/10.1142/9789812813718_0001

Ross, A. N., Wooster, M. J., Boesch, H., \& Parker, R. (2013). First satellite measurements of carbon dioxide and methane emission ratios in wildfire plumes. Geophysical Research Letters, 40(15), 4098-4102. https://doi.org/10.1002/grl.50733

Sherlock, V., Connor, B., Robinson, J., Shiona, H., Smale, D., \& Pollard, D. (2014). TCCON data from Lauder, New Zealand, 120HR, Release GGG2014R0. https://doi.org/10.14291/tccon.ggg2014.lauder01.R0/1149293

Stephens, B. B., Gurney, K. R., Tans, P. P., Sweeney, C., Peters, W., Bruhwiler, L., et al. (2007). Weak Northern and Strong Tropical Land Carbon Uptake from Vertical Profiles of Atmospheric $\mathrm{CO}_{2}$. Science, 316(5832), 1732-1735. https://doi.org/10.1126/science.1137004 
Sussmann, R., \& Rettinger, M. (2014). TCCON data from Garmisch, Germany, Release GGG2014R0. https://doi.org/10.14291/tccon.ggg2014.garmisch01.R0/1149299

Tans, P. P., Fung, I. Y., \& Takahashi, T. (1990). Observational Contrains on the Global Atmospheric $\mathrm{CO}_{2}$ Budget. Science, 247(4949), 1431-1438. https://doi.org/10.1126/science.247.4949.1431

Tans, P. P., \& Keeling, C. D. (2017). Atmospheric Monthly In Situ CO2 Data - Mauna Loa Observatory, Hawaii. In Scripps CO2 Program Data [Data set]. UC San Diego Library Digital Collections. https://doi.org/10.6075/j08w3bhw

Warneke, T., Messerschmidt, J., Notholt, J., Weinzierl, C., Deutscher, N., Petri, C., et al. (2014). TCCON data from Orleans, France, Release GGG2014R0.

https://doi.org/10.14291/tccon.ggg2014.orleans01.R0/1149276

Washenfelder, R. A., Toon, G. C., Blavier, J.-F., Yang, Z., Allen, N. T., Wennberg, P. O., et al. (2006). Carbon dioxide column abundances at the Wisconsin Tall Tower site. Journal of Geophysical Research, 111(D22), D22305. https://doi.org/10.1029/2006jd007154

Wennberg, P. O., Roehl, C., Wunch, D., Toon, G. C., Blavier, J.-F., Washenfelder, R., et al. (2014). TCCON data from Park Falls, Wisconsin, USA, Release GGG2014R0. https://doi.org/10.14291/tccon.ggg2014.parkfalls01.R0/1149161

Wennberg, P. O., Wunch, D., Roehl, C., Blavier, J.-F., Toon, G. C., Allen, N., et al. (2014). TCCON data from Lamont, Oklahoma, USA, Release GGG2014R0. https://doi.org/10.14291/tccon.ggg2014.lamont01.R0/1149159

Williams, I. N., Riley, W. J., Torn, M. S., Biraud, S. C., \& Fischer, M. L. (2014). Biases in regional carbon budgets from covariation of surface fluxes and weather in transport model inversions. Atmospheric Chemistry and Physics, 14(3), 1571-1585. https://doi.org/10.5194/acp-14-1571-2014

Wofsy, S. C. (2011). HIAPER Pole-to-Pole Observations (HIPPO): fine-grained, global-scale measurements of climatically important atmospheric gases and aerosols. Philosophical Transactions of the Royal Society A: Mathematical, Physical and Engineering Sciences, 369(1943), 2073-2086. https://doi.org/10.1098/rsta.2010.0313

Wofsy, S., Daube, B., Jimenez, R., Kort, E., Pittman, J., Park, S., et al. (2017). HIPPO Pressure-Weighted Mean Total, 10-km, and 100-m Interval Column Concentrations. Version 1.0 (Data set). UCAR/NCAR - Earth Observing Laboratory. https://doi.org/10.3334/cdiac/hippo_011. Accessed 03 Mar 2018.

Worden, R. J., Doran, G., Kulawik, S., Eldering, A., Crisp, D., Frankenberg, C., et al. (2017). Evaluation and attribution of OCO-2 $\mathrm{X}_{\mathrm{CO}_{2}}$ uncertainties. Atmospheric Measurement Techniques, 10(7), 27592771. https://doi.org/10.5194/amt-10-2759-2017 
Wunch, D., Toon, G. C., Wennberg, P. O., Wofsy, S. C., Stephens, B. B., Fischer, M. L., et al. (2010). Calibration of the Total Carbon Column Observing Network using aircraft profile data. Atmospheric Measurement Techniques, 3(5), 1351-1362. https://doi.org/10.5194/amt-3-1351-2010

Wunch, D., Toon, G. C., Blavier, J.-F. L., Washenfelder, R. A., Notholt, J., Connor, B. J., et al. (2011). The Total Carbon Column Observing Network. Philosophical Transactions of the Royal Society A: Mathematical, Physical and Engineering Sciences, 369(1943), 2087-2112. https://doi.org/10.1098/rsta.2010.0240

Wunch, D., Toon, G. C., Sherlock, V., Deutscher, N. M., Liu, C., Feist, D. G., \& Wennberg, P. O. (2015). The Total Carbon Column Observing Network's GGG2014 Data Version. Carbon Dioxide Information Analysis Center, Oak Ridge National Laboratory, Oak Ridge, Tennessee, U.S.A. https://doi.org/10.14291/tccon.ggg2014.documentation.R0/1221662

Wunch, D., P. O. Wennberg, G. B. Osterman, B. Fisher, B. Naylor, C. M. Roehl, C. O’Dell, L. Mandrake, C. Viatte, M. Kiel, D. W. T. Griffith, N. M. Deutscher, V. A. Velazco, J. Notholt, T. Warneke, C. Petri, M. De Maziere, M. K. Sha, R. Sussmann, M. Rettinger, D. Pollard, J. Robinson, I. Morino, O. Uchino, F. Hase, T. Blumenstock, D. G. Feist, S. G. Arnold, K. Strong, J. Mendonca, R. Kivi, P. Heikkinen, L. Iraci, J. Podolske, P. W. Hillyard, S. Kawakami, M. K. Dubey, H. A. Parker, E. Sepulveda, O. E. Garc?a, Y. Te, P. Jeseck, M. R. Gunson, D. Crisp, and A. Eldering (2017), Comparisons of the Orbiting Carbon Observatory-2 (OCO-2) $\mathrm{X}_{\mathrm{CO}_{2}}$ measurements with TCCON, Atmos. Meas. Tech., 10(6), 2209-2238, doi:10.5194/amt-10-2209-2017.

Yang, D., Liu, Y., Cai, Z., Chen, X., Yao, L., \& Lu, D. (2018). First Global Carbon Dioxide Maps Produced from TanSat Measurements. Advances in Atmospheric Sciences, 35(6), 621-623. https://doi.org/10.1007/s00376-018-7312-6

Yokota, T., Yoshida, Y., Eguchi, N., Ota, Y., Tanaka, T., Watanabe, H., \& Maksyutov, S. (2009). Global Concentrations of $\mathrm{CO}_{2}$ and $\mathrm{CH}_{4}$ Retrieved from GOSAT: First Preliminary Results. SOLA, 5, 160163. https://doi.org/10.2151/sola.2009-041 


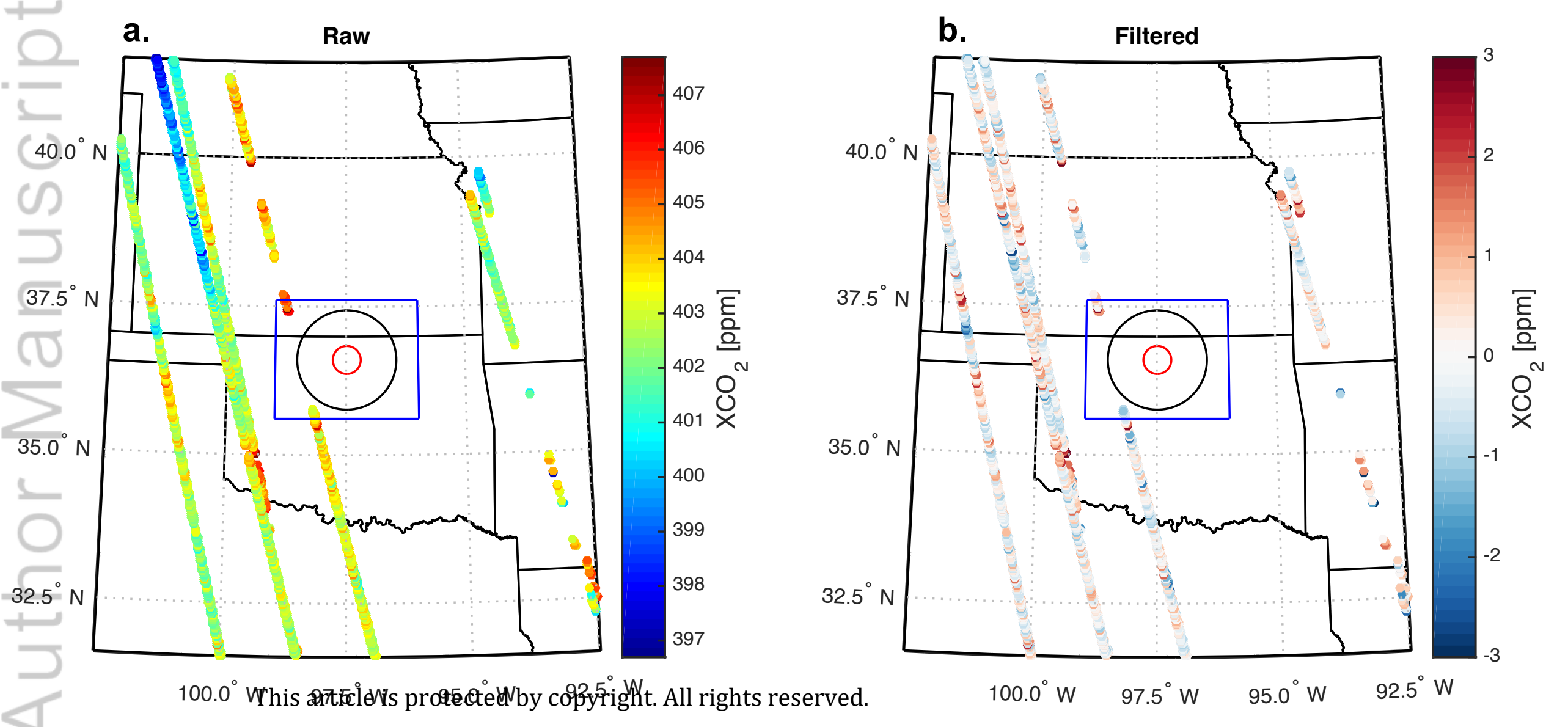




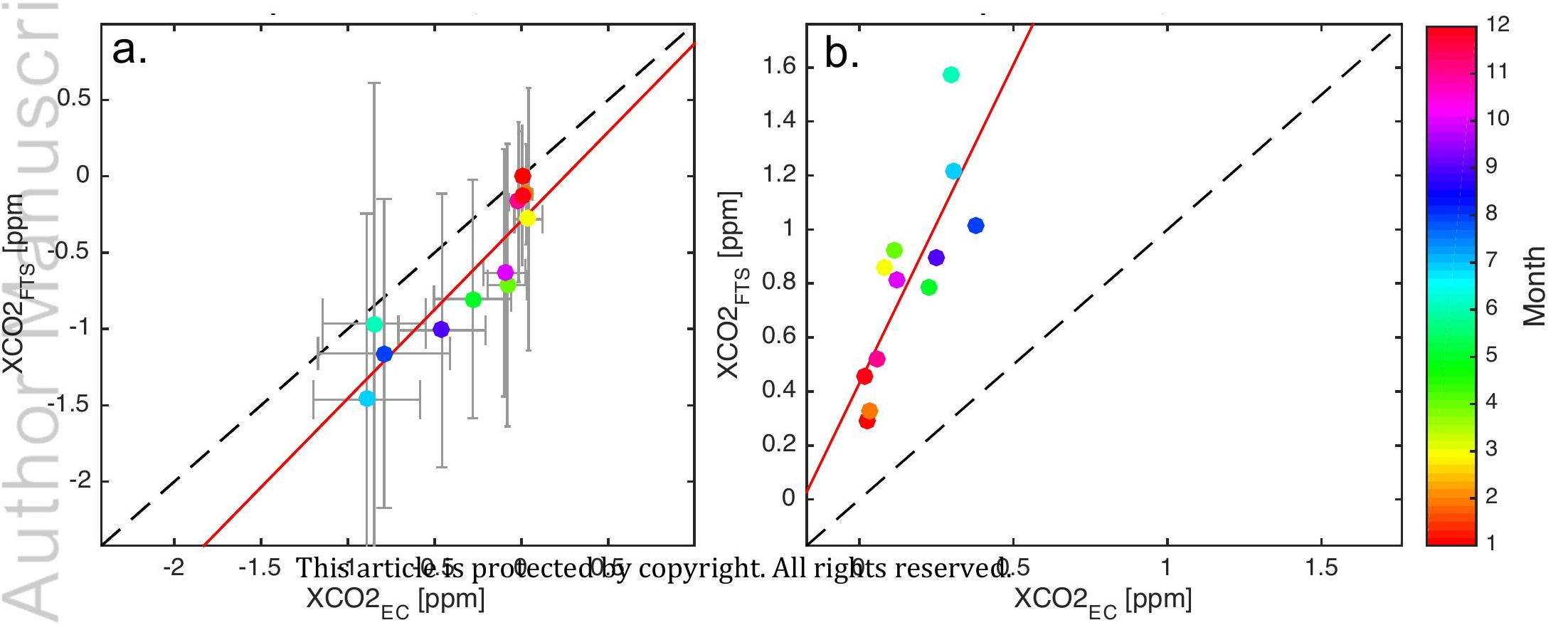




\section{a. \\ $\mathrm{XCO}_{2}$ Diurnal Amplitude [ppm]}

(3)

Bialystok, Poland

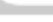

Karlsruhe, Germany $\mathrm{CO}$

Orleans, France

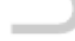

Garmisch, Germany

\section{Park Falls, WI}

Lamont, OK

$\begin{array}{lllllllllllll}-0.4 & 0.5 & 0.9 & 1.1 & 1.2 & 1.2 & 1.1 & 1.0 & 0.8 & 0.5 & 0.4 & 0.3-\end{array}$

$\begin{array}{lllllllll}-0.3 & 0.3 & 0.8 & 1.2 & 0.9 & 1.1 & 0.7 & 0.5 & 0.4\end{array}$

$\begin{array}{llllllllllll}-0.7 & 1.0 & 1.0 & 1.3 & 1.7 & 1.8 & 1.7 & 1.0 & 0.6 & 1.0 & 0.5\end{array}$

$-0.0 \quad 0.2 \quad 0.8$

$\begin{array}{lllll}0.9 & 0.8 & 0.7 & 0.3 & 0.2\end{array}$

$\begin{array}{lllllllllll}-0.1 & -0.4 & 0.5 & 1.3 & 1.4 & 1.8 & 1.8 & 2.0 & 1.4 & 0.5 & -0.5\end{array}$

$\left.\begin{array}{|ccccccccccccc|}-0.2 & 0.1 & -0.4 & 0.7 & 0.9 & 1.3 & 1.2 & 0.7 & 0.9 & 0.4 & 0.1 & -0.1-1 \\ -0.4 & 0.5 & 0.9 & 1.1 & 1.2 & 1.2 & 1.1 & 1.0 & 0.8 & 0.5 & 0.4 & 0.3\end{array}\right]$

Darwin, Australia $\begin{array}{llllllllllll}-1.3 & 1.3 & 1.2 & 1.1 & 1.0 & 0.7 & -0.9 & 1.0 & 0.9 & 0.6 & 1.0 & 0.9-1\end{array}$

Reunion Island $-1.0 \quad 1.4$ $\begin{array}{llllllllll}0.6 & 0.6 & 0.5 & 0.5 & -0.6 & 0.7 & 0.7 & 1.2 & -0.5 & -1.1\end{array}$ - 1.3 $\begin{array}{llllllllllll}-1.3 & 1.3 & 1.2 & 0.7 & 0.3 & 0.1 & 0.1 & 0.3 & 0.7 & 1.0 & 1.2 & 1.2\end{array}$ This article Ms prôtectedd by copyright. AlP rights reserRed. b. $\quad \mathrm{XH}_{2} \mathrm{O}$ Diurnal Amplitude [ppm]

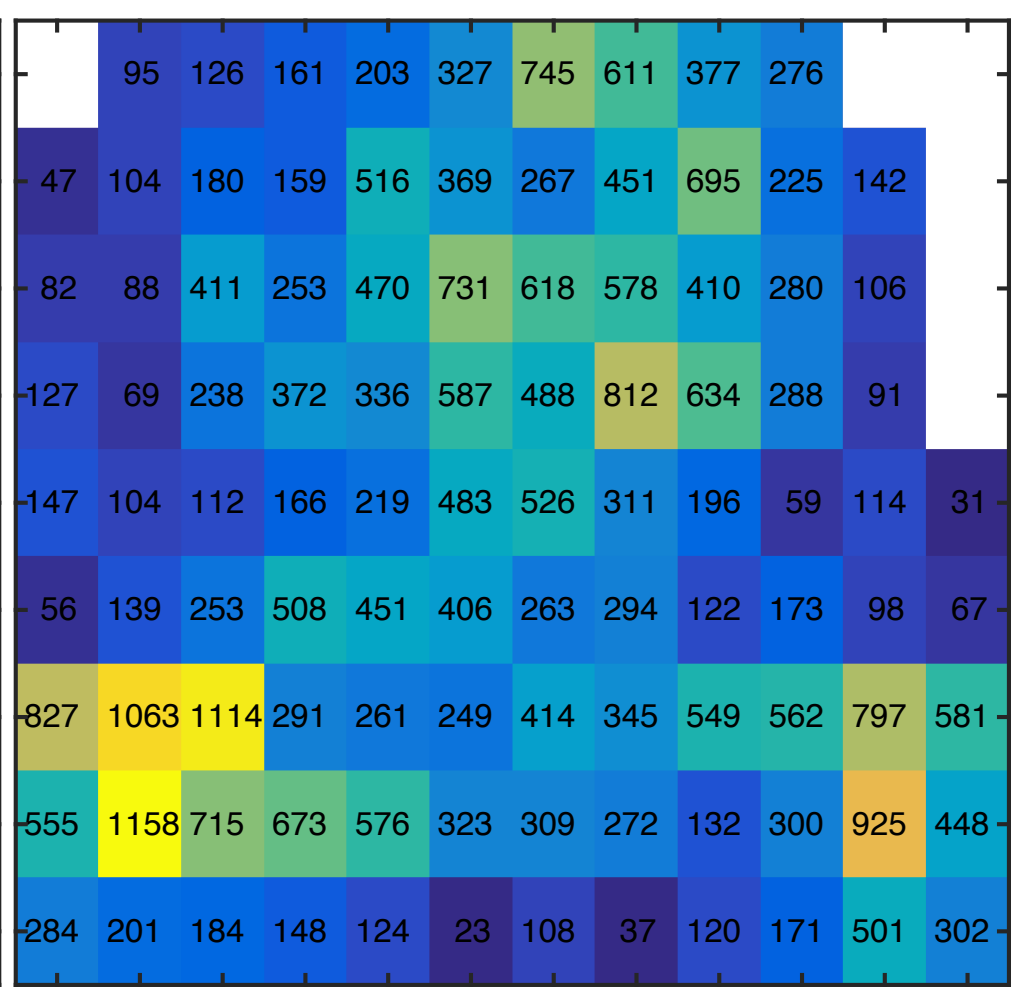




\section{a. Synoptic-scale Variability $\left(\mathrm{XH}_{2} \mathrm{O}\right)[\mathrm{ppm}]$}

Bialystok, Poland Karlsruhe, Germany

Orleans, France (ror

Garmisch, Germany

Park Falls, WI

Lamont, OK

Darwin, Australia res

Reunion Island

Lauder, New Zealand
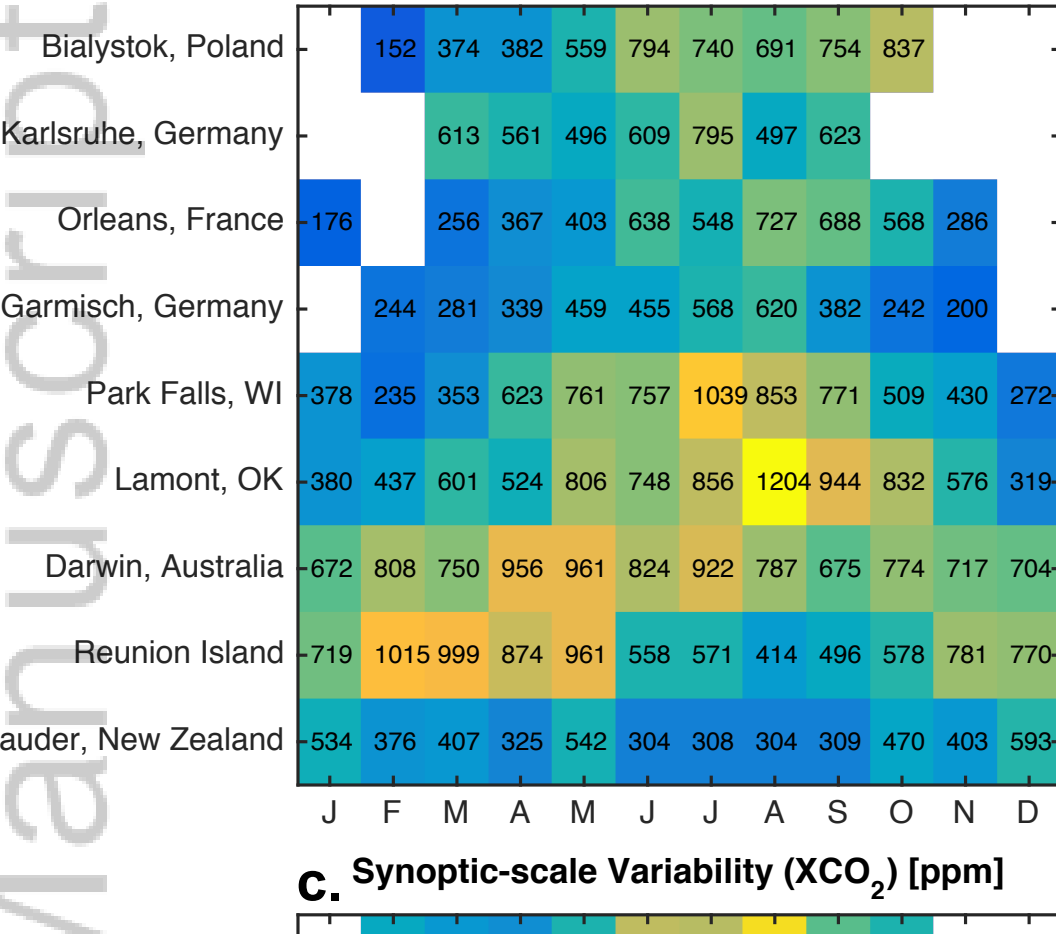

Bialystok, Poland

Karlsruhe, Germany

Orleans, France

Garmisch, Germany

re

Park Falls, WI Lamont, OK

Darwin, Australia

Reunion Island

Re

Lauder, New Zealand

Lauder,

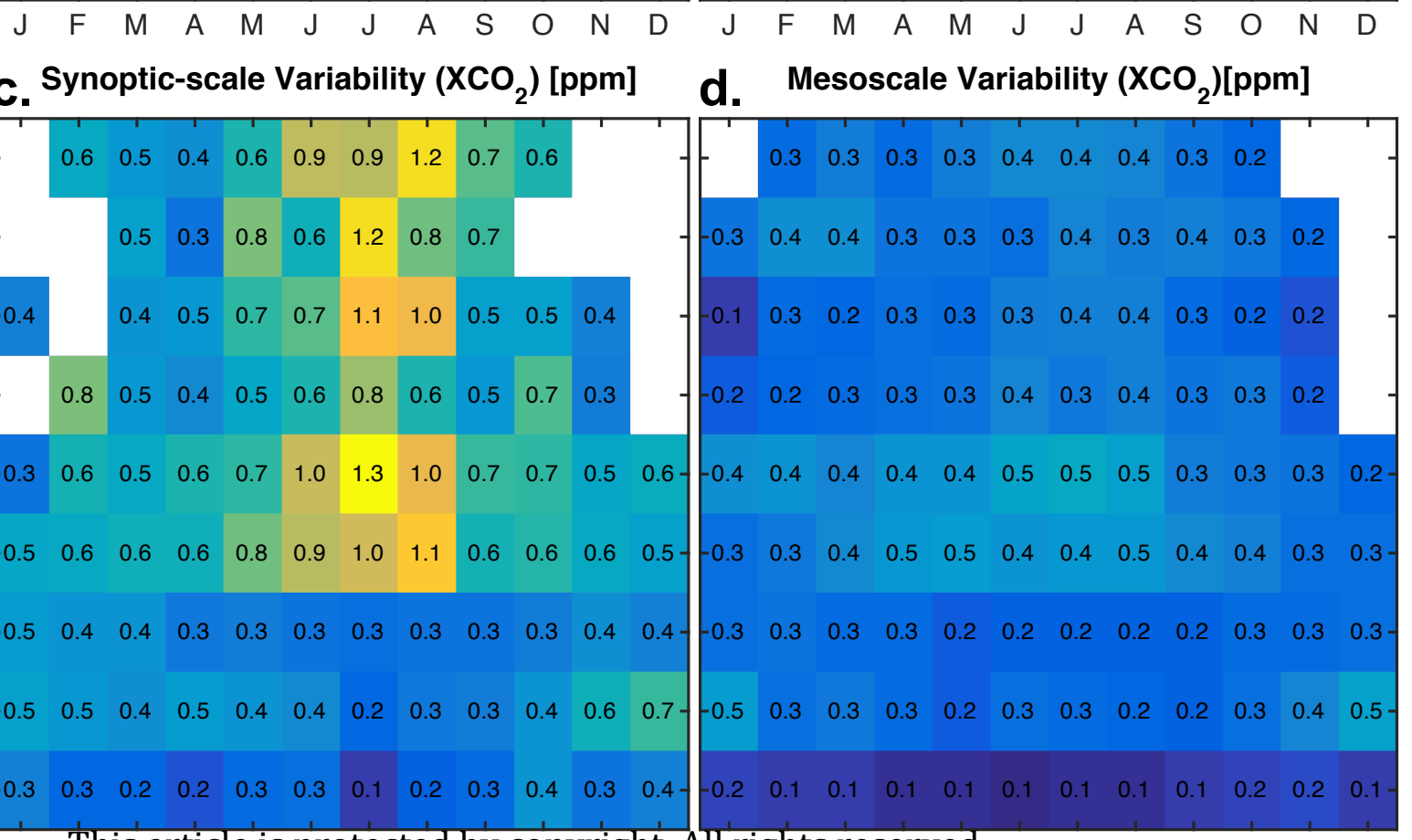

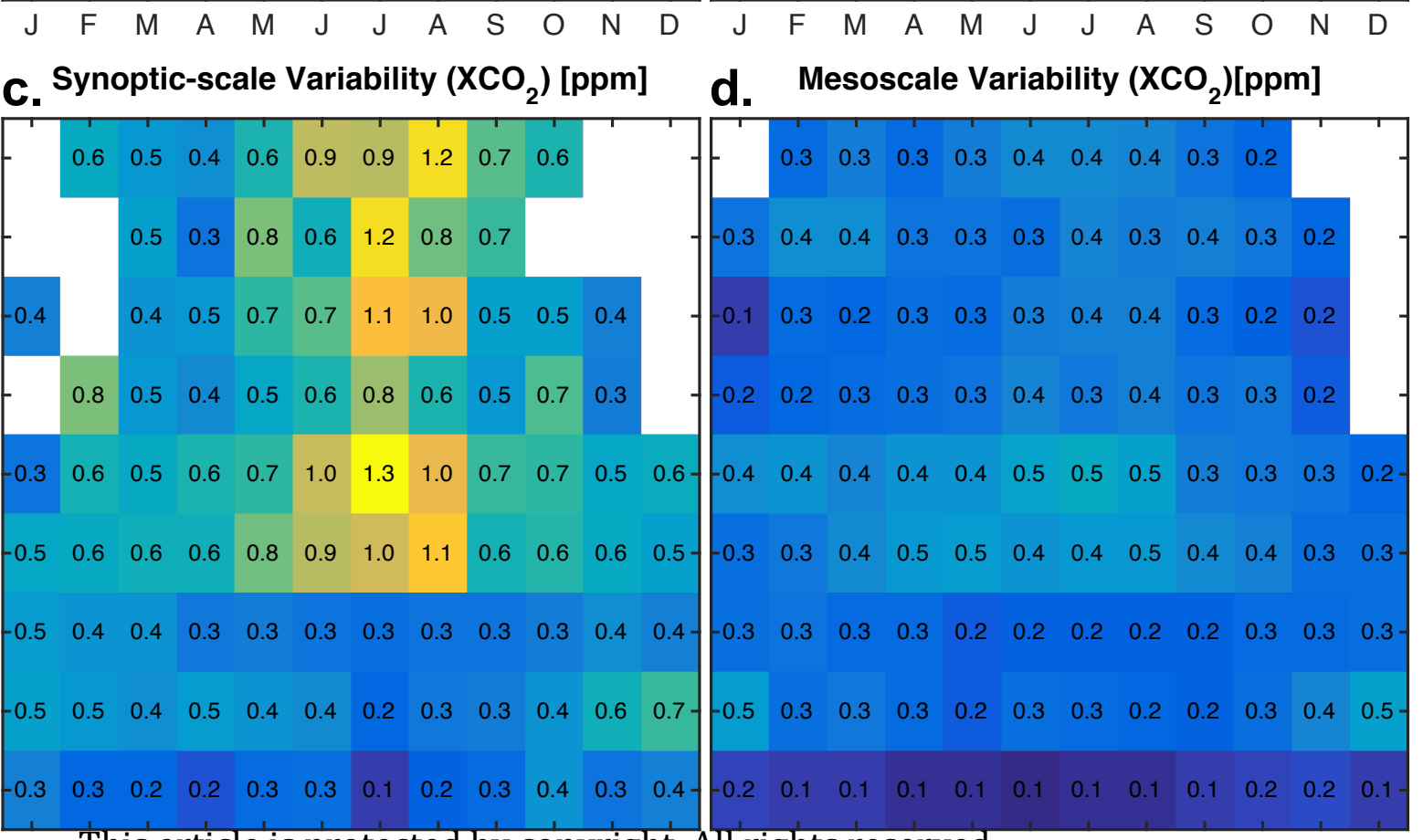

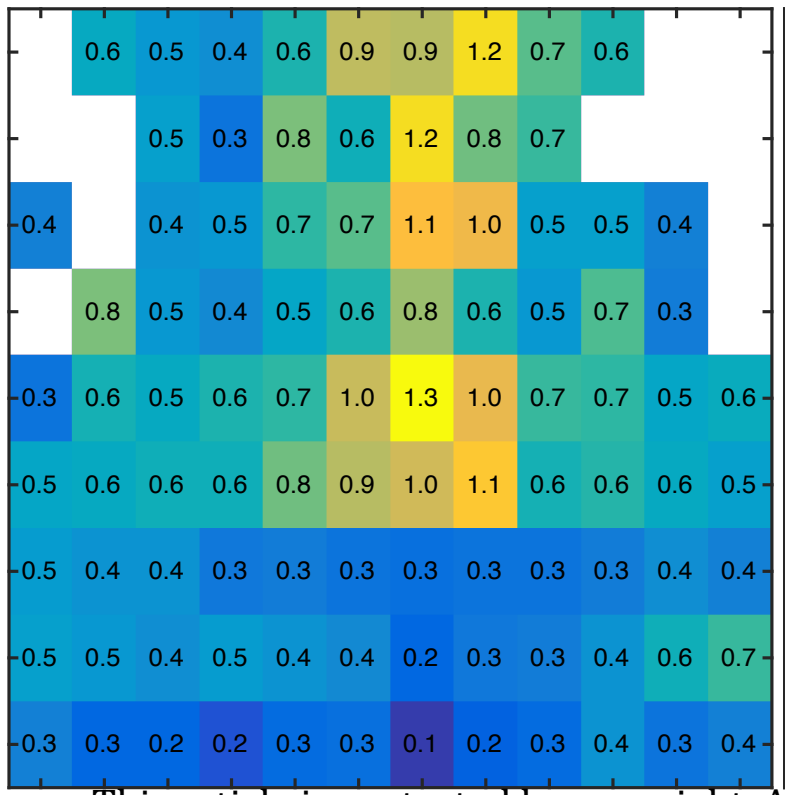

J This/articleis protected bø cøpyinght All.rights meserved.

Month b. Mesoscale Variability $\left(\mathrm{XH}_{2} \mathrm{O}\right)$ [ppm]
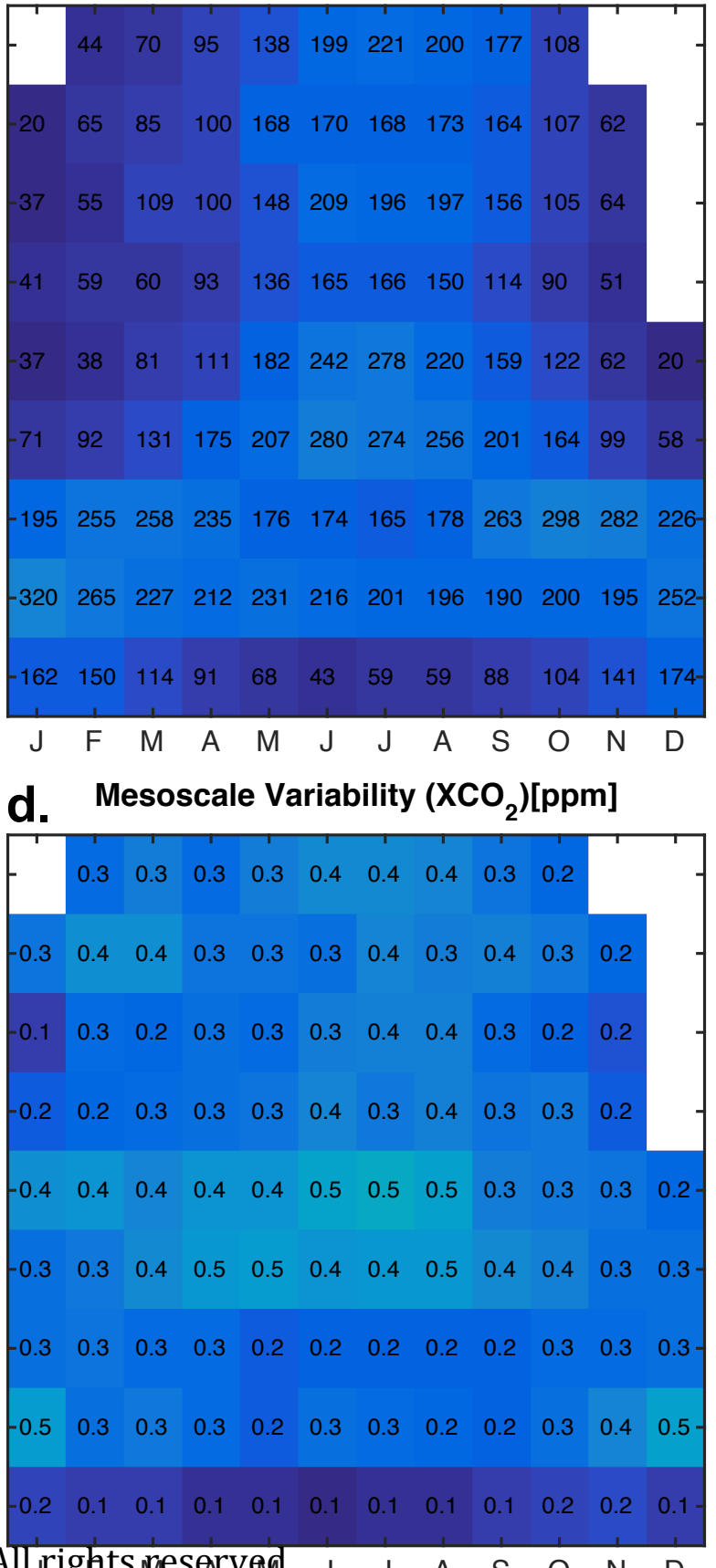

Month 

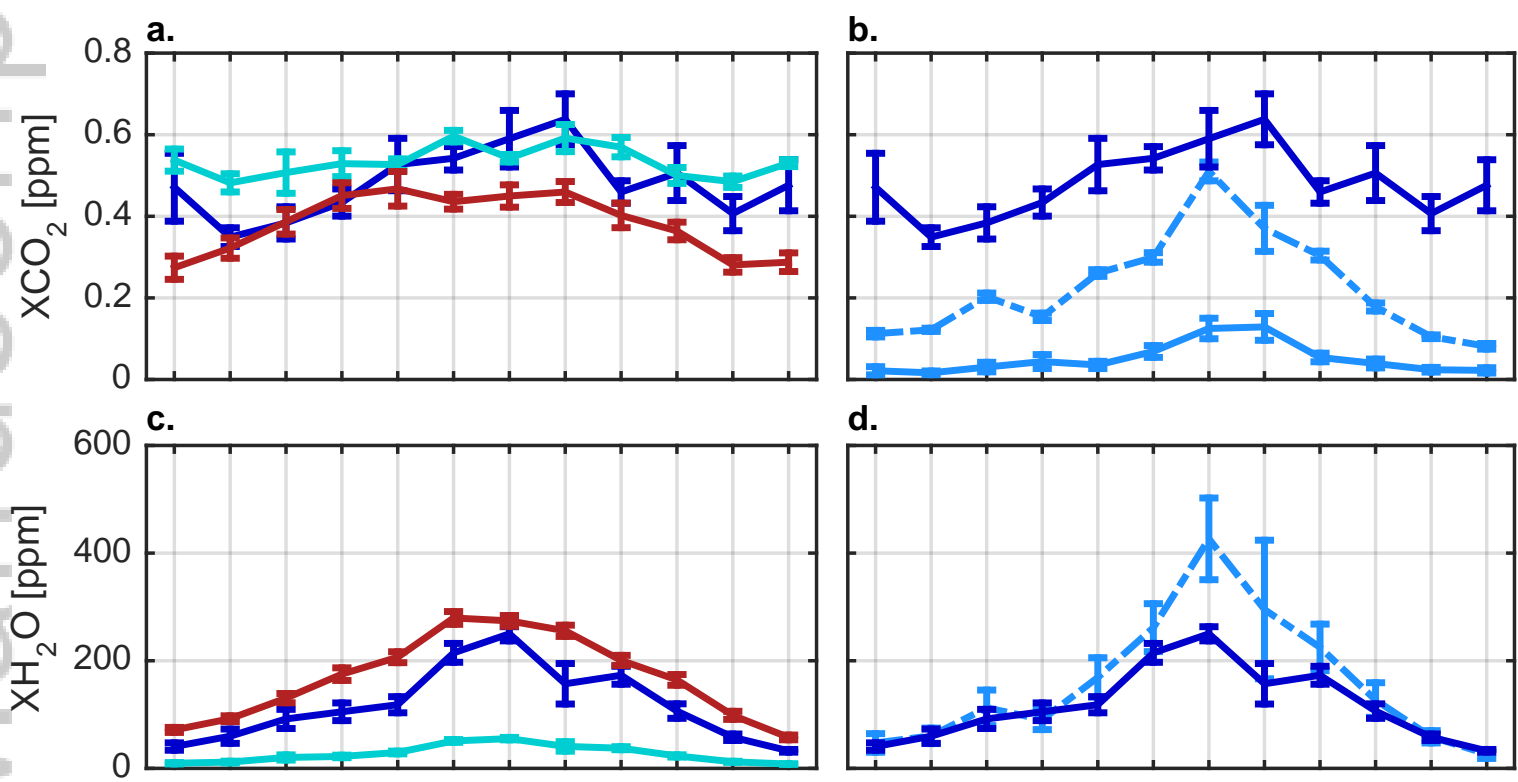

d.
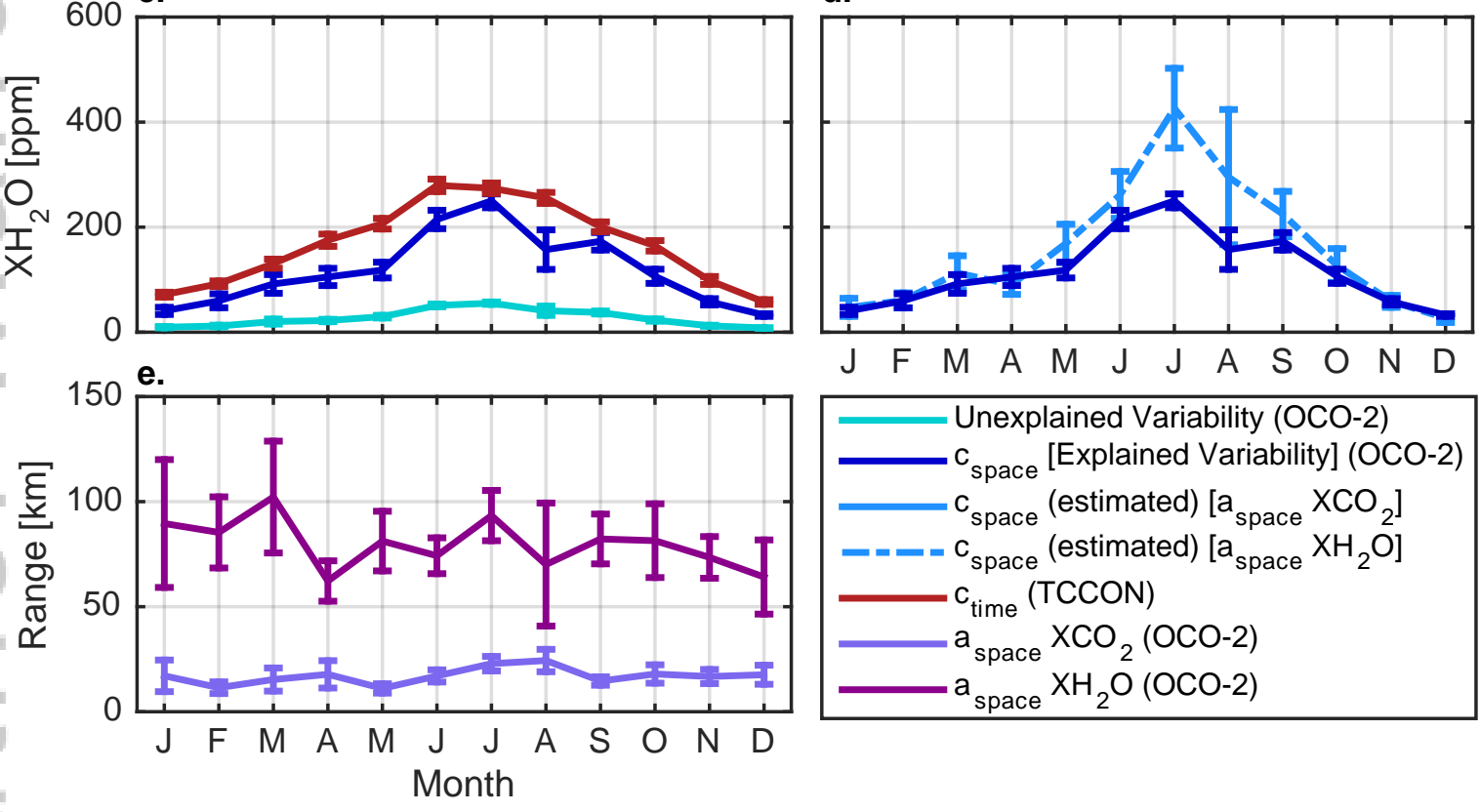

This article is protected by copyright. All rights reserved. 


\section{a. Unexplained Variability $\left(\mathrm{XH}_{2} \mathrm{O}\right)$ [ppm]}

Bialystok, Poland Karlsruhe, Germany : Orlean

Orleans, France Orisch

Garmisch, Germany ( Par Park Falls, WI Lamont, OK Darwin, Australia Darwin

Reunion Island auder, New Zealand (1)

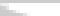

Bialystok, Poland Bialystok

Karlsruhe, Germany

Orleans, France Garmisch, Germany (a)

Park Falls, WI Lamont, OK l.

Darwin, Australia (Deser

Reunion Island Lauder, New Zealand Lauder

\section{d. Unexplained Variability $\left(\mathrm{XCO}_{2}\right)$ [ppm]}
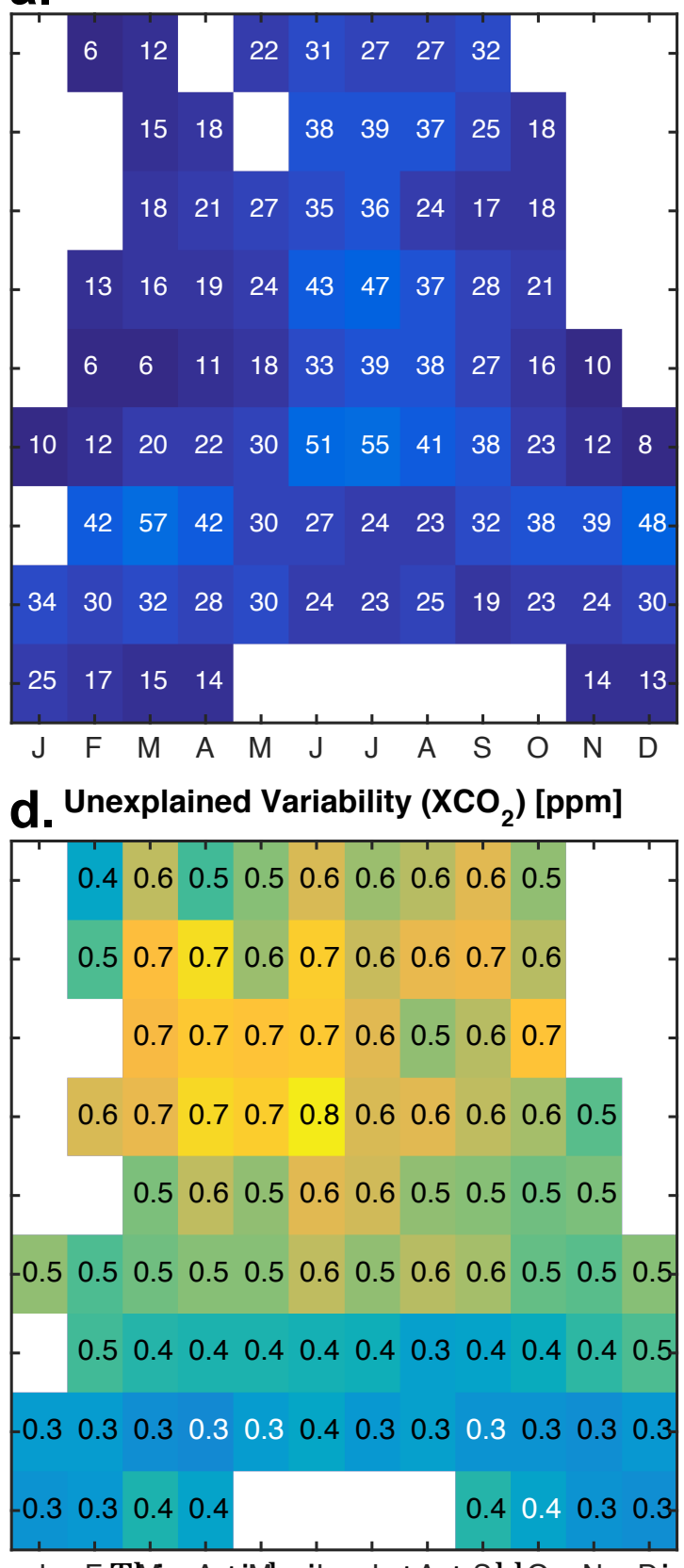

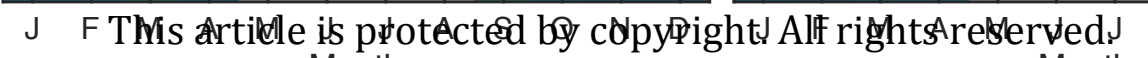
Month b. Explained Variability $\left(\mathrm{XH}_{2} \mathrm{O}\right)$ [ppm]

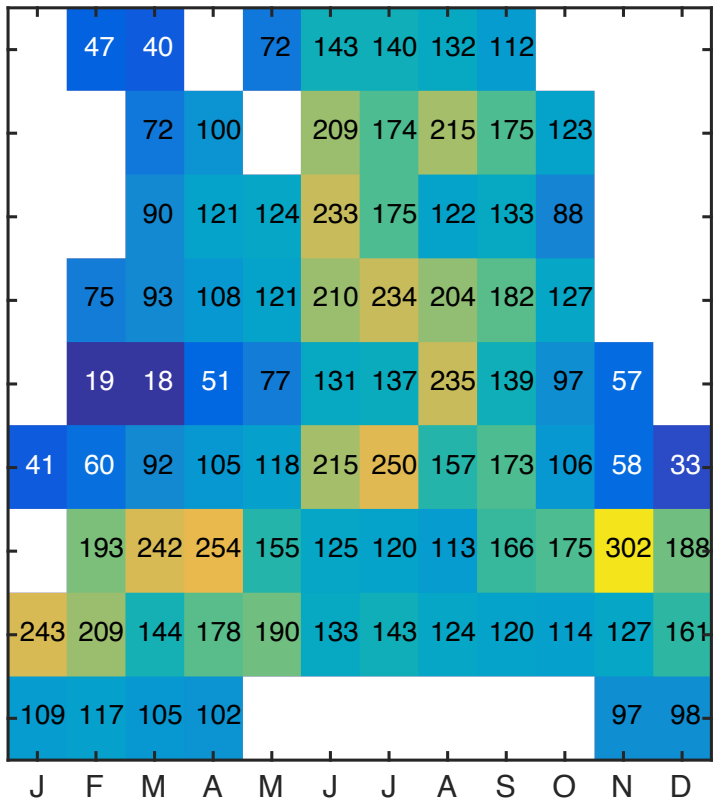

e. Explained Variability $\left(\mathrm{XCO}_{2}\right)[\mathrm{ppm}]$

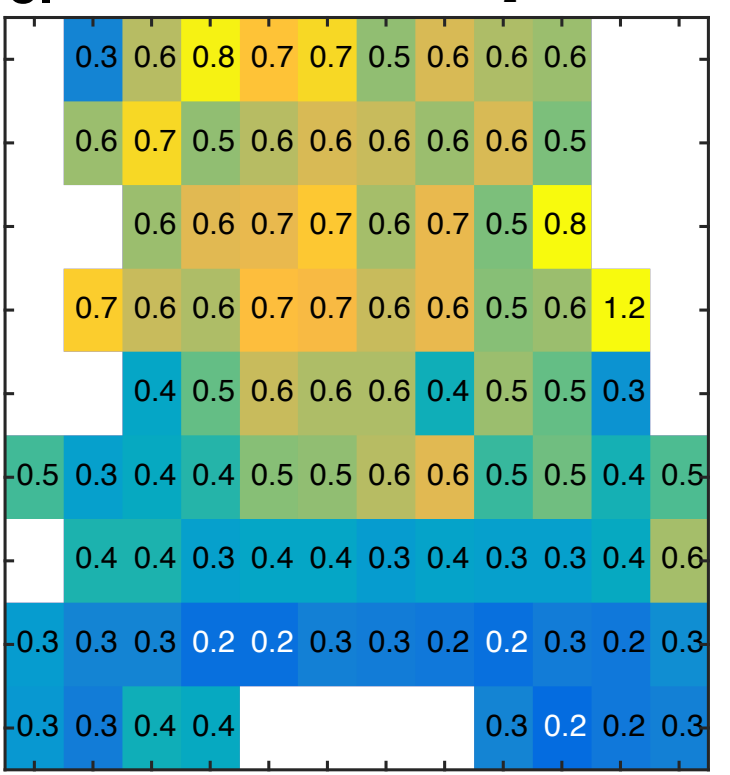

Month
C. Mesoscale Variability $\left(\mathrm{XH}_{2} \mathrm{O}\right)$ [ppm]

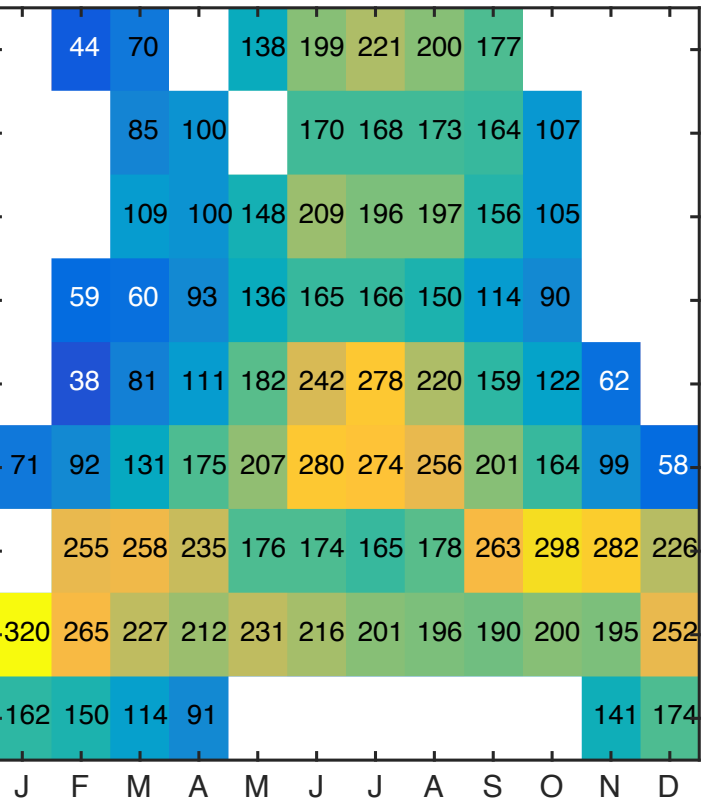

f. Mesoscale Variability $\left(\mathrm{XCO}_{\mathbf{2}}\right)$ [ppm]

$\begin{array}{llllllllll}0.3 & 0.3 & 0.3 & 0.3 & 0.4 & 0.4 & 0.4 & 0.3 & 0.2\end{array}$

$\begin{array}{lllllllll}0.4 & 0.4 & 0.3 & 0.3 & 0.3 & 0.4 & 0.3 & 0.4 & 0.3\end{array}$ $\begin{array}{llllllll}0.2 & 0.3 & 0.3 & 0.3 & 0.4 & 0.4 & 0.3 & 0.2\end{array}$

$\begin{array}{llllllllll}0.2 & 0.3 & 0.3 & 0.3 & 0.4 & 0.3 & 0.4 & 0.3 & 0.3 & 0.2\end{array}$ $\begin{array}{lllllllll}0.4 & 0.4 & 0.4 & 0.5 & 0.5 & 0.5 & 0.3 & 0.3 & 0.3\end{array}$

$\begin{array}{llllllllllll}0.3 & 0.3 & 0.4 & 0.5 & 0.5 & 0.4 & 0.4 & 0.5 & 0.4 & 0.4 & 0.3 & 0.3\end{array}$ $\begin{array}{lllllllllll}0.3 & 0.3 & 0.3 & 0.2 & 0.2 & 0.2 & 0.2 & 0.2 & 0.3 & 0.3 & 0.3\end{array}$

$\begin{array}{llllllllllll}0.5 & 0.3 & 0.3 & 0.3 & 0.2 & 0.3 & 0.3 & 0.2 & 0.2 & 0.3 & 0.4 & 0.5\end{array}$ $\begin{array}{llll}0.2 & 0.1 & 0.1 & 0.1\end{array}$ $\begin{array}{llll}0.1 & 0.2 & 0.2 & 0.1\end{array}$ 


\section{a. \\ Range $\mathrm{XCO}_{2}[\mathrm{~km}]$}

\section{b. Range $\mathrm{XH}_{2} \mathrm{O}[\mathrm{km}]$}

Bialystok, Poland

Karlsruhe, Germany

(O)

\section{Orleans, France}

Garmisch, Germany

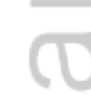

Park Falls, WI

$$
\text { Lamont, OK }
$$

Darwin, Australia

Reunion Island

\section{.}

$-3$
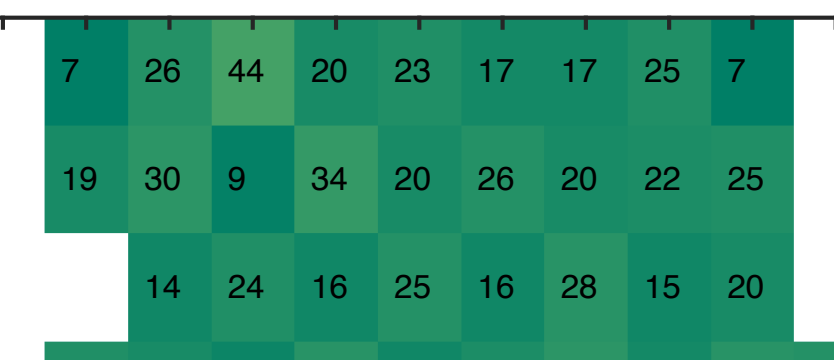

$\begin{array}{llllllllll}24 & 19 & 13 & 29 & 16 & 22 & 29 & 18 & 29 & 26\end{array}$

\begin{tabular}{llllllll|l|l}
8 & 18 & 16 & 25 & 30 & 31 & 26 & 15 & 6
\end{tabular}

$\begin{array}{llllllllllll}-17 & 11 & 15 & 18 & 11 & 17 & 23 & 24 & 15 & 18 & 17 & 18\end{array}$

\begin{tabular}{|lllllllllll}
20 & 29 & 20 & 21 & 18 & 16 & 18 & 24 & 26 & 26 & 30
\end{tabular}

$\begin{array}{llllllllllll}-23 & 24 & 27 & 30 & 24 & 25 & 29 & 22 & 29 & 28 & 27 & 29\end{array}$

$-33 \quad 27 \quad 25 \quad 30$

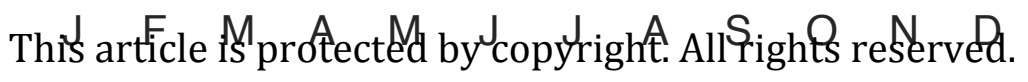

b.

Lauder, New Zealand

$\longrightarrow$ 
Bialystok, Poland

\section{C. $\left\langle\mathrm{C}^{\prime}\right\rangle_{\text {space }} \mathrm{XCO}_{2}[\mathrm{ppm}]\left(\mathrm{XCO}_{2}\right.$ Range $)$}

Karlsruhe, Germany

Orleans, France

Garmisch, Germany Park Falls, WI Lamont, OK Darwin, Australia Reunion Island Lauder, New Zealand Laud

\section{a. $\left\langle\mathrm{C}^{\prime}\right\rangle_{\text {space }} \mathrm{XH}_{2} \mathrm{O}\left(\mathrm{XH}_{2} \mathrm{O}\right.$ Range $)[\mathrm{ppm}]$}

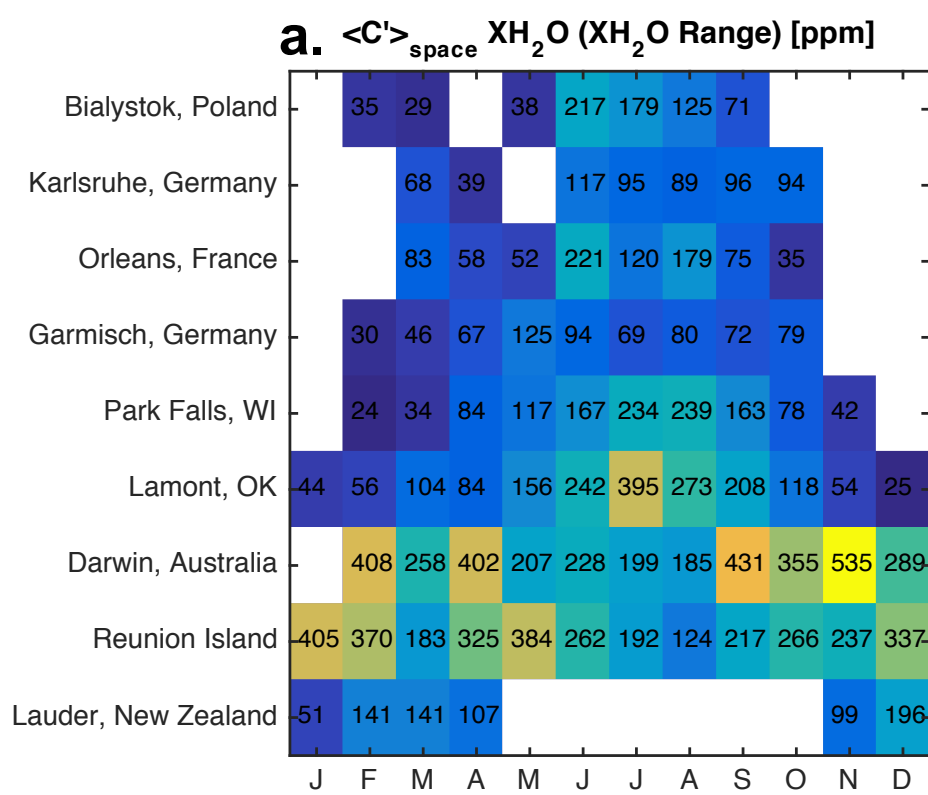

b. $\left\langle\mathrm{C}^{\prime}\right\rangle_{\text {space }} \mathrm{XH}_{2} \mathrm{O}$ [ppm] (Observed)

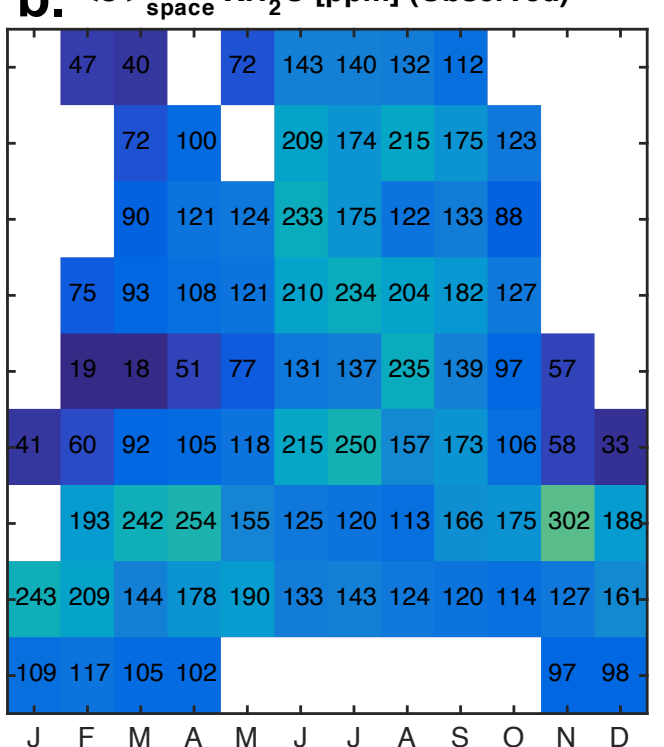

e. $\langle\mathrm{C}\rangle_{\text {space }} \mathrm{XCO}_{2}[\mathrm{ppm}]$ (Observed)
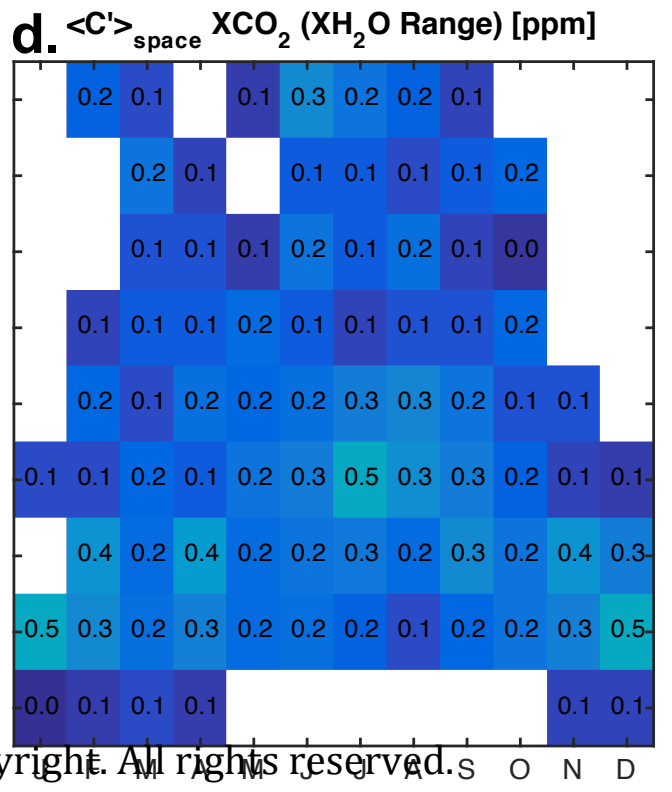
Month

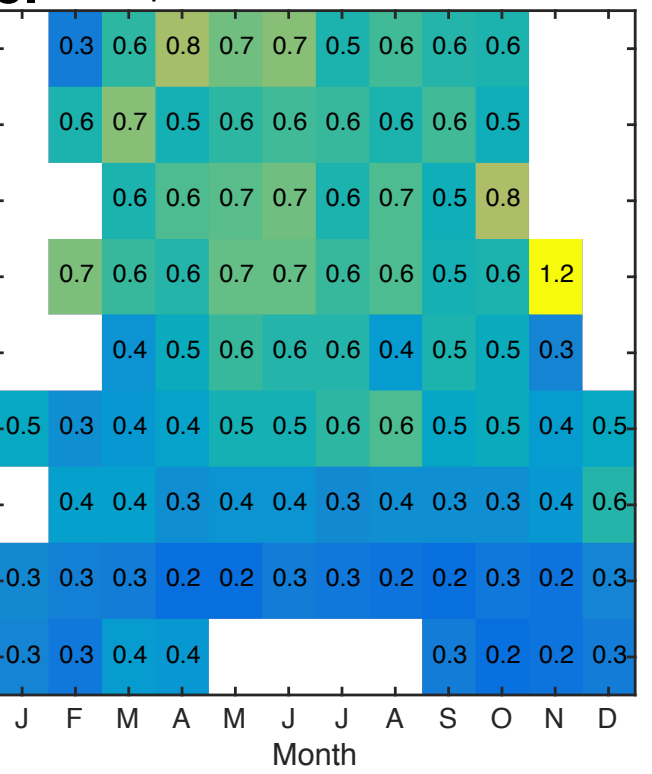


a.Unexplained Variability [ppm]

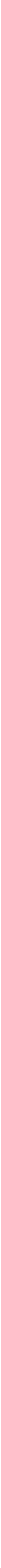

b. Explained Variability [ppm]

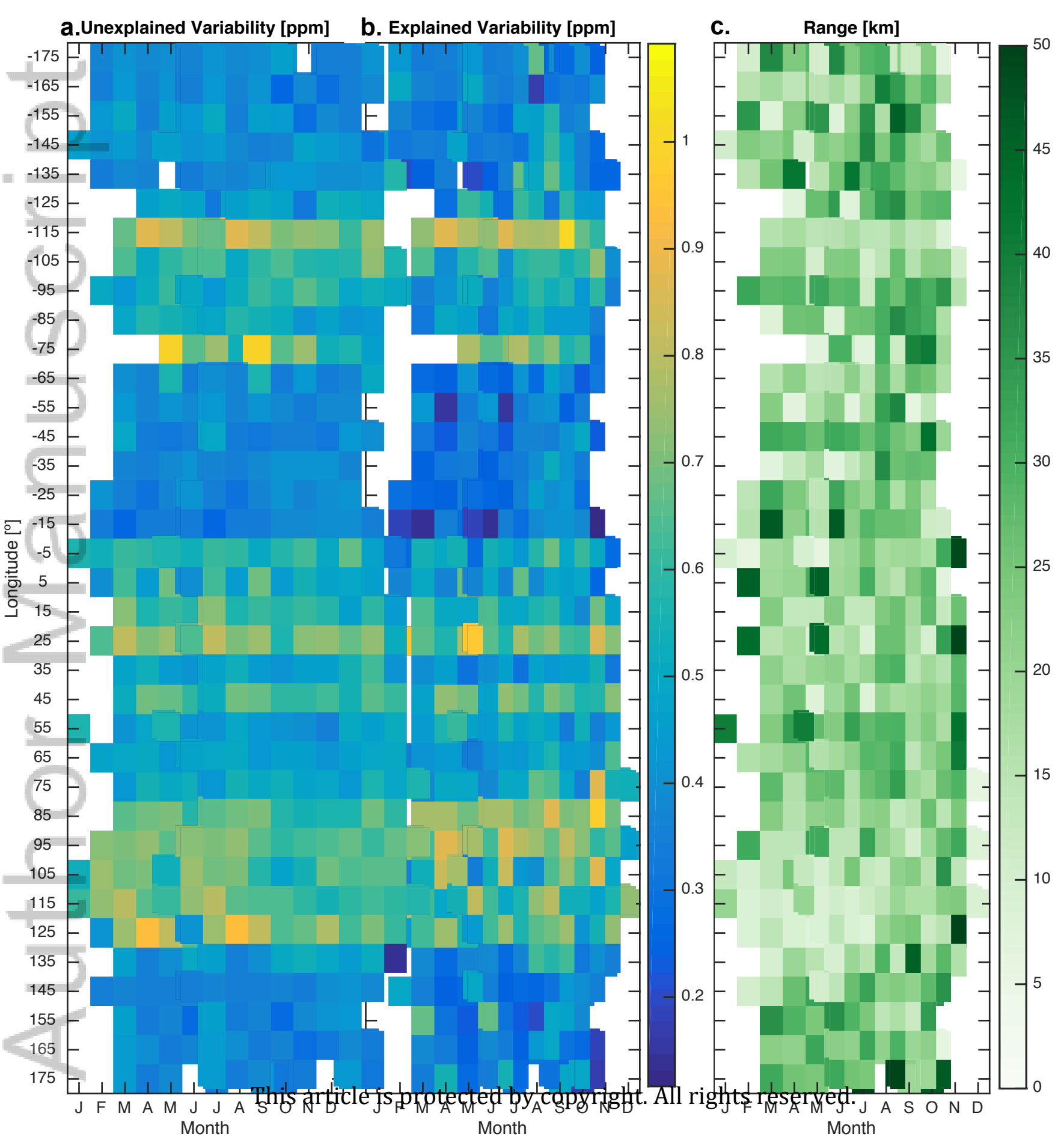

\section{政}

